\title{
Spatially Referenced Models of Streamflow and Nitrogen, Phosphorus, and Suspended-Sediment Loads in Streams of the Pacific Region of the United States
}

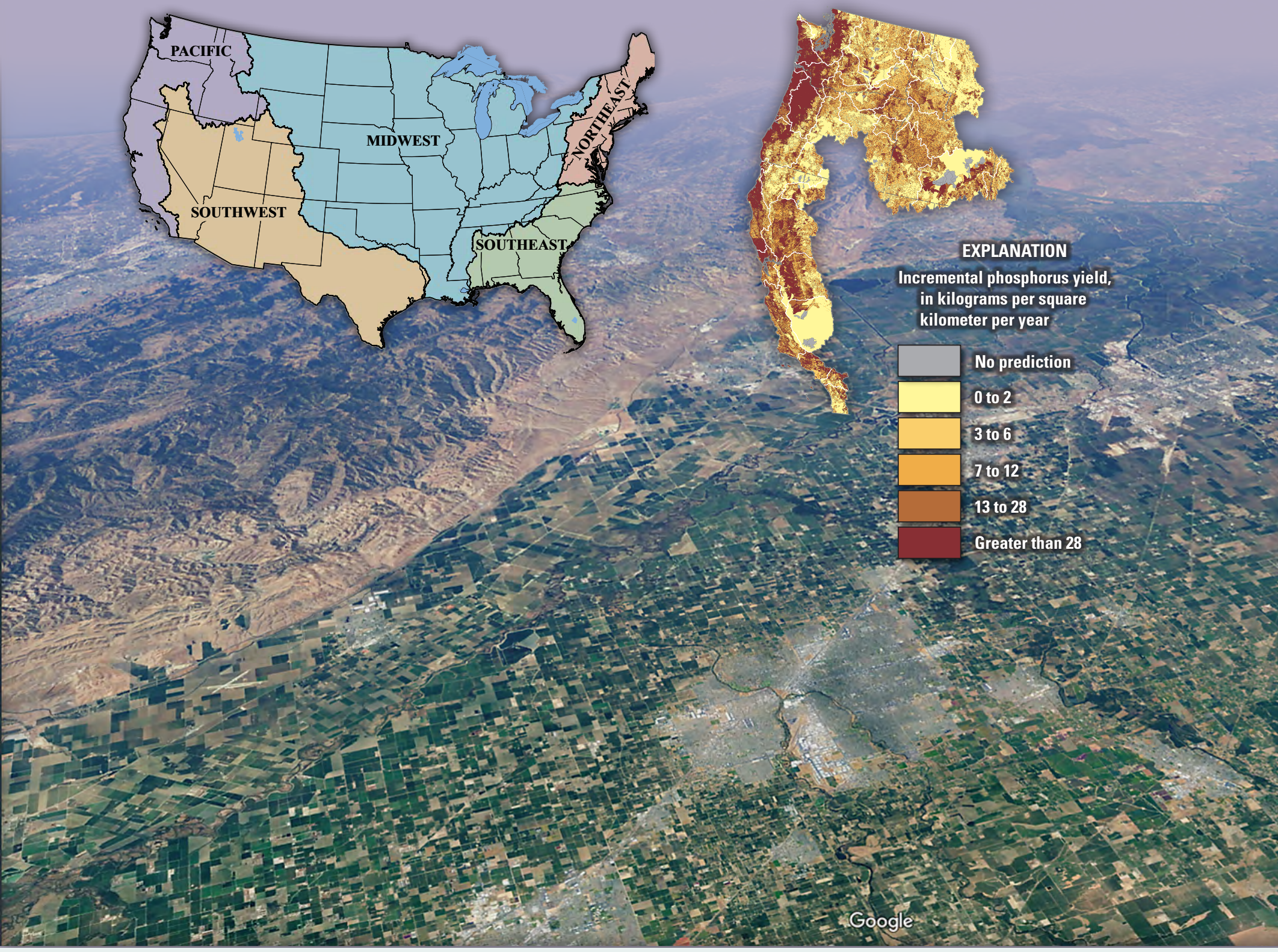

Scientific Investigations Report 2019-5112 Version 1.1, June 2020 


\section{Cover:}

Upper left: SPAtially Referenced Regression On Watershed attritutes (SPARROW) modeling regions of the conterminous United States.

Upper right: SPARROW simulated total phosphorus incremental yield, in kilograms per square kilometer per year.

Lower center: Aerial view looking north over northern San Joaquin River Valley and San Francisco Bay, California. Credit: Satellite image courtesy of Google Earth. 


\section{Spatially Referenced Models of Streamflow and Nitrogen, Phosphorus, and Suspended-Sediment Loads in Streams of the Pacific Region of the United States}

By Daniel R. Wise

National Water Quality Program

Scientific Investigations Report 2019-5112

Version 1.1, June 2020 


\title{
U.S. Department of the Interior DAVID BERNHARDT, Secretary
}

\author{
U.S. Geological Survey \\ James F. Reilly II, Director
}

\author{
U.S. Geological Survey, Reston, Virginia \\ First release: 2019 \\ Revised: June 2020 (ver. 1.1)
}

For more information on the USGS - the Federal source for science about the Earth, its natural and living resources, natural hazards, and the environment—visit https://www.usgs.gov or call 1-888-ASK-USGS.

For an overview of USGS information products, including maps, imagery, and publications, visit https://store.usgs.gov.

Any use of trade, firm, or product names is for descriptive purposes only and does not imply endorsement by the U.S. Government.

Although this information product, for the most part, is in the public domain, it also may contain copyrighted materials as noted in the text. Permission to reproduce copyrighted items must be secured from the copyright owner.

Suggested citation:

Wise, D.R., 2019, Spatially referenced models of streamflow and nitrogen, phosphorus, and suspended-sediment loads in streams of the Pacific region of the United States (ver. 1.1, June 2020): U.S. Geological Survey Scientific Investigations Report 2019-5112, 64 p., https://doi.org/10.3133/sir20195112.

Associated data for this publication:

Wise, D.R., 2020, SPARROW model inputs and simulated streamflow, nutrient and suspended-sediment loads in streams of the Pacific Region of the United States, 2012 Base Year (ver 1.1, June 2020): U.S. Geological Survey data release, https://doi.org/10.5066/P9AXLOSM.

ISSN 2328-0328 


\section{Foreword}

Sustaining the quality of the Nation's water resources and the health of our diverse ecosystems depends on the availability of sound water-resources data and information to develop effective, science-based policies. Effective management of water resources also brings more certainty and efficiency to important economic sectors. Taken together, these actions lead to immediate and long-term economic, social, and environmental benefits that make a difference to the lives of the almost 400 million people projected to live in the United States by 2050.

In 1991, Congress established the National Water-Quality Assessment (NAWQA) to address where, when, why, and how the Nation's water quality has changed, or is likely to change in the future, in response to human activities and natural factors. Since then, NAWQA has been a leading source of scientific data and knowledge used by national, regional, state, and local agencies to develop science-based policies and management strategies to improve and protect water resources used for drinking water, recreation, irrigation, energy development, and ecosystem needs (https://water.usgs.gov/nawqa/applications/). Plans for the third decade of NAWQA (2013-21) address priority water-quality issues and science needs identified by NAWQA stakeholders, such as the Advisory Committee on Water Information and the National Research Council, and are designed to meet increasing challenges related to population growth, increasing needs for clean water, and changing land-use and weather patterns.

Federal, State, and local agencies have invested billions of dollars to reduce the amount of pollution entering rivers and streams that millions of Americans rely on for a variety of water needs and biota rely on for habitat. Understanding the sources and transport of pollution is crucial for designing strategies to improve water quality. The United States Geological Survey's (USGS) SPAtially Referenced Regression On Watershed attributes (SPARROW) model was developed to aid in the understanding of sources and transport of pollution across large spatial scales. The SPARROW model is calibrated by statistically relating watershed sources and transport-related properties to monitoring-based water-quality load estimates. The report contained herein describes the methods and results of SPARROW models recently developed to estimate streamflow, and total nitrogen, total phosphorus and suspended-sediment transport in streams of the Pacific region of United States. The model results are expected to provide useful information for understanding the hydrology and water quality of streams in the Pacific region. They are also expected to provide useful information for understanding anthropogenic influences on surface-water resources and for managing those resources to ensure adequate water supply for human needs and to ensure ecological integrity for fish and other aquatic life.

We hope this publication will provide you with insights and information to meet your waterresource needs and will foster increased citizen awareness and involvement in the protection and restoration of our Nation's waters. The information in this report is intended primarily for those interested or involved in resource management and protection, conservation, regulation, and policymaking at the regional and national levels.

Dr. Donald W. Cline

Associate Director for Water

U.S. Geological Survey 


\section{Contents}

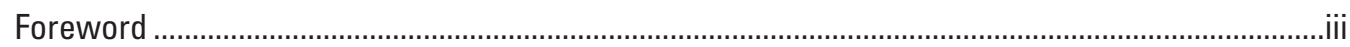

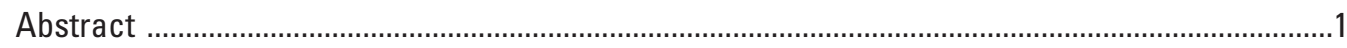

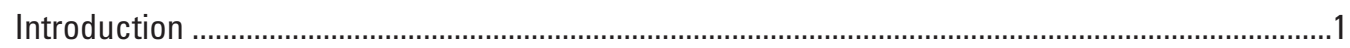

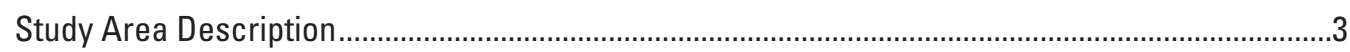

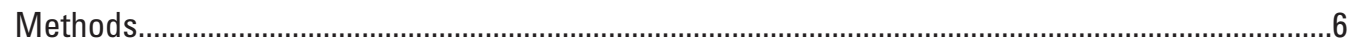

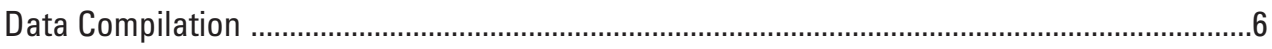

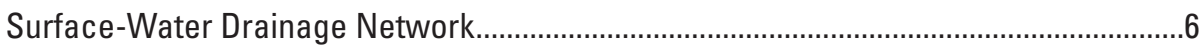

Streamflow and Calibration Load Information .................................................................

Catchment Attributes ...................................................................................................10

The Spatially Referenced Regression on Watershed Attributes Model ................................................................................10

Interpreting the SPARROW Model Coefficients .....................................................................

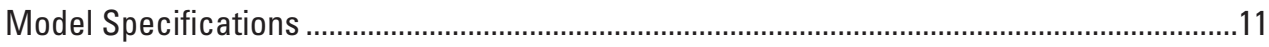

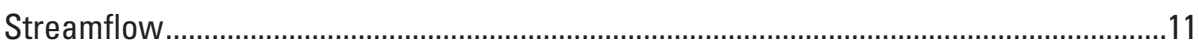

Total Nitrogen and Total Phosphorus Transport .........................................................12

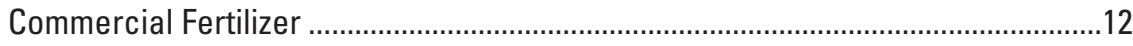

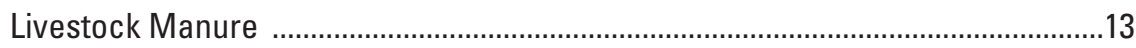

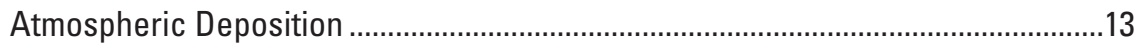

Developed Land ........................................................................................... 13

On-Site Wastewater Treatment...............................................................................13

Point-Source Wastewater Discharge .....................................................................13

Suspended-Sediment Transport.............................................................................14

Accounting for Systematic Differences in Calibration Loads ........................................16

Addressing Spatial Bias in the Model Calibration .......................................................16

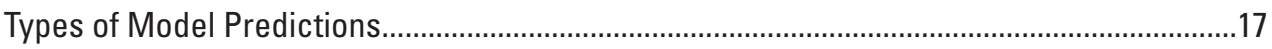

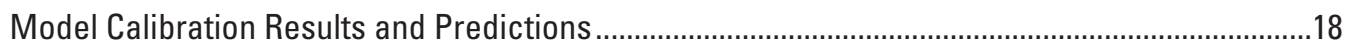

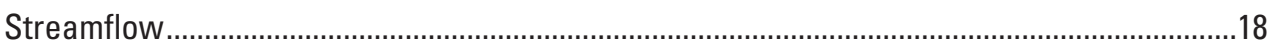

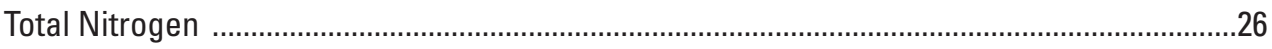

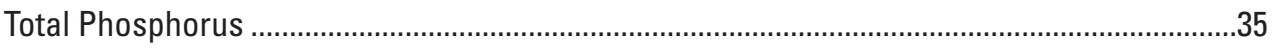

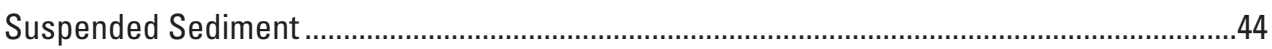

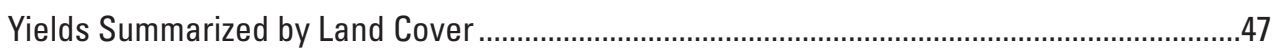

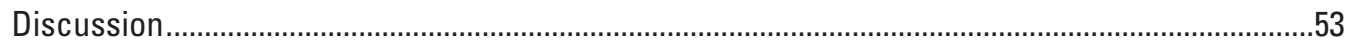

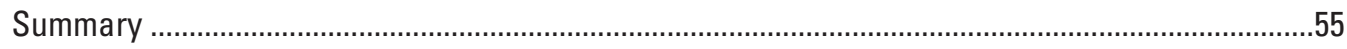

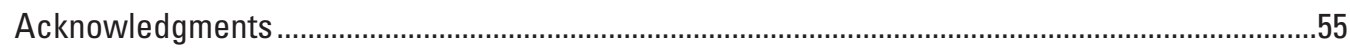

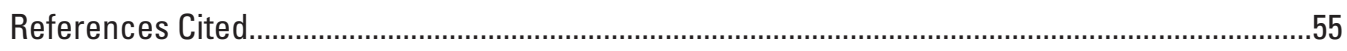

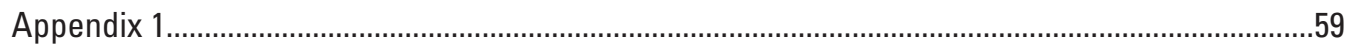

Appendix 2 


\section{Figures}

1. Map showing spatial extent of the Pacific region SPARROW model.

2. Map showing the modeling domain for the SPARROW streamflow, total nitrogen, total phosphorus, and suspended-sediment models developed for the Pacific region of the United States

3. Map showing land cover in the Pacific region of the United States, 2011

4. Map showing mean annual precipitation within the Pacific region of the United States

5. Maps showing surface-water diversions within the Pacific region of the United States

6. Graphs showing diagnostic plots for the Pacific region SPARROW streamflow model.

7. Maps showing spatial distribution of conditioned and unconditioned residuals from the Pacific region SPARROW streamflow model

8. Maps showing predicted mean annual incremental yield and delivered incremental yield of water from the Pacific region SPARROW streamflow model........24

9. Graph showing predicted mean annual water yield, by source, for Hydrologic Unit Code 6 (HUC6) watersheds in the Pacific region of the United States..

10. Graphs showing diagnostic plots for the Pacific region SPARROW total nitrogen model

11. Maps showing spatial distribution of conditioned and unconditioned residuals from the Pacific region SPARROW total nitrogen model

12. Map showing predicted mean annual incremental yield and delivered incremental yield of total nitrogen from the Pacific region SPARROW total nitrogen model

13. Graphs showing predicted mean annual total nitrogen yield, by source, for Hydrologic Unit Code 6 watersheds in the Pacific region of the United States.

14. Graphs showing diagnostic plots for the Pacific region SPARROW total phosphorus model.....

15. Maps showing spatial distribution of conditioned and unconditioned residuals from the Pacific region SPARROW total phosphorus model

16. Map showing predicted mean annual incremental yield and delivered incremental yield of total phosphorus from the Pacific region SPARROW total phosphorus model.

17. Graph showing predicted mean annual total phosphorus yield, by source, for Hydrologic Unit Code watersheds in the Pacific region of the United States.

18. Graphs showing diagnostic plots for the Pacific region SPARROW suspended-sediment model. 


\section{Figures-Continued}

19. Map showing spatial distribution of conditioned and unconditioned residuals from the Pacific region SPARROW suspended-sediment model

20. Map showing predicted mean annual incremental yield and delivered incremental yield of total phosphorus from the Pacific region SPARROW suspended-sediment model.

21. Graph showing predicted mean annual suspended-sediment yield, by source, for Hydrologic Unit Code 6 watersheds in the Pacific region of the UnitedStates.

\section{Tables}

1. Sources of water-quality data used to estimate the calibration loads for total nitrogen, total phosphorus, suspended sediment, and total suspended solids used in the SPatially Referenced Regression On Watershed attributes models developed for the Pacific region of the United States

2. Generalized land cover and surface geology combinations evaluated as upland sources in the SPAtially Referenced Regression On Watershed attributes suspended-sediment model for the for the Pacific region of the United States

3. Model statistics for the explanatory variables included in the SPAtially

Referenced Regression On Watershed attributes streamflow model for the Pacific region of the United States

4. Model statistics for the explanatory variables included in the SPAtially Referenced Regression On Watershed attributes total nitrogen model for the for the Pacific region of the United States

5. Model statistics for the explanatory variables included in the SPAtially Referenced Regression On Watershed attributes total phosphrous model for the for the Pacific region of the United States

6. Model statistics for the explanatory variables included in the SPAtially Referenced Regression On Watershed attributes suspended-sediment model for the for the Pacific region of the United States

7. Media yields of total nitrogen, total phosphorus, and suspended sediment from areas dominated by different land cover types in the Pacific region of the United States dominated by different land cover types. 


\section{Conversion Factors}

International System of Units to U.S. customary units

\begin{tabular}{|c|c|c|}
\hline Multiply & By & To obtain \\
\hline \multicolumn{3}{|c|}{ Length } \\
\hline millimeter $(\mathrm{mm})$ & 0.03937 & inch (in.) \\
\hline $\operatorname{meter}(\mathrm{m})$ & 3.281 & foot $(\mathrm{ft})$ \\
\hline kilometer (km) & 0.6214 & mile (mi) \\
\hline kilometer (km) & 0.5400 & mile, nautical (nmi) \\
\hline $\operatorname{meter}(\mathrm{m})$ & 1.094 & yard (yd) \\
\hline \multicolumn{3}{|c|}{ Area } \\
\hline square kilometer $\left(\mathrm{km}^{2}\right)$ & 247.1 & acre \\
\hline square kilometer $\left(\mathrm{km}^{2}\right)$ & 0.3861 & square mile $\left(\mathrm{mi}^{2}\right)$ \\
\hline \multicolumn{3}{|c|}{ Volume } \\
\hline liter $(\mathrm{L})$ & 33.81402 & ounce, fluid (fl. oz) \\
\hline liter $(\mathrm{L})$ & 2.113 & $\operatorname{pint}(p t)$ \\
\hline liter (L) & 1.057 & quart (qt) \\
\hline liter $(\mathrm{L})$ & 0.2642 & gallon (gal) \\
\hline liter $(\mathrm{L})$ & 61.02 & cubic inch $\left(\mathrm{in}^{3}\right)$ \\
\hline \multicolumn{3}{|c|}{ Flow rate } \\
\hline cubic meter per second $\left(\mathrm{m}^{3} / \mathrm{s}\right)$ & 35.31 & cubic foot per second $\left(\mathrm{ft}^{3} / \mathrm{s}\right)$ \\
\hline millimeter per year $(\mathrm{mm} / \mathrm{yr})$ & 0.03937 & inch per year (in/yr) \\
\hline \multicolumn{3}{|c|}{ Mass } \\
\hline milligram (g) & 0.00003527 & ounce, avoirdupois (oz) \\
\hline kilogram $(\mathrm{kg})$ & 2.205 & pound avoirdupois (lb) \\
\hline metric ton $(\mathrm{t})$ & 1.102 & ton, short [2,000 lb] \\
\hline metric ton $(\mathrm{t})$ & 0.9842 & ton, long $[2,240 \mathrm{lb}]$ \\
\hline \multicolumn{3}{|c|}{ Yield } \\
\hline $\begin{array}{l}\text { kilogram per square kilometer per } \\
\text { year }\left(\left[\mathrm{kg} / \mathrm{km}^{2}\right] / \mathrm{yr}\right) \\
\text { metric tons per square kilometer per } \\
\text { year }\left(\left[\mathrm{t} / \mathrm{km}^{2}\right] / \mathrm{yr}\right)\end{array}$ & $\begin{array}{l}0.00892 \\
8.92\end{array}$ & $\begin{array}{l}\text { pound per acre per year }([\mathrm{lb} / \mathrm{acre}] / \mathrm{yr}) \\
\text { pound per acre per year }([\mathrm{lb} / \mathrm{acre}] / \mathrm{yr})\end{array}$ \\
\hline
\end{tabular}




\section{Datums}

Vertical coordinate information is referenced to the North American Vertical Datum of 1988 (NAVD 88).

Horizontal coordinate information is referenced to the North American Datum of 1983 (NAD 83).

\section{Abbreviations}

EPA U.S. Environmental Protection Agency

SPARROW SPAtially Referenced Regression On Watershed attributes

USGS U.S. Geological Survey 


\title{
Spatially Referenced Models of Streamflow and Nitrogen, Phosphorus, and Suspended-Sediment Loads in Streams of the Pacific Region of the United States
}

\author{
By Daniel R. Wise
}

\section{Abstract}

Although spatial information describing the supply and quality of surface water is critical for managing water resources for human uses and for ecological health, monitoring is expensive and cannot typically be done over large scales or in all streams or waterbodies. To address the need for such data, the U.S. Geological Survey developed SPAtially Referenced Regression On Watershed attributes (SPARROW) for the Pacific region of the U.S. for streamflow and three water-quality constituents-total nitrogen, total phosphorus, and suspended sediment, based on a decadal time frame centered on the year 2012. The domain for these models included the Columbia River basin, the Puget Sound, the coastal drainages of Washington, Oregon, and California, and the Central Valley of California. Landscape runoff (represented by the difference between precipitation and evapotranspiration) was the largest source of streamflow, wastewater discharge, and atmospheric deposition were the largest contributors to total nitrogen yield from the Pacific region, wastewater discharge was the largest contributor to total phosphorus yield, and forest land was the largest contributor to suspended-sediment yield. Watersheds with relatively high water yields also generally had relatively high yields of total nitrogen, total phosphorous, and suspended sediment-except where there were large contributions from developed land and wastewater discharge.

The data used in this study, including many that improved upon existing national data or were compiled specifically for the Pacific region, characterized the complex hydrologic and water-quality conditions in the region more completely than previous models. By using these new datasets, this investigation was able to account for the complex network of water diversions and transfers, quantify the contribution of nutrients from different sources of livestock manure, discern a signal from unpaved logging roads in the suspended-sediment yields from forested coastal watersheds, show how recent wildfire disturbance influences phosphorus and sediment delivery to streams, and how sediment delivery to streams is also sensitive to the intensity of cattle grazing. The results from this study could complement research and inform water-quality management activities in the Pacific region. Examples might include identifying potentially impaired waterbodies and guiding remediation efforts where impairment has been documented, explaining the spatial patterns in harmful algal blooms, and providing estimates of sediment and nutrient loadings to Pacific coast estuaries where such data are scarce or non-existent.

\section{Introduction}

Nutrient over-enrichment is recognized as a serious threat to inland and coastal waters throughout most of the United States (U.S. Geological Survey, 1999; U.S. Environmental Protection Agency, 2010) and while suspended sediment in streams is a natural consequence of weathering and erosion of surficial materials in a watershed, high levels can adversely affect in-stream biota and public water supplies (Griffiths and Walton, 1978; Morris and Fan, 1998). These water-quality issues have also been identified as problems across California and the Pacific Northwest (California Water Resources Control Board, 2017; Idaho Department of Environmental Quality, 2017; Montana Department of Environmental Quality, 2017; Oregon Department of Environmental Quality, 2017; Washington Department of Environmental Conservation, 2017; Wyoming Department of Environmental Quality, 2017). Additionally, water availability is a serious concern in the arid areas of the western United States because of the way surface water is allocated, the depletion of groundwater from over-pumping, and diminishing supplies due to drought stress (Anderson and Woosley, 2005). Spatial information describing the supply and quality of surface water, therefore, is critical for managing water resources for human uses and for ecological health. However, monitoring is expensive and cannot typically be done over large scales or in all streams or waterbodies.

Modeling is one technique that can be used to extend the information gathered by monitoring to estimate the spatial distribution of water supply and water-quality conditions and identify linkages between those conditions and environmental factors that affect them. Modeling also plays a central role in water-supply and water-quality management by providing 
a means for evaluating the effectiveness of proposed improvement strategies (National Research Council, 2001). SPAtially Referenced Regression On Watershed attributes (SPARROW) models represent one technique that is specifically designed to extrapolate the information developed from local monitoring data to all waterbodies within a specific spatial domain and provide a tool for evaluating proposed improvement strategies such as total maximum daily load regulations. The SPARROW model is a hybrid statistical and mechanistic model for estimating the transport of mass through the landscape and stream networks under long-term, steady state conditions (Schwarz and others, 2006). The model uses data describing catchment attributes (sources of contaminant mass and landscape characteristics) and stream and waterbody properties to explain the spatial variation in the measured, mean annual streamflow or load at a set of calibration stations. The measured, mean annual streamflow or load is the dependent variable (the calibration data set) in the models, and the watershed attributes are the explanatory variables. SPARROW can simulate the net effect of landscape properties (such as land cover, climate, soil properties, geology, and hydrology) on the delivery of water, sediment, and nutrients from land to streams as well as the processes that lead to permanent loss within free-flowing streams and impoundments. A calibrated SPARROW model can then be used to predict hydrologic and water-quality conditions throughout a surface-water network, including areas where no such data exist.

SPARROW models offer several advantages for assessing hydrologic and water-quality conditions across large regions. One is that they are developed using statistical algorithms that optimize the fit of model coefficients and, therefore, can be used to objectively identify the environmental factors that have an observable linkage with in-stream conditions. In that way, the models can be used to identify such things as the primary sources of a water-quality constituent. A second advantage is that SPARROW models are designed to utilize the detailed spatial information inherent in digital geographic datasets and synthesize that information in a way that can be related to the spatial scale of available monitoring data, while still retaining the underlying spatial resolution for prediction purposes. In that way, SPARROW models provide a framework for integrating a wide range of different types of data and utilizing all that information to provide spatially detailed estimates of in-stream conditions. A third example of those advantages is that SPARROW models provide estimates that are fully linked in space through a digital stream network so that upstream environmental factors can be related to downstream conditions. All these advantages of SPARROW provide a means of mapping water-quality conditions over large regions while retaining significant spatial detail, mapping the factors that affect in-stream conditions, and relating upstream environmental factors such as sources of model constituents to downstream conditions.
SPARROW nutrient models have been developed previously for large regions of the conterminous U.S. as part of a larger effort conducted by the U.S. Geological Survey (USGS) National Water Quality Assessment (NAWQA) (Preston and others, 2011; Wise and Johnson, 2013; Domagalski and Saleh, 2015; Saleh and Domagalski, 2015). Those models were focused on nutrients, were based on a 2002 time frame and extended over six large regions covering all but the southwestern part of the conterminous U.S. Since those models were developed, technology, scientific understanding, and data availability have all advanced, and the work described in this report was performed to develop improved models based on those advancements. The new models are based upon many improved datasets, which should provide water-quality information that better supports management agencies as they perform their important work. The new models build upon the previous models in several important ways. First, the new models are based on a 2012 time frame, a full 10 years after the previous set of models, and in that way are more representative of the current decade. The list of water-quality constituents for which models were developed was also expanded from one that includes only nutrients (nitrogen and phosphorus) to one that includes streamflow and suspended sediment. These additional constituents are of value in themselves, but they are also related to nutrient levels and provide a broader basis of information for understanding the factors affecting nutrient conditions in waterbodies.

This report describes SPARROW models developed to simulate long-term mean annual streamflow, and total nitrogen, total phosphorus, and suspended-sediment transport in streams and rivers in the Pacific region of the U.S. (fig. 1) based on inputs and management practices centered near 2012, the base year of the model. The Pacific region is one of five areas of the U.S. for which SPARROW models for similar constituents were developed as part of a national modeling effort by the USGS. The other four areas include the Northeast, Southeast, Midwest, and Southwest regions of the U.S. The models were based on the most detailed databases available for describing hydrologic and water-quality conditions and the environmental factors affecting them in the 2012 time frame. These databases include hydrologic and water-quality information for streams throughout the region, sources of contaminants such as point-source discharges and agricultural practices, and environmental characteristics that affect fate and transport of contaminants. All these databases were integrated by relating them to a spatial framework defined by a digital stream network. The models were then calibrated to optimize the fit of model coefficients and identify the dominant factors affecting hydrologic and water-quality conditions locally as well as downstream. 
The objectives of this study were to:

1. Estimate mean annual water, total nitrogen, total phosphorus, and suspended-sediment yields in monitored and unmonitored stream reaches in the Pacific region of the United States;

2. To quantify the relative contribution of different sources to the water, total nitrogen, total phosphorus, and suspended-sediment yields; and
3. To provide model results for use in a variety of research and water-quality management applications.

SPARROW models were developed to represent streamflow and the sources, fate, and transport of nutrients and suspended sediment in streams and rivers of the Pacific region of the United States during 2012 (Wise, 2020).

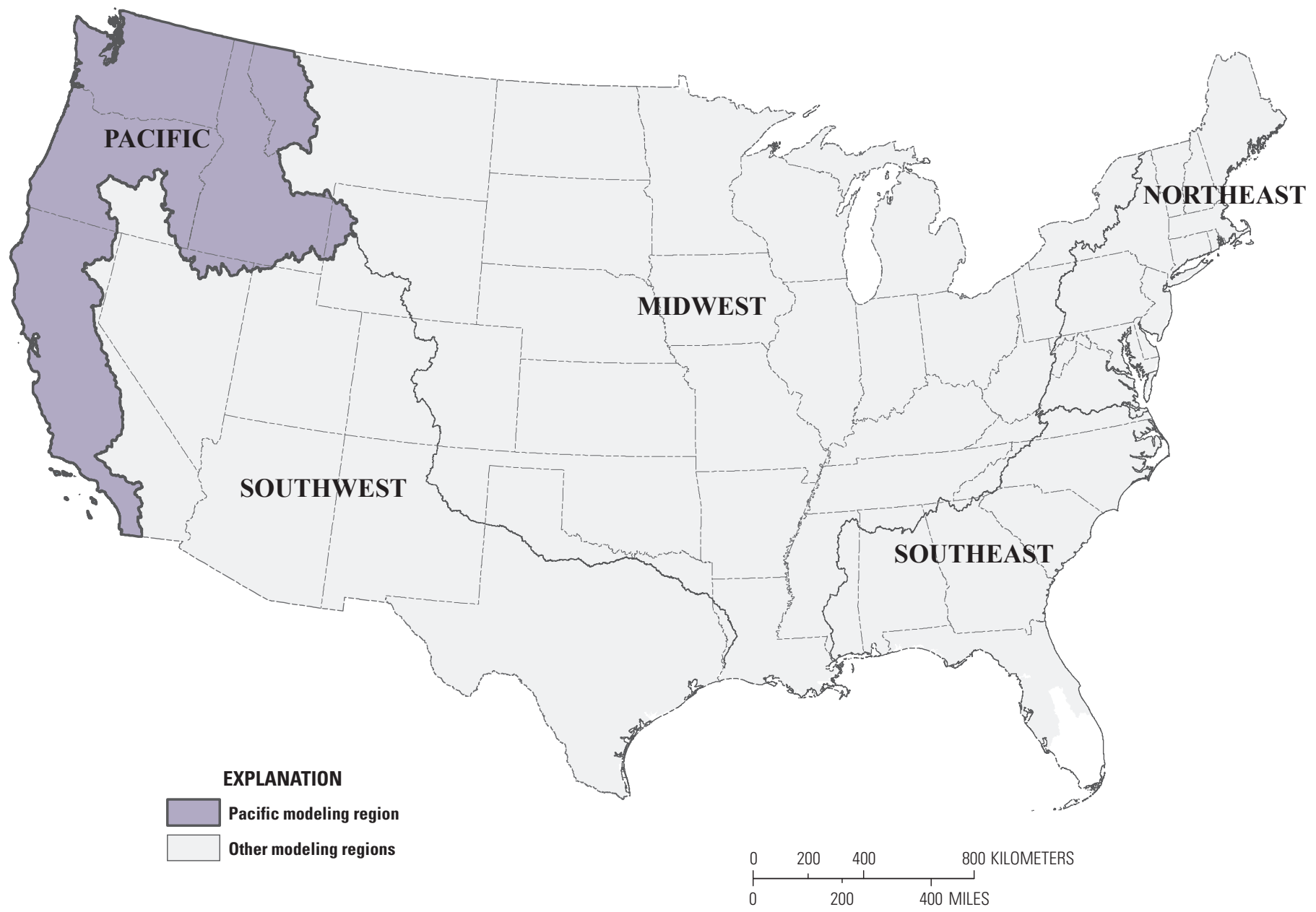

Figure 1. Spatial extent of the Pacific region SPARROW (SPAtially Referenced Regression On Watershed attributes) model.

\section{Study Area Description}

The domain for this study included the Pacific drainages of the United States and covered a total area of 1,060,580 square kilometers $\left(\mathrm{km}^{2}\right)$. The domain covered parts of 8 states and included 32 six-digit Hydrologic Unit Code (HUC6) watersheds (fig. 2) (Seaber and others, 1987). All but one of these watersheds regularly drain to the Pacific Ocean. The exception is the watershed containing the Tulare-Buena and Vista Lakes basins, which had in the past drained to the Pacific Ocean, but its only current connection is due to intermittent pumping of water to the San Joaquin River as a flood control measure (California Department of Water Resources, 2010).
Extensive manipulation of the natural hydrology occurs throughout the modeling domain and includes diversions for power generation, municipal water supply, and irrigation, as well as transfers between stream reaches for power generation. In 2011, scrub and grassland covered 39 percent of the modeling domain, forest land covered 34 percent, agriculture covered 10 percent, urbanized areas covered 4.3 percent, while the remaining areas consisted of various minor land cover types (fig. 3) (Homer and others, 2015). Most of the people within the modeling domain live in a small number of large metropolitan areas-Los Angeles, San Diego, San Francisco Bay, Seattle, and Portland, but there are also a few medium-sized cities located in the San Joaquin, Sacramento, Willamette, Spokane, and Boise River basins. 


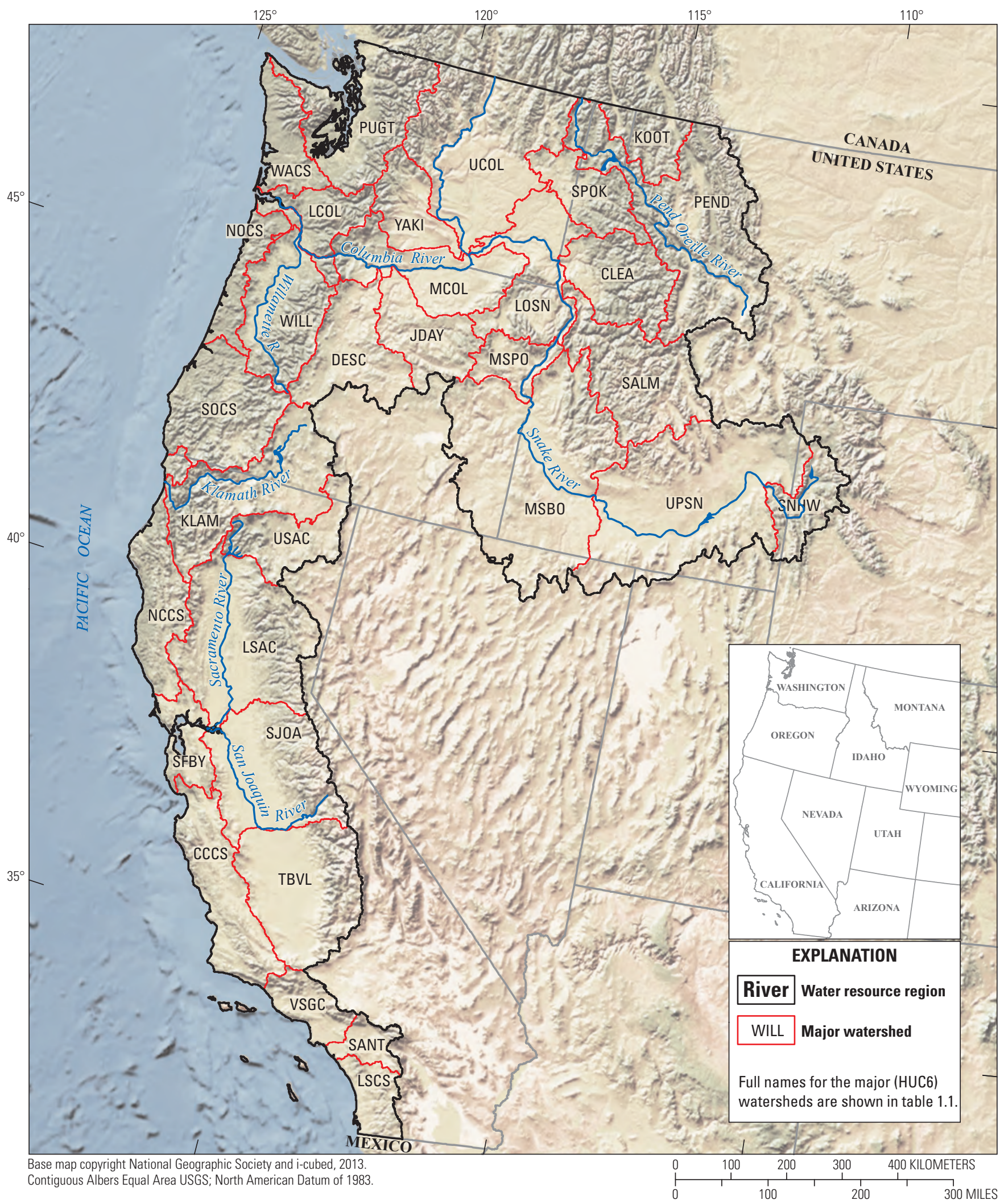

Figure 2. Modeling domain for the SPARROW (SPAtially Referenced Regression On Watershed attributes) streamflow, total nitrogen, total phosphorus, and suspended-sediment models developed for the Pacific region of the United States. 


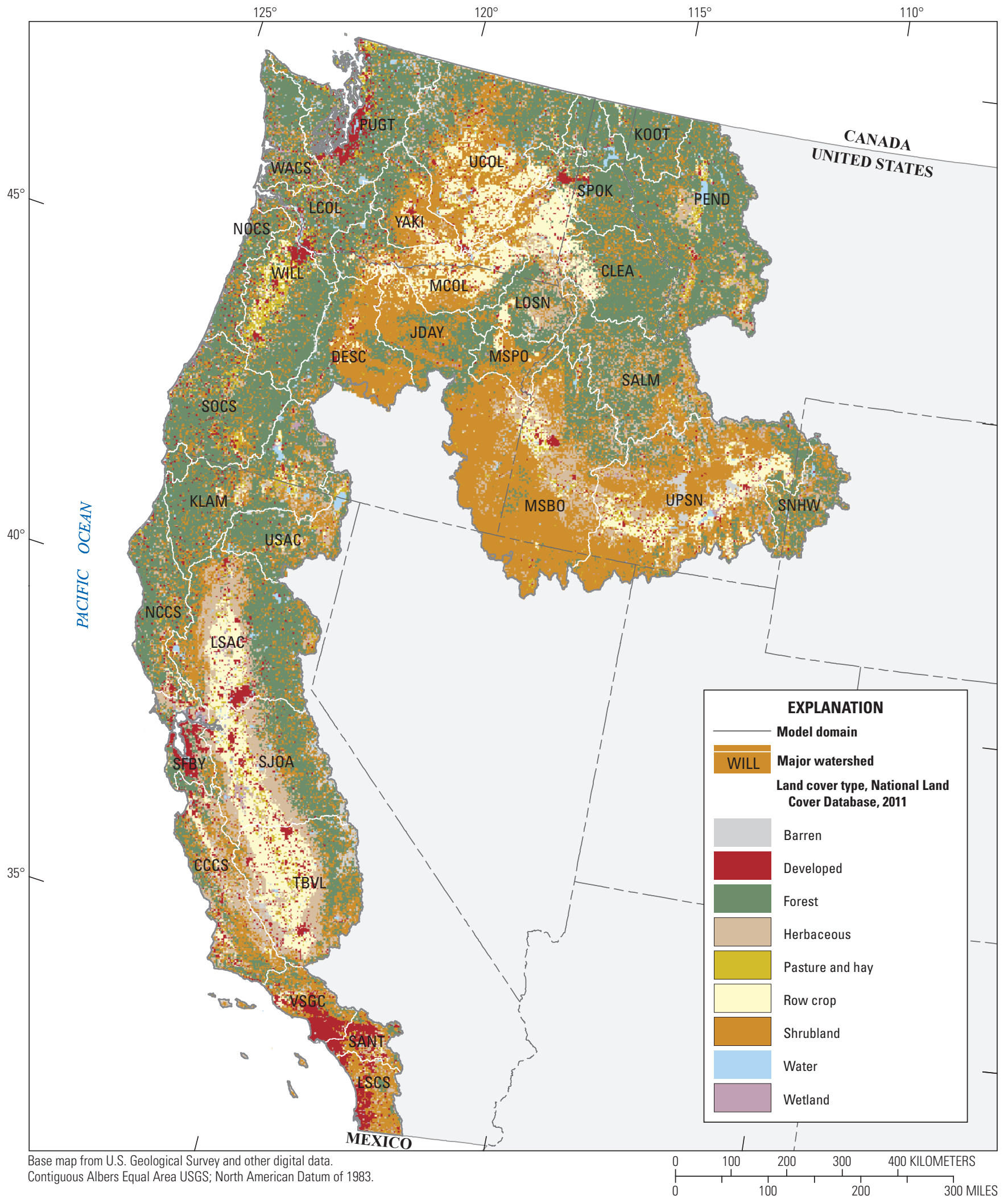

Figure 3. Land cover in the Pacific region of the United States, 2011 (Homer and others, 2015). 
The climate varies widely across the modeling domain, with a humid continental climate in western Washington and Oregon, a semi-arid steppe climate in eastern Oregon and Washington and most of Idaho, a Mediterranean climate along most of the California coast and in the Central Valley, a desert climate in southern California, and an alpine climate in the Sierra Mountains in California, the Cascade Range in Northern California, Washington, Oregon, and the Rocky Mountains in Idaho, Montana, and Wyoming. As a result, there is also a wide variation in mean annual precipitation across the modeling domain, ranging from less than 200 millimeters per year $(\mathrm{mm} / \mathrm{yr})$ in the southwestern part of the San Joaquin Valley to close to $6,000 \mathrm{~mm} / \mathrm{yr}$ along the west slope of the Olympic Mountains in Washington (fig. 4; Wieczorek and others, 2019). Seasonal precipitation patterns, however, are consistent across the entire modeling domain-most of the annual precipitation falls during late autumn through early spring and very little falls during summer. Additionally, a substantial amount of the precipitation in some mountainous areas falls as snow while almost all the precipitation in lower elevation areas falls as rain, and the annual precipitation typically falls during a small number of intense storm events in some areas while it is spread relatively consistently over a few months in other areas.

\section{Methods}

Detailed databases were compiled that describe water-quality conditions in the 2012 time frame and the environmental factors affecting those conditions. These databases include water-quality information for streams throughout the region, sources of contaminants such as point-source discharges and agricultural practices, and environmental characteristics that affect the fate and transport of contaminants.

\section{Data Compilation}

\section{Surface-Water Drainage Network}

The surface-water drainage network used for this study was an enhanced version of the NHDPlus Version 2 (Brakebill and others, 2020; Horizon Systems, 2013). This enhanced version of NHDPlus Version 2, hereinafter referred to as "E2NHDPlus2," is a comprehensive set of digital spatial data that includes attributes for surface water features such as streams, lakes, ponds, and reservoirs (Simley and Carswell,
2009). The surface-water features represented in E2NHDPlus2 largely correspond to the features on 1:100,000 scale USGS topographic maps. The attributes used in this study include the mean annual streamflow, velocity, and time of travel for each reach, the identification of perennial and intermittent reaches, and the morphometry and hydraulic properties of impoundments such as ponds, lakes, and reservoirs. Each reach in the E2NHDPlus2 starts at any point of channel initiation or a tributary junction and most reaches represent streams or inland waterbodies, such as lakes and reservoirs. The E2NHDPlus2 also identifies the incremental catchment for each reach, which is defined as the area that drains directly to a reach without passing through another reach. While E2NHDPlus2 contains minimal information for stream reaches and watersheds in Canada and Mexico, it does provide sufficient information to properly route surface water into the United States.

The E2NHDPlus2 network for the Pacific SPARROW models contains 338,949 reaches, which vary in size from small, intermittent streams that can go years without flow to the Columbia River with a mean annual streamflow of 340,000 cubic feet per second near its confluence with the Pacific Ocean (U.S. Geological Survey, 2015). About 48 percent of the free-flowing stream length within the domain for the Pacific SPARROW models was identified as having perennial flow in E2NHDPlus2 and 52 percent was identified as having intermittent flow. E2NHDPlus2 does not differentiate, however, between intermittent streams where flow ceases for weeks or months each year and ephemeral streams that flow only for hours or days following rainfall and can go many years without any flow.

Attributes were added to the E2NHDPlus2 to account for the diversion and transfer of water within the Pacific region. The diversions included 91 intakes for consumptive use for power generation, 248 irrigation withdrawals, and 642 municipal water supply intakes (fig. 5). The amount diverted was estimated from records of consumptive use maintained by power plants, local irrigation districts, and municipal water suppliers, or records of population served by municipal water suppliers (Wieczorek and others, 2019) that were then multiplied by a regionally weighted value for per capita water (Maupin and others, 2014). When those sources of information were not available the amount diverted was estimated from records of streamflow above and below the point of diversion. The amount of water removed for the 72 instream transfers (fig. 5) was estimated from discharge records at the transfer intakes or of streamflow records above and below those intakes. 


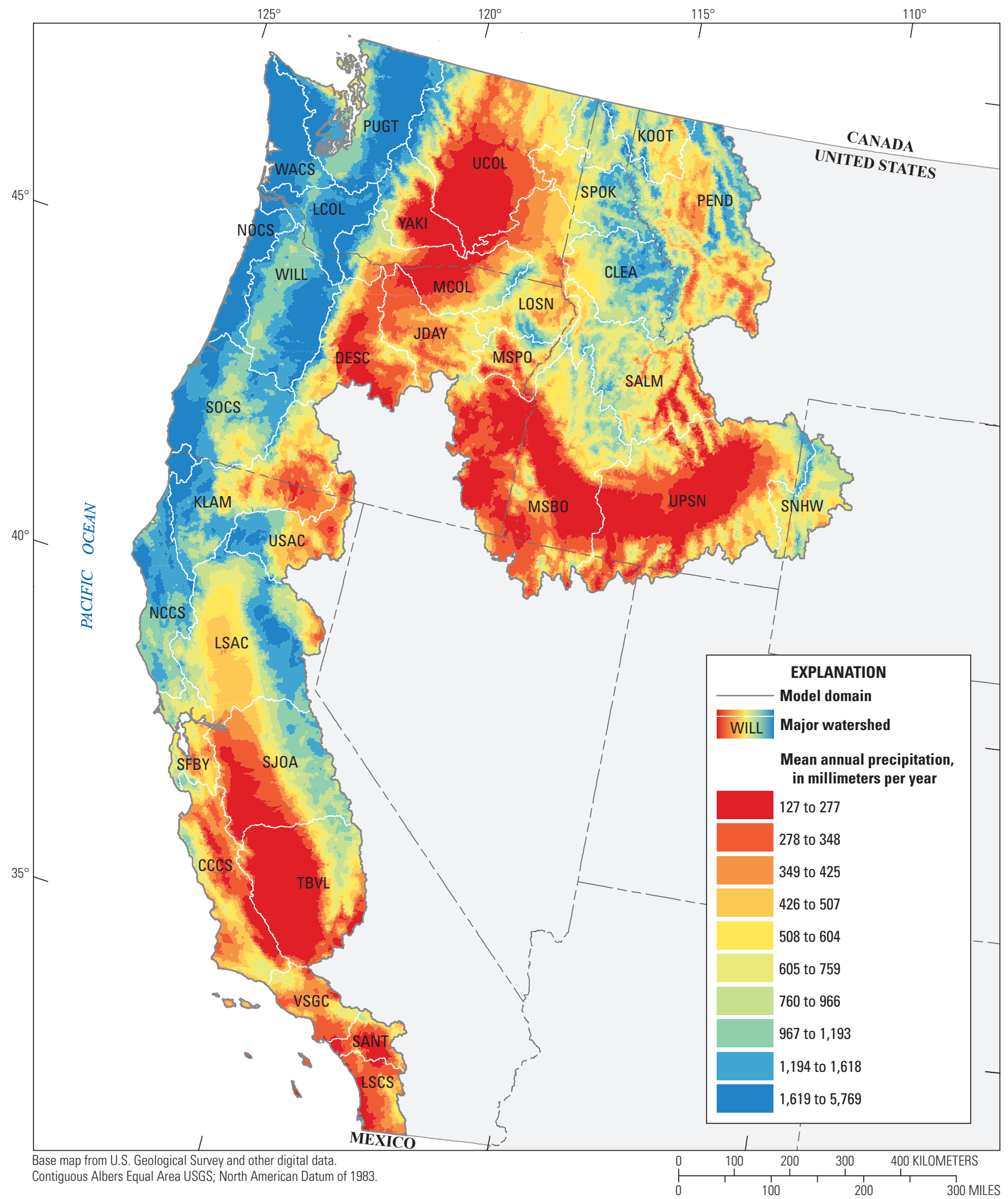

Figure 4. Mean annual precipitation within the Pacific region of the United States (Wieczorek and others, 2019). 

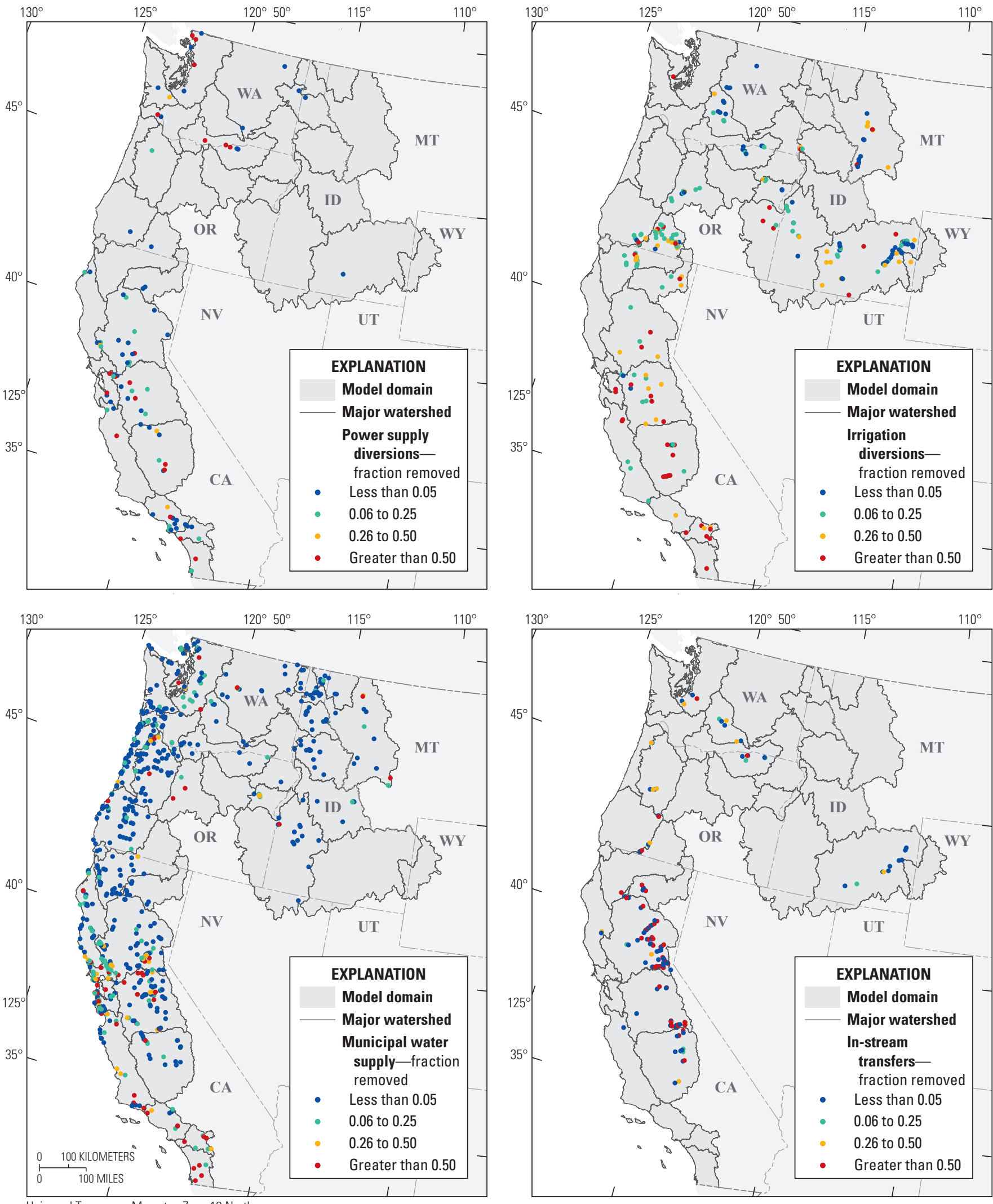

North American Datum of 1983

Figure 5. Surface-water diversions within the Pacific region of the United States. 


\section{Streamflow and Calibration Load Information}

SPARROW is a steady-state, mass balance model that relies on the assumption that the dependent and explanatory variables reflect conditions for comparable time periods (Schwarz and others, 2006). Use of a uniform period of record (or closely comparable periods of record) to estimate all variables removes the confounding effect of temporal variability from the SPARROW spatial analysis. For the streamflow model, comparability among estimates of the dependent variable was achieved by using the mean annual value for a common 15-year period (2000-14) for all stations that was based on continuous daily streamflow records. Stations missing more than 2 years of record were excluded from the calibration dataset for the streamflow model, however. Where appropriate, comparability between dependent and explanatory variables for the streamflow model was achieved by using mean values for 2000-14.

For the total nitrogen, total phosphorus, and suspendedsediment models, however, comparability of conditions could not be guaranteed using mean values for 2000-14 for the dependent and explanatory variables for two reasons (Schwarz and others, 2006):

- The water-quality monitoring data used to estimate loads represented different periods of record, sample size, and hydrologic conditions at different stations, or was affected by long-term trends in water quality, thus potentially introducing artificial differences in load among the calibration stations; and

- Information for some important explanatory variables was not available for multiple periods and, therefore, it was not possible to compute long-term averages over the same period used to summarize the dependent variable. For example, estimates of source inputs from fertilizer and wastewater discharge using the improved estimation methods described in this report were available only for 2012 .

To compensate for these limitations, estimates for the dependent variable (constituent load) in the total nitrogen, total phosphorus, and suspended-sediment models were detrended to a selected base year; that is, they were estimated to represent the load that would have been observed during the period 2000-14 if the dynamic factors causing trend in load were held constant throughout that period, equal to their values in the base year (Schwarz and others, 2006). The base year selected for the Pacific region SPARROW models was water year 2012. The watershed attributes used as explanatory variables (for example, source inputs, climatic data, and land management practices) in these models represented 2012 conditions or conditions as close to 2012 as possible. The predictions from the total nitrogen, total phosphorus, and suspended-sediment models, therefore, represented conditions that would have been observed between 2000 and 2014 given the hydrologic conditions throughout that period and given source inputs and management practices that were similar to the ones occurring in 2012.

The calibration loads used in the Pacific region total nitrogen, total phosphorus, and suspended-sediment models were based on water-quality data obtained from the USGS and other federal, state and local agencies (table 1; Saad and others, 2019) and streamflow data collected by the USGS and the Oregon Water Resources Department. The mean annual load for each model calibration station for 2000-14 was estimated using one of two methods (Saad and others, 2019). The Beale's Ratio Estimator (BRE) was used to estimate a mean annual load for 2000-14 when there was no trend in the load, because this approach was shown to have little bias and was better at estimating long-term mean annual loads than most regression approaches (Lee and others, 2016). When there was a significant trend in load, however, the USGS Fluxmaster regression method (Schwarz and others, 2006) was used to estimate a mean annual load for 2000-14 that was then detrended to the 2012 base year to account for differences in record length, hydrologic conditions, and sample size among the calibration stations.

The final set of calibration loads for the total nitrogen, total phosphorus, and suspended-sediment models were selected based on the results from an evaluation of their accuracy. Mean load estimates with a standard error greater than 50 percent were removed from the set of potential calibration loads regardless of which estimation method was used, which is consistent with the approach used in previous SPARROW studies. Potential bias in the Fluxmaster-estimated loads were evaluated using the methods described in Saad and others (2019), and those with unacceptable bias were removed from the dataset of potential calibration loads. Additionally, some of the mean annual streamflow values and mean annual loads were removed because they were found to include substantial bias related to local hydrology (these were usually related to cases of losing reaches and the presence of large diversions). The streamflow model included 726 calibration values, the total nitrogen model included 131 calibration loads, the total phosphorus model included 233 calibration loads, and the suspended-sediment model included 220 calibration loads. 
Table 1. Sources of water-quality data used to estimate the calibration loads for total nitrogen, total phosphorus, suspended sediment, and total suspended solids used in the SPARROW (SPatially Referenced Regression On Watershed attributes) models developed for the Pacific region of the United States.

\begin{tabular}{|c|c|c|c|c|c|}
\hline \multicolumn{6}{|c|}{ Agencies } \\
\hline Federal & $\begin{array}{l}\text { No. of } \\
\text { stations }\end{array}$ & State & $\begin{array}{l}\text { No. of } \\
\text { stations }\end{array}$ & Local & $\begin{array}{l}\text { No. of } \\
\text { stations }\end{array}$ \\
\hline $\begin{array}{l}\text { U.S. Bureau of } \\
\text { Reclamation }\end{array}$ & 23 & $\begin{array}{l}\text { California Environmental Protection } \\
\text { Agency }\end{array}$ & 19 & $\begin{array}{l}\text { San Joaquin County and Delta Water } \\
\text { Quality Coalition (California) }\end{array}$ & 1 \\
\hline \multirow{4}{*}{$\begin{array}{l}\text { U.S. Department of } \\
\text { Agriculture }\end{array}$} & & $\begin{array}{l}\text { Nevada Department of Conservation } \\
\text { and Natural Resources }\end{array}$ & 5 & Yurok Tribe (California) & 3 \\
\hline & & $\begin{array}{l}\text { Oregon Department of } \\
\text { Environmental Quality }\end{array}$ & 71 & $\begin{array}{l}\text { Tri-State Water Quality Council, } \\
\text { (Montana) }\end{array}$ & 6 \\
\hline & & $\begin{array}{l}\text { Washington State Department of } \\
\text { Ecology }\end{array}$ & 66 & $\begin{array}{l}\text { Kalispel Tribe Natural Resources } \\
\text { Department (Montana) }\end{array}$ & 1 \\
\hline & & & & $\begin{array}{l}\text { Klamath Tribes Natural Resources } \\
\text { Department (Oregon) }\end{array}$ & 4 \\
\hline
\end{tabular}

\section{Catchment Attributes}

Most of the catchment attributes used in the Pacific region SPARROW models were compiled as part of the NAWQA national SPARROW effort described earlier (Wieczorek and others, 2019), but some catchment attributes were compiled specifically for the Pacific region. These attributes were processed for use in the SPARROW model by summarizing them for each incremental E2NHDPlus2 catchment as either a total amount or mean value, and details about each of the catchment attributes evaluated in each of the models are included in the Model Specifications section.

\section{The Spatially Referenced Regression on Watershed Attributes Model}

The SPARRROW model uses an iterative process to estimate coefficients for user-selected model variables and evaluates the statistical significance of those variables. Beginning in the headwater reaches, SPARROW starts the calibration by using initial model coefficients to estimate the load (or streamflow) generated within the incremental catchment for each stream reach and the permanent loss in free-flowing streams and impoundments (ponds, lakes, and artificial reservoirs). The incremental load is accumulated moving downstream through the surface-water drainage network until a calibration station is reached-at which point the accumulated load is adjusted to match the measured value at the calibration station. The accumulation process continues downstream after each calibration station adjustment and stops when a terminal reach (such as an estuary or internal drainage) is encountered. At this point, a nonlinear least squares (NLSS) regression is applied to adjust the initial coefficients based on the differences between the measured loads at calibration stations and the non-adjust estimated loads at those calibration stations. Accumulated loads are then re-estimated using the adjusted coefficients. This continues until the difference between the measured and estimated loads is minimized. Ninety percent confidence intervals were estimated for each coefficient using the standard errors from each model and the quantile from its standard $t$ distribution. For the application of SPARROW to the Pacific region 90 percent confidence intervals were also estimated for the model predictions by using a bootstrap resampling method (Schwarz and others, 2006) that entailed repeated estimation of the model using subsets of the calibration data (200 times in these applications of the model). 


\section{Interpreting the SPARROW (Spatially Referenced Regression On Watershed Attributes) Model Coefficients}

The watershed attributes evaluated in the Pacific region SPARROW models represented processes that were expected to add water, sediment, or nutrients to streams (source terms), or to enhance or attenuate their delivery from the land (delivery terms). The reach and impoundment attributes that were evaluated in the models represented processes that were expected to cause permanent reductions in the volume of water or mass of sediment or nutrients in either free-flowing streams or impoundments. The final set of explanatory variables for each model represented important watershed, reach, and impoundment attributes. The significance of all model terms was evaluated at the 5 percent level (alpha $=0.05$ ), using a onesided $t$-test for the source and loss terms because they could only be positive and a two-sided $t$-test for the delivery terms because they could be either positive or negative.

The coefficients estimated by the SPARROW model provide insight into the important properties and processes that control how water, sediment, and nutrients move through a watershed. The coefficients for the source terms have a physical interpretation that depends upon the form by which each source is expressed. Coefficients estimated for source terms with units of volume per time or mass per time represent the average volume or mass of that source delivered to streams, whereas coefficients estimated for source terms with units of area represent the average yield from that source. The signs of the coefficients for the delivery terms, rather than their value, provide insight into how they act on the sourcesdelivery terms with positive coefficients enhance delivery to stream compared to average conditions while those with negative coefficients attenuate delivery compared to average conditions. The coefficients for the stream and impoundment loss terms, when multiplied by the values for those terms, represent the ratio between the amount of water, sediment, or nutrients entering a waterbody and the amount that is discharged from that waterbody.

\section{Model Specifications}

\section{Streamflow}

Streamflow in a reach is a combination of direct surface runoff and groundwater baseflow derived from local precipitation within a watershed as well as supplemental water that is diverted from another watershed or pumped from deep aquifers and used primarily for irrigation or municipal water supply. Seven potential sources of streamflow were evaluated in the Pacific region streamflow model. Precipitation minus actual evapotranspiration (PME; expressed in cubic feet per second $\left[\mathrm{ft}^{3} / \mathrm{s}\right]$ to be consistent with the calibration data set) represented the mean annual difference between precipitation and evapotranspiration for water years 2000-14 for each E2NHDPlus2 catchment (McCabe and Wolock, 2011) and, as a result, these estimates did not account for consumptive water use or transfers, or the local variations in watershed properties that can influence this parameter. Irrigated land represented the total area of land with active irrigation in 2012 within each E2NHDPlus2 catchment (Pervez and Brown, 2010). Spring discharge represented the discharge from natural springs within each E2NHDPlus2 catchment, which was estimated by either taking a mean value of instantaneous measurements (for sites with at least 10 measurements that spanned at least 2 years) or estimating the contribution due to springs located between 2 streamgages. All the data used to estimate spring discharge were collected by the USGS (2015). Wastewater discharge represented the total 2012 discharge to surface water within each E2NHDPlus2 catchment from municipal wastewater treatment plants with NPDES permits (Skinner and Wise, 2019) while wastewater discharge to land represented the application of treated municipal wastewater to nearby land within each E2NHDPlus2 catchment primarily for irrigation (U.S Environmental Protection Agency, 2017). Inter-basin transfers were those that occurred between stream reaches that were located on different primary flow paths as defined by E2NHDPlus2 (between watersheds) while local transfers were those that occurred between stream reaches that were located on the same primary flow path (within the same watershed).

Additional factors were evaluated for their influence on the delivery of water from land to waterbodies and for their role in the loss of water from free-flowing streams and impoundments (Wieczorek and others, 2019). Although most of these were naturally occurring they also included some anthropogenic factors as well. The natural loss of water from free-flowing streams represented evaporation and transfer to underlying material while the anthropogenic factors evaluated represented diversions for consumptive use for power generation, municipal water supply, and irrigation, as well as instream transfers. Natural water losses were modeled as a first-order decay rate, based on the reach time of travel (days), which represented the fraction of streamflow that was lost to evaporation and groundwater recharge in each reach. The effect of evaporation and other losses from impoundments was evaluated by estimating an evaporation rate that was based on the reciprocal areal hydraulic load of the impoundments.

Diversions for water supply and irrigation were represented by the proportion of water remaining in an affected reach. Coefficients were estimated for each diversion type, and these coefficients represented scaling factors for those proportions. These estimated coefficients were then used in the total nitrogen, total phosphorus, and suspendedsediment models based on two assumptions. First, that the streamflow model provided more accurate estimates of 
the effects of water diversions compared to the constituent models. The streamflow model had many more calibration stations than the constituent models and, as a result, provided much better spatial coverage. Additionally, the calibration data used in the streamflow model were likely more precise than the calibration data used in the constituent models because the streamflow calibration data were based on measured daily values rather than estimated loads. The second assumption was that nitrogen, phosphorus, and suspended-sediment are removed at the diversions in the same proportion as streamflow. There is no information available that shows what proportion of nitrogen, phosphorus, and suspended-sediment is removed at diversions compared to streamflow in the Pacific region nor is there information readily available that could be used to make that estimate (for example, the typical design or construction of the diversions, the relative proportion of dissolved and particulate load, or the degree of stream mixing). Therefore, an assumption that the values are equal likely provided the best possible estimates.

In contrast to the approach for specifying diversions, instream transfers were specified in the model as fixed valuesthat is, without a model-estimated coefficient. Because of the way the streamflow model was configured, a portion of the water diverted for municipal water supply, irrigation, and instream transfers was returned to the stream network through the sources representing municipal wastewater discharge, irrigated land, and inter-basin and local transfers, respectively.

\section{Total Nitrogen and Total Phosphorus Transport}

Nitrogen and phosphorus in surface water originate from both natural and anthropogenic sources. Most natural nitrogen in surface water is fixed from the atmosphere by soil bacteria and then transported to streams either through surface runoff or through groundwater, and this potential source of nitrogen was evaluated in two different ways. Nitrogen fixation by common soil bacteria was represented by the area of land cover types with minimal human impact within each E2NHDPlus2 catchment (deciduous evergreen and mixed forest and shrub, scrub, and grasslands). Nitrogen fixation due to the symbiotic association of red alder trees (Alnus rubra) with certain soil bacteria was represented by the basal area of that tree species in each E2NHDPlus2 catchment (Oregon State University, 2019). The only substantial source of natural phosphorus in the Pacific region is from the weathering of phosphorus-containing minerals and this source has been parameterized in previous SPARROW models in different ways-as runoff from land cover types with minimal human impact (Moore and others, 2004; Wise and Johnson, 2013), as a function of the natural phosphorus content of local soil and rock (Garcia and others, 2011; Domagalski, and Saleh, 2015), and as weathering of specific geologic units that were expected to be important contributors to instream phosphorus (Ator and others, 2011). Two different approaches were evaluated in the total phosphorus model to represent natural phosphorus from upland areas. In one approach, natural phosphorus was represented by the area of each E2NHDPlus2 catchment scaled by an estimate of the natural phosphorus content of local soil and rock (Nardi, 2014). In the other approach natural phosphorus was represented by the area of each E2NHDPlus2 catchment with no scaling, but the model included a delivery term representing the natural phosphorus content of local soil and rock that acted exclusively on that source.

Additional sources of nutrients evaluated in the total nitrogen and total phosphorus models were phosphorus contributed from stream channels, nutrients in spring discharge, and the nutrients originating from anthropogenic activities. Phosphorus contributed from bank erosion and resuspension of sediment in stream channels was evaluated in a similar same way as natural phosphorus from upland areas. In the first approach this source was represented by the E2NHDPlus2 reach length scaled by an estimate of the natural phosphorus content of local soil and rock, and in the second approach this source was represented by the unscaled reach length acted upon exclusively by a delivery term representing the natural phosphorus content of local soil and rock. Anthropogenic activities such as agriculture, fossil fuel combustion, and urbanization can introduce large amounts of nitrogen and phosphorus into a watershed, and in the nutrient models the sources associated with these activities included commercial fertilizer, livestock manure, atmospheric deposition, developed land, on-site wastewater treatment, and point-source wastewater discharge. The following sections provide more detail on how each anthropogenic nutrient source was estimated.

\section{Commercial Fertilizer}

Commercial fertilizer applied to each E2NHDPlus2 catchment in 2012 was estimated from regression models that relate county-level commercial fertilizer sales data to spatially referenced data on incremental catchment attributes (Stewart and others, 2019). Separate regression models for nitrogen and phosphorus were developed to estimate nationally weighted, elemental fertilizer used on agricultural lands for the conterminous United States. This approach built on earlier efforts that used Association of American Plant Food Control Officials data on fertilizer sales to provide county-level estimates of nitrogen and phosphorus fertilizer use (Gronberg and Spahr, 2012). The spatially referenced method improves on these previous efforts by allowing nitrogen to phosphorus ratios to vary at the catchment scale depending on what types of fertilizer were used and expanding the set of variables used to allocate county-level sales data to the catchment scale. The models included catchment-level factors that were either primary determinants of fertilizer use, such as the acreage of different crop types, or measures reflecting the intensity of use. 


\section{Livestock Manure}

Four types of livestock manure nutrients were evaluated in the SPARROW nutrient models:

1. Manure nutrients from cattle housed at animal feeding operations (AFOs; such as dairies and feedlots) that were retained and applied to the farmland surrounding each AFO, estimated based on the number of cattle housed there in 2012 (Wise, 2019a);

2. Manure nutrients from cattle housed at AFO'S exported to market and applied to farmland within the county in which each AFO was located (Wise, 2019a);

3. Manure nutrients from non-cattle livestock that were applied to farmland within the county in which the livestock were located in 2012 (Wise, 2019b);

4. Manure nutrients from grazing cattle (those not house in AFO's) that was applied to the grazing land within the county in which the cattle were located in 2012 (Wise, 2019c).

The spatial datasets were disaggregated and summed for each E2NHDPlus2 catchment.

\section{Atmospheric Deposition}

The total deposition of atmospheric nitrogen within each E2NHDPlus2 catchment was represented by the mean total deposition for 2010-12 estimated by the U.S. EPA's Community Multiscale Air Quality Modeling System (CMAQ; U.S. Environmental Protection Agency, 2018a). The estimates of total atmospheric nitrogen deposition were summed from:

1. Bias and precipitation adjusted wet deposition of oxidized nitrogen;

2. Bias and precipitation adjusted wet deposition of reduced nitrogen;

3. Dry deposition of total oxidized nitrogen; and

4. Dry deposition of total reduced nitrogen.

\section{Developed Land}

The runoff of nutrients from developed land within each E2NHDPlus2 catchment in 2012 was represented by the total area of NLCD low, medium, and high intensity developed land, and open space (Homer and others, 2015).

\section{On-Site Wastewater Treatment}

The leaching of nitrogen from on-site wastewater treatment within each E2NHDPlus2 catchment in 2012 was represented the number of people with on-site wastewater treatment (Wise, 2019d). This dataset was created by disaggregating census block populations to NLCD developed land (as defined above) across the Pacific region and retaining those populations that were outside of the service boundaries for municipal wastewater treatment plants. The resulting spatial dataset was disaggregated and summed for each E2NHDPlus2 catchment.

\section{Point-Source Wastewater Discharge}

Previous SPARROW modeling has shown that some of the largest contributors to surface water nutrient loads are point-source facilities such as municipal wastewater treatment facilities (WWTFs) that discharge directly to streams (Preston and others, 2009). As part of a nationwide effort, Skinner and Wise (2019) compiled effluent discharge and estimated total nitrogen and phosphorous loads for water year 2012 for 356 major NPDES point-source facilities and 716 non-major NPDES point-source facilities that discharged to surface water within the Pacific region. Skinner and Wise (2019) provide detailed descriptions of the methods used to estimate the 2012 nutrient loads, their data quality assurance and quality control procedures, and the ways that their approach differed from previous efforts to estimate point-source nutrient loads. The general approach was to estimate monthly loads of total nitrogen and total phosphorus from each facility based on measured daily discharge and either measured or surrogate total nitrogen and total phosphorus concentrations, and then sum the monthly load estimates for water year 2012 .

The 2012 nutrient loads estimated for the NPDES wastewater relied on surrogate effluent nutrient concentration values where sufficient facility-specific monitoring data were not available. Specifically, 77 percent of the total nitrogen load and 55 percent of the total phosphorus load for the Pacific region were estimated using some type of surrogate nutrient concentration. Ideally, the nutrient loads for all the NPDES wastewater facilities would have been based on measured values-but this was not possible and using the surrogate nutrient concentrations not only filled in the data needed to calibrate the SPARROW nutrient models, it allowed for a regional picture of point-source loads (table 1.1). For example, the point-source facilities in six watersheds-Puget Sound (PUGT), Lower Sacramento River (LSAC), San Francisco Bay (SFBY), Ventura-San Gabriel Coastal (VSCS), Santa Ana River (SANT), and Laguna-San Diego Coastal (LSCS), were responsible for about 76 percent of the total point-source 
nutrient loads generated within the Pacific region in 2012. About 85 percent of the nutrient loads generated within those six watersheds, however, were discharged to estuaries and open ocean instead of inland waters. The values for reach time of travel and impoundment settling velocity were based on predictions from the Pacific Region SPARROW streamflow model.

The Pacific region also contains an extensive network of federal, state, and tribal fish hatcheries that serve to mitigate the impacts on Pacific salmonids (salmon and steelhead trout [Oncorhynchus mykiss]) from habitat alteration, hydroelectric development and consumptive fisheries. Additionally, there are many commercial aquaculture facilities that produce fish primarily for consumption by consumers. Unlike most NPDES municipal/domestic wastewater treatment facilities, however, for which the original source of water is relatively pristine (typically from municipal water supplies and drinking water wells), hatcheries and aquaculture facilities use less pristine source water and therefore the estimated effluent loads from these facilities may over-represent actual nutrient loads contributed to streams. To avoid this problem, the approach used to estimate total nitrogen and total phosphorus discharged from hatcheries and other aquaculture facilities in the Pacific region was a mass balance on feed usage and fish production (Hal Michael, Washington Department of Fish and Wildlife, oral commun., December 2009). When this information was not available, however, the loads were estimated in the same way as other NPDES facilities as described above.

The estimated nutrient discharge from hatcheries and other aquaculture facilities in the Pacific region accounted for 2.9 and 4.3 percent, respectively, of the total nitrogen and total phosphorus discharged from all NPDES wastewater facilities in 2012. Although these facilities contributed relatively little to the estimated total wastewater nutrient loads discharged across the region in 2012, they were responsible for a substantial amount of the nutrient load in some watersheds. For example, they accounted for 72 percent of the estimated total phosphorus discharged within the Deschutes River watershed, 45 percent of the estimated total phosphorus discharged within the Upper Snake River watershed, and 41 percent of the estimated total phosphorus discharged within the Salmon River watershed.

Watershed factors were evaluated for their influence on the delivery of nitrogen and phosphorus from upland areas to streams and the loss of nitrogen and phosphorus in both freeflowing streams and impoundments. The mean incremental water yield predicted by the streamflow model (that is, the water generated exclusively within each incremental catchment), along with other landscape properties that might influence nutrient delivery (Wieczorek and others, 2019), were evaluated as a potential delivery terms in the total nitrogen and total phosphorus models. Particle settling in streams and impoundments can permanently remove nitrogen and phosphorous from waterbodies (although some particles can be re-suspended). Denitrification by benthic bacteria can also permanently remove nitrogen from waterbodies. Plant growth and decay in free-flowing streams and impoundments, however, was assumed to balance for a steady-state model; therefore, no net gain or loss of nutrients was expected from these processes and they were not evaluated in the models (Schwarz and others, 2006). The fraction of nitrogen and phosphorous load removed through in-stream processes was represented in the models through the multiplication of a firstorder decay rate (inverse days) by the reach time of travel. The loss of nitrogen and phosphorous in impoundments was represented in the models by a hypothetical settling velocity.

\section{Suspended-Sediment Transport}

Suspended-sediment enters streams through erosion of upland areas (due to surface erosion, soil creep, debris avalanches, and slump and earth flow) and erosion within stream corridors (Swanson and others, 1982). Upland sediment sources include weathering and erosion from various land cover types and geologic formations whereas stream corridor sources include erosion of stream banks and re-suspension of sediment from channel beds in addition to sediment derived from mass wasting where channels intersect valley sides and terrace walls (Gellis and others, 2016). The amount of sediment exported from a watershed from these two types of sources depends on many factors-such as climate, topography, geology, landslides and wildfire history, stream morphology, and hydrology. Stream power, which is a function of streamflow and channel slope, is the rate at which the potential energy of a stream is dissipated against its bed and banks and is also an important control on the amount of suspendedsediment in fluvial systems (Yang and Stall, 1974). A stream reach over which there is an increase in stream power would be expected to gain suspended-sediment from corridor sources whereas a reach over which there is a decrease in stream power would be expected to lose suspended-sediment via deposition as bed sediment.

Sediment generated by upland sources and within stream corridors were both evaluated in the suspended-sediment model. Additionally, two different datasets (one based on land cover and one based on surface geology) were combined to represent upland sediment sources. The Pacific region consists of 9 different NLCD land cover categories (Homer and others, 2015) and 19 different surface geology classes (Soller and others, 2009). To facilitate model development, the individual land cover categories were aggregated into four generalized land cover groups that represented similar land cover-agricultural land (10 percent of modeling domain), developed land and other cleared areas (4.3 percent), forest land (41 percent), and the remaining land consisting of scrub, grass, and barren land ( 34 percent). Similarly, the surface geology classes were aggregated into four generalized groups that represented similar texture-igneous and metamorphic rocks (8.4 percent of modeling domain), alluvial material 
(18 percent), residual material (65 percent), and other miscellaneous material (13 percent). Open water and wetlands made up 12 percent of the modeling domain, but they were assumed to represent minimal sources of sediment. The intersections of the four generalized land cover groups and the four generalized surface geology groups produced 16 landscape classes that were initially used to represent upland sources in the suspended-sediment model (table 2). The resulting spatial dataset was disaggregated and summed for each E2NHDPlus2 catchment. The sediment generated within stream corridors was evaluated as both a function of reach length and as a function of stream power gain.

Based on the results from previous field studies (O'Connor and others, 2014) and SPARROW modeling (Wise and O'Connor, 2016), the areas within the Pacific region consisting of igneous and metamorphic rocks were expected to yield negligible amounts of sediment compared to the mostly unconsolidated material that makes up the remaining surface geology (alluvial sediments, residual soils, fluvial and glacial deposits, and lacustrine, eolian, and coastal zone sediments).
To test this hypothesis, two types of upland sediment sources were evaluated in the model:

1. The area of igneous and metamorphic rocks inclusive of all land uses; and

2. The area of each individual land cover group for all surface geology except igneous and metamorphic rocks.

Watershed factors were evaluated for their influence on the delivery of sediment from upland areas to streams and the permanent loss of sediment in both free-flowing streams and impoundments. The mean incremental water yield predicted by the streamflow model, along with other landscape properties that might influence sediment delivery (Wieczorek and others, 2019), were evaluated as potential delivery terms in the suspended-sediment model. Another potential delivery term, "grazing density" (defined as the likely number of grazing cattle in 2012 divided by the area of potential grazing land), was compiled specifically for the Pacific region (Wise, 2019e).

The suspended-sediment model also accounted for the loss of sediment in both free-flowing streams and

Table 2. Generalized land cover and surface geology combinations evaluated as upland sources in the SPARROW (SPAtially Referenced Regression On Watershed attributes) suspended-sediment model for the for the Pacific region of the United States.

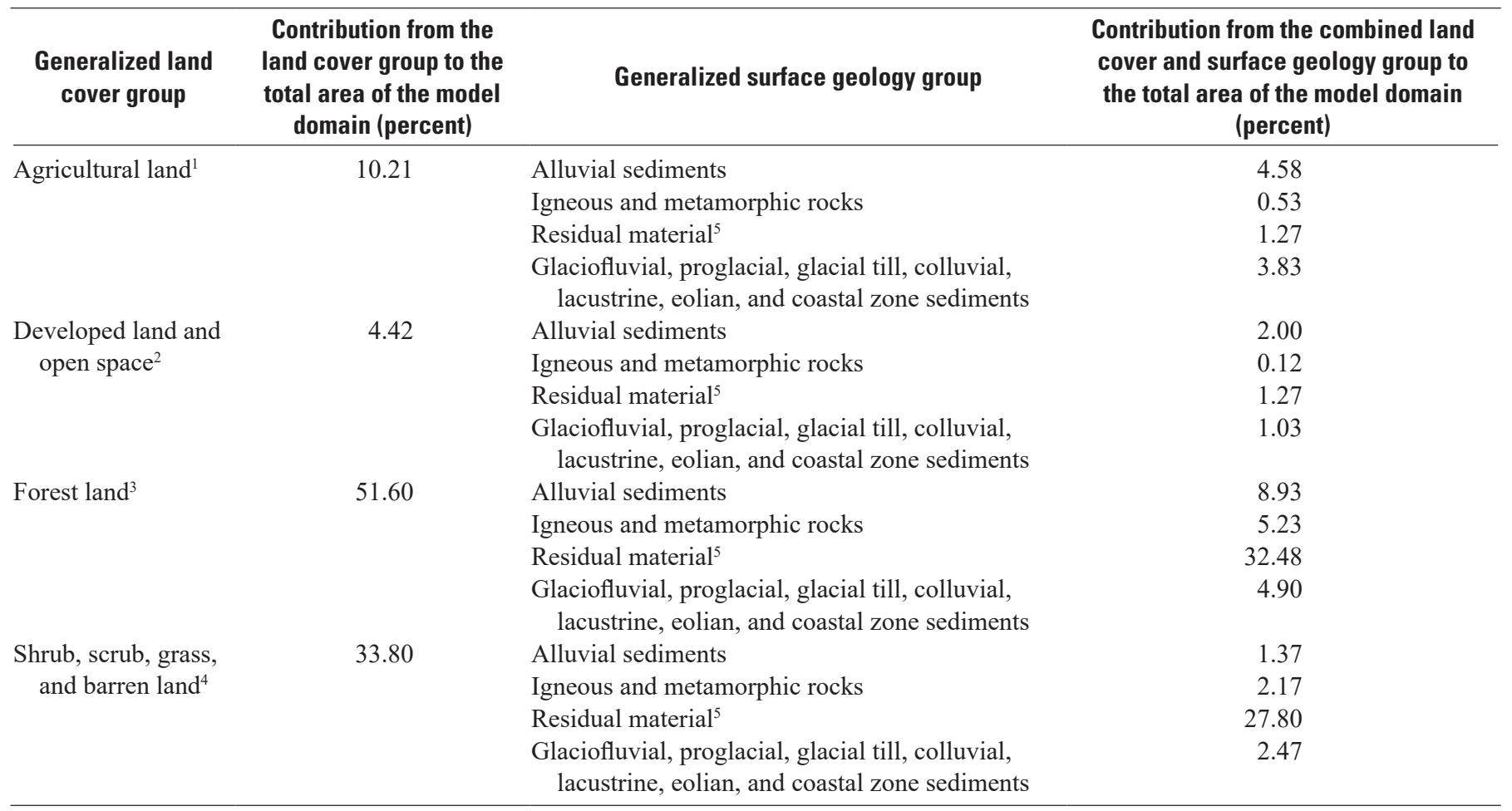

${ }^{1}$ Cultivated crops and pasture in 2011.

${ }^{2}$ Low, medium, and high intensity developed land and open space in 2011.

${ }^{3}$ Deciduous, evergreen, and mixed forest land in 2011.

${ }^{4}$ Shrub, scrub, grass, and barren land in 2011.

${ }^{5}$ Soil parent material which has formed in its place of origin. 
impoundments. In addition to natural sediment loss via deposition in channel beds and banks that is expected to occur in free-flowing streams, sediment loss was also evaluated for selected free-flowing reaches of Blacktail Creek in Montana where mine waste remediation activities have likely removed large amounts of suspended material (U.S. Environmental Protection Agency, 2018b). Permanent sediment loss in free-flowing streams was evaluated using two approaches. In the first approach a first-order decay rate (inverse days) was estimated that, when multiplied by the reach time of travel (days), represented the fraction of the load that settles to the bottom of the reach and is retained. The second approach employed a first-order decay rate, but one that was based on the percentage loss in stream power over each reach. Permanent sediment loss in impoundments was evaluated by estimating a hypothetical settling velocity that, when multiplied by reciprocal areal hydraulic load, represented the fraction of incoming load that was retained within the impoundment. The values for reach time of travel and impoundment settling velocity were based on predictions from the Pacific Region SPARROW streamflow model.

\section{Accounting for Systematic Differences in Calibration Loads}

The water-quality data used to estimate the calibration loads for the suspended-sediment model were collected by the USGS and state and local water-quality agencies and those agencies often have different techniques for collecting and processing water-quality samples. All USGS samples are collected using cross-sectionally integrated and flowintegrated techniques whereas most other agencies use surface grab sampling. Additionally, the calibration loads used in the suspended-sediment model were based on two different analytical techniques:

1. The standard suspended-sediment method (American Society for Testing and Materials, 2006) used by the USGS; and

2. The total suspended solids (TSS) method (Rice, 2012) generally used by other state and local water-quality agencies.

Standard suspended-sediment concentration is the mass of all the sediment within a known volume of a water-sediment mixture collected directly from a waterbody (Guy, 1969). In contrast, TSS is the mass of suspended material within a subsample of a water-sediment mixture collected from a waterbody. Such subsampling introduces negative bias and more variability, especially when the percentage of sandsize sediment is high because of sediment settling before subsampling (Gray and others, 2000).

Measurements of suspended-sediment determined by the two analytical methods described above are generally not used interchangeably (Gray and others, 2000), but limiting SPARROW model estimation to include only loads determined by a single analytical method would induce spatial biases and have too-few observations to produce reasonable model accuracy. An alternative approach is to include suspended-sediment load estimates based on both analytic methods, but also specify a term in the model that can account for relative bias. The study by Gray and others (2000) identified a proportional downward bias in TSS measurements by as much as 20 percent. Given this finding, the presumption in the SPARROW model is that TSS loads are smaller than the equivalent suspended-sediment load by a fixed proportion.

The SPARROW model includes a technique to account for systemic differences between two groups of calibration loads (Gregory Schwarz, U.S. Geological Survey, written commun., April 7, 2017). The model evaluates an independent variable that takes either a value of one (to indicate one group) or a value of zero (to indicate the other group). During model calibration SPARROW estimates a coefficient for this independent variable and, because it only applies to reaches associated with the first group of loads, it can be interpreted as a scaling factor for converting between the two groups. The inverse of the exponential function of the estimated coefficient represents an average conversion factor between the two groups of loads.

\section{Addressing Spatial Bias in the Model Calibration}

SPARROW calibration stations are often nested within the basin of downstream stations. When this occurs the model prediction at each upstream calibration station is replaced with its monitored value to eliminate errors from propagating down the stream network and to reduce the correlation across the sub-basin error terms (Smith and others, 1997). The resulting downstream value that is estimated using the upstream measured value is referred to as the "conditioned" value used in model calibration, whereas the value estimated without adjustment is referred to as the "unconditioned" value. This use of conditioned values reduces the potential influence of the downstream station on the coefficients in the SPARROW model and can result in an underestimation of the residuals compared to when the model is used to completely estimate values throughout the basin (Wellen and others, 2015). During calibration, it is optimal for each station to have similar influence on the determination of coefficient estimates in the SPARROW model. However, because calibration stations with small nested shares (the fraction of drainage area that is downstream of other calibration stations) tend to have lower residual variance, these stations may be under-represented in the SPARROW statistical calibration process.

To account for the potential unequal influence of the nested basins during SPARROW model calibration, 
a statistical algorithm was developed in which weights are computed for each calibration station based on its nested share and, if necessary, these weights are used in a subsequent re-estimation of the model using weighted NLLSR (WNLLSR; Schwarz and others, 2006, eq. 1.55). The models were first calibrated with equal weights applied to all calibration stations and the squares of the residuals were then regressed on the nested share. If the nested share was found to be a statistically significant predictor of the squares of the residuals the WNLLSR was then used to re-calibrated the models, using the inverse of the predicted values from this regression as weights. The potential bias related to nested calibration stations was also accounted for by calculating two different RMSE values. A conditioned RMSE value was calculated for each model that reflected the difference between the measured calibration values and the estimated accumulated values that were reset to the measured values during model calibration. An unconditioned RMSE was calculated for each model that reflected the difference between the measured calibration values and the estimated accumulated values without such adjustments.

Because SPARROW model predictions are spatially distributed across a landscape, it is important to consider the spatial pattern of model error. Spatial autocorrelation among model residuals, which may introduce bias into the model parameterization, can be either positive (meaning the residual values at nearby calibration stations are similar) or negative (meaning they are dissimilar). Autocorrelation in the calibration residuals was evaluated for three types of spatial structures or patterns, which corresponded to three different types of modeling or measurement error. The results from these evaluations were then used to make corrections to the model input when spatial correlation was found to be statistically significant at the 5 percent level.

1. Spatial correlation among loose clusters of calibration stations-for example, those located within the same large watershed or ecoregion or within a large area having homogenous land cover, was evaluated using the Moran's I statistic. A positive and significant value for the Moran's I statistic indicated that important watershed processes or sources were not included in the model. This type of spatial correlation can be addressed by including additional predictor variables in the model when possible.

2. Spatial correlation among tight clusters of nested calibration stations - those within five kilometers of each other, with similar drainage areas (a ratio less than a factor of 2) was evaluated using the Pearson correlation coefficient. A negative and significant Pearson coefficient indicated that the calibration value was mis-estimated at the upstream station in the nested pairs. This type of spatial correlation can be addressed by removing the upstream stations in each pair from the calibration data set.
3. Spatial correlation among tight clusters of nonnested calibration stations and nested calibration stations with dissimilar drainage areas (a ratio greater than a factor of 2) was also evaluated using the Pearson correlation coefficient. A negative and significant Pearson coefficient indicated that the spatial scale of a source variable was coarser than the spatial scale of the catchment network. This type of spatial correlation can be addressed by randomly selecting one station in each pair and removing it from the calibration data set.

\section{Types of Model Predictions}

The predictions from the SPARROW models are presented here in four ways:

1. The models were used to estimate the mean annual incremental yield of water, total nitrogen, total phosphorus, and suspended sediment for each of the 338,949 E2NHDPlus2 catchments. Incremental yield, expressed as millimeters per year ( $\mathrm{mm} / \mathrm{yr}$ ) for streamflow, kilograms per square kilometer per year ([kg/km²] $] / \mathrm{yr}$ ) for total nitrogen and total phosphorus, and metric tons per square kilometer per year $\left(\left[\mathrm{t} / \mathrm{km}^{2}\right] / \mathrm{yr}\right]$ for suspended sediment, is equal to the estimated streamflow or load generated within each incremental catchment divided by the catchment area. These values are useful for comparing the relative intensity of the streamflow and load generated among catchments because they are normalized for contributing area.

- The contribution from each source to the total amount of nitrogen, phosphorus, and suspended sediment delivered to Pacific coast estuaries and open ocean were estimated.

2. The incremental yields of water, total nitrogen, total phosphorus, and suspended sediment were aggregated for each of the HUC6 watersheds within the study domain along with the relative contribution from each modeled source to those yields. These values are equal to the total incremental streamflow or load delivered to the outlet of each watershed divided by the watershed area, where the outlet was either a collection of estuary reaches for coastal watersheds or a single stream reach for non-coastal watersheds.

3. The median yields of water, total nitrogen, total phosphorus, and suspended-sediment were estimated for E2NHDPlus2 catchments dominated by specific land cover and landscape types. 


\section{Model Calibration Results and Predictions}

\section{Streamflow}

The streamflow model included six source terms, four land-to-water delivery terms, and four aquatic loss terms (table 3). The coefficient for PME (0.720) indicated that about 72 percent (on average) of the estimated amount of this source reaches streams. The model results implied that the actual discharge from wastewater treatment, inter-basin transfers, and local transfers was less than the estimated discharge for each source (the coefficients were less than one), whereas the actual discharge from springs was greater than the estimated discharge (the coefficient was greater than one). The coefficient for irrigated land (which is equivalent to $237 \mathrm{~mm} /$ yr) represents the average water yield from that type of land cover across the modeling domain.

The streamflow model included three land-to-water delivery terms with negative coefficients and one term with a positive coefficient. The negative coefficient for evapotranspiration deficit, which is the difference between potential and actual evapotranspiration, suggests that in areas with higher evapotranspiration deficits a greater fraction of runoff is loss to evaporation than in areas with lower deficits. The negative coefficient for soil permeability could reflect increased infiltration and plant transpiration in areas with greater permeability whereas the positive coefficient for impervious surface is likely due to lower infiltration and increased surface runoff in urbanized areas. The negative coefficient for local groundwater use reinforces the connection between groundwater and surface water in the hydrologic cycle. Many other climate and landscape factors were evaluated as potential delivery terms but were not included because they were not significant.

The streamflow model included a term representing the combined effect of evaporation and streambed infiltration from intermittent streams (those processes were not significant, however for perennial streams), separate terms representing irrigation diversions and municipal water-supply intakes (but consumptive use by power plants was not a significant loss), and a term representing evaporation from impoundments.

The streamflow model was generally successful at matching the mean annual streamflow measured at the 726 streamgages used in the calibration-the model explained about 91 percent of the variability in measured water yield (based on the yield $R^{2}$ value in table 3 ). The success in explaining such a large percent of variability is in part due to the inclusion of a comprehensive dataset representing the diversion and transfer of surface water across the modeling domain. Figure 6 shows the diagnostic plots for the calibration of the streamflow model. Residual variance decreased slightly as conditioned predicted streamflow (fig. $6 A$ ) and conditioned predicted water yields (fig. $6 B$ ) increased, meaning that the model residuals were slightly heteroskedastic. The conditioned RMSE $(0.400)$ and unconditioned RMSE (0.405) were close in value, which is reflected in the similarities between the plots shown in figures $6 C$ and $6 D$ and the similarities between the conditioned and unconditioned residuals shown in figure 7.

The nested areas for the calibration stations were a significant predictor of the squares of the residuals from the streamflow model and, therefore, were used as weights in its calibration. There was significant spatial correlation among some loose clusters of residuals located within the same HUC6 watershed-specifically, underprediction in the Tulare-Buena Vista Lakes (TBVL) and the Central California Coastal (CCCS) watersheds and overprediction in the Upper Sacramento River (USAC) and Deschutes River (DESC) watersheds, but no landscape characteristics could be found to explain this regional pattern. There was no significant spatial correlation, however, among tight clusters of nested or nonnested residuals.

The mean incremental yields predicted by the streamflow model are shown in figure 8, where the total incremental yields represent the total amount of water generated within each incremental catchment and the delivered incremental yields represent the amount generated within each catchment that was delivered to an estuary or the Pacific Ocean. The difference between the two values reflects permanent losses in free-flowing streams, losses in impoundments, and diversions for consumptive use, as well as in-stream transfers. PME is by far the largest source of streamflow, but spring discharge, wastewater discharged to surface water, and runoff from irrigated land are also substantial sources in some watersheds. This is apparent in figure 9 and table 2.1, which show the total yields predicted for each of the HUC6 watersheds within the Pacific region, along with the contribution from the modeled sources to those yields. Because of the large range in yields across the watersheds, the main plot includes a break at 600 $\mathrm{mm} / \mathrm{yr}$. The inset plot, however, shows the full range of water yields without any axis breaks. As expected, the largest water yields were predicted for watersheds with the highest precipitation (the coastal drainages in Washington, Oregon, and northern California) and the lowest water yields were 


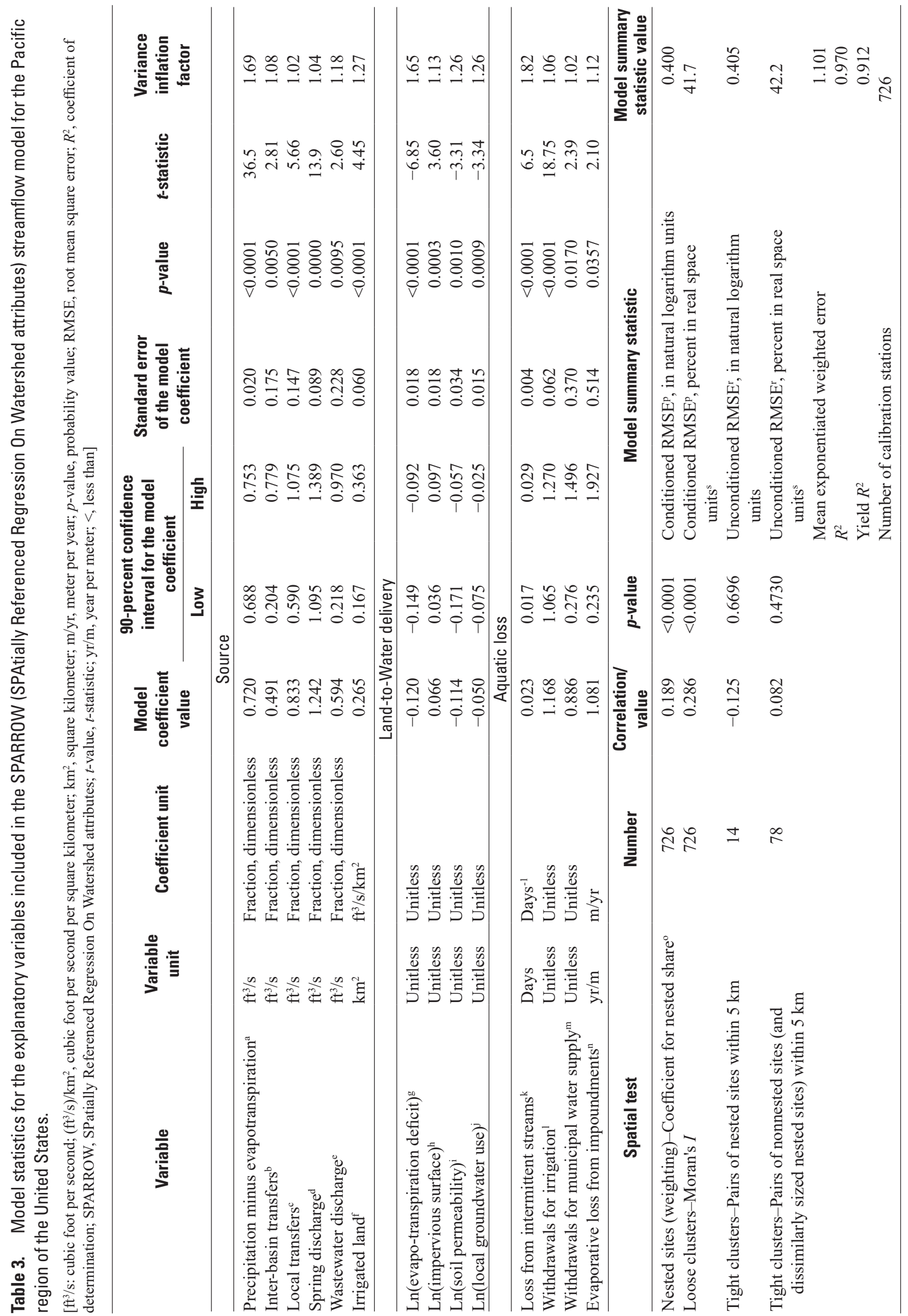




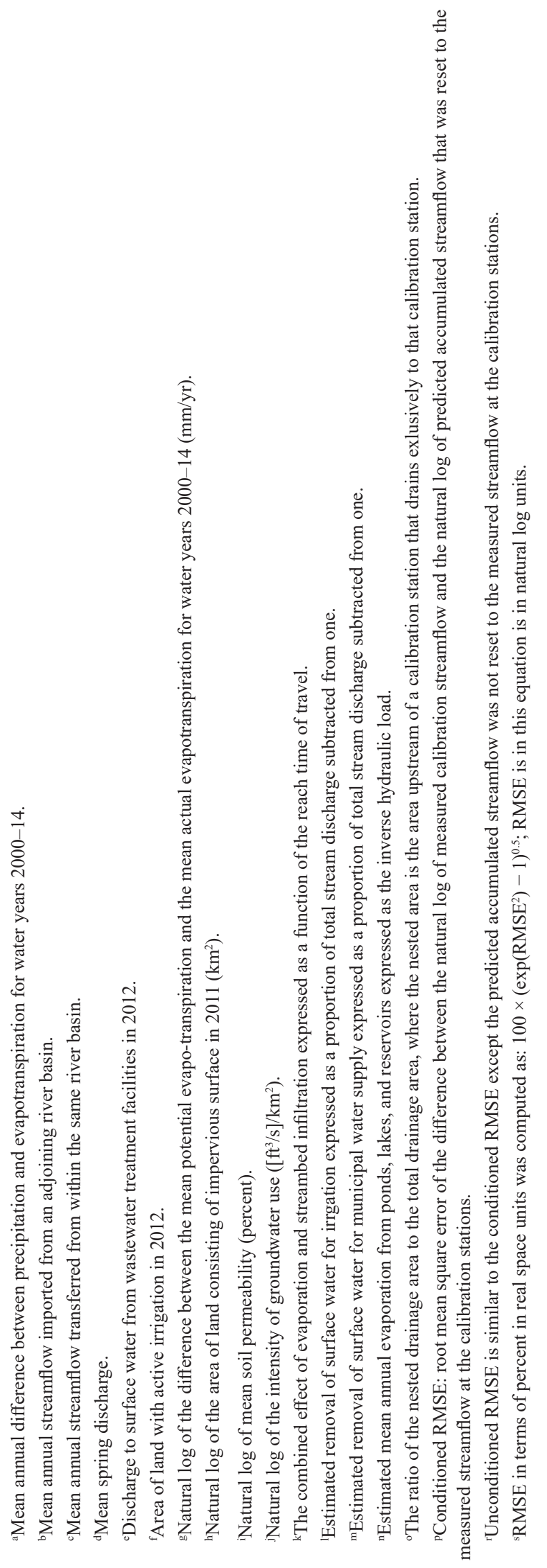



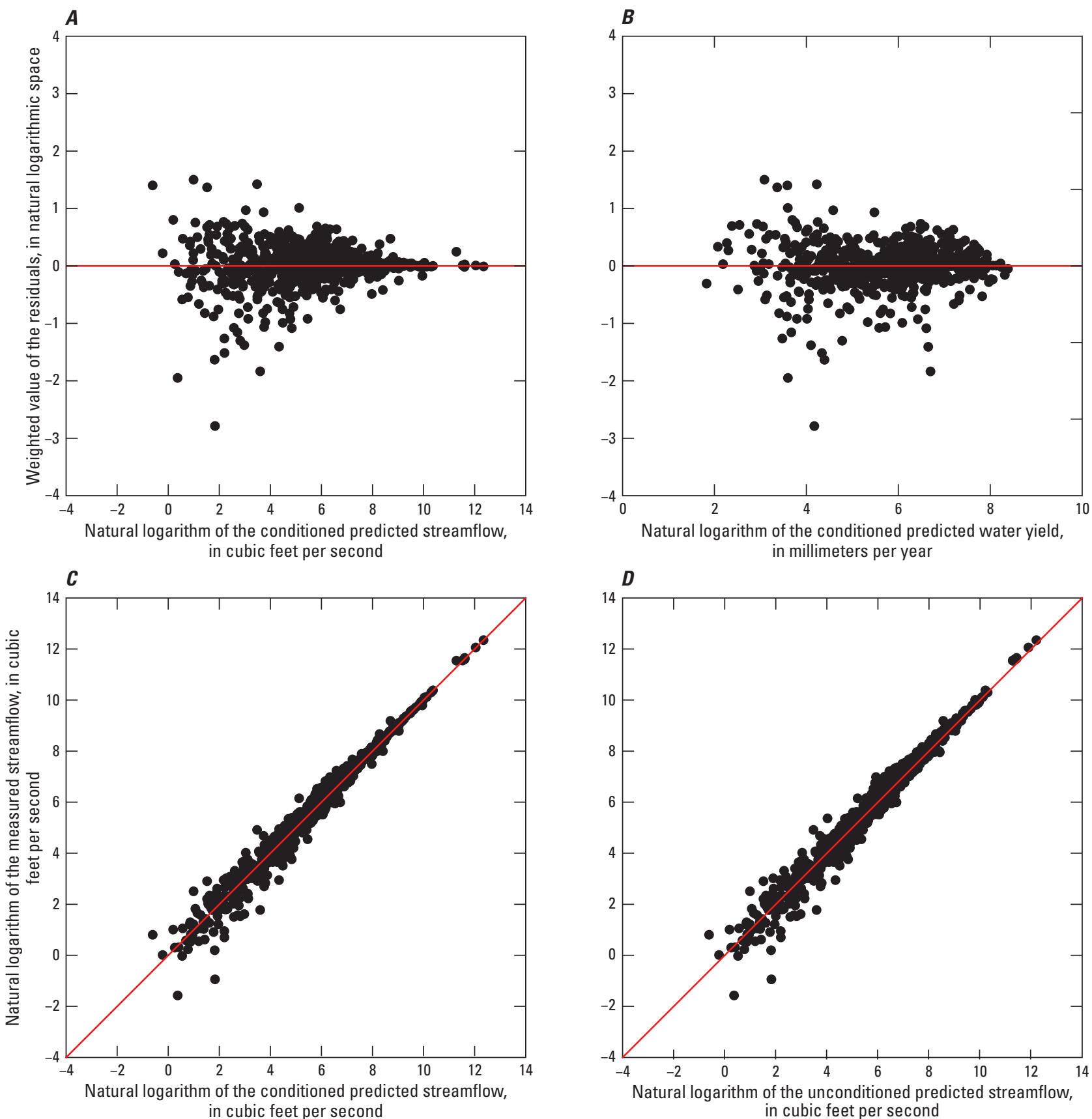

Figure 6. Diagnostic plots for the Pacific region SPARROW (SPAtially Referenced Regression On Watershed attributes) streamflow model. [( $A)$ Weighted residuals versus predicted streamflow. $(B)$ Weighted residuals versus predicted yield. $(C)$ Measured streamflow versus conditioned predicted streamflow (model calibration). (D) Measured streamflow versus unconditioned predicted streamflow (full prediction).] 


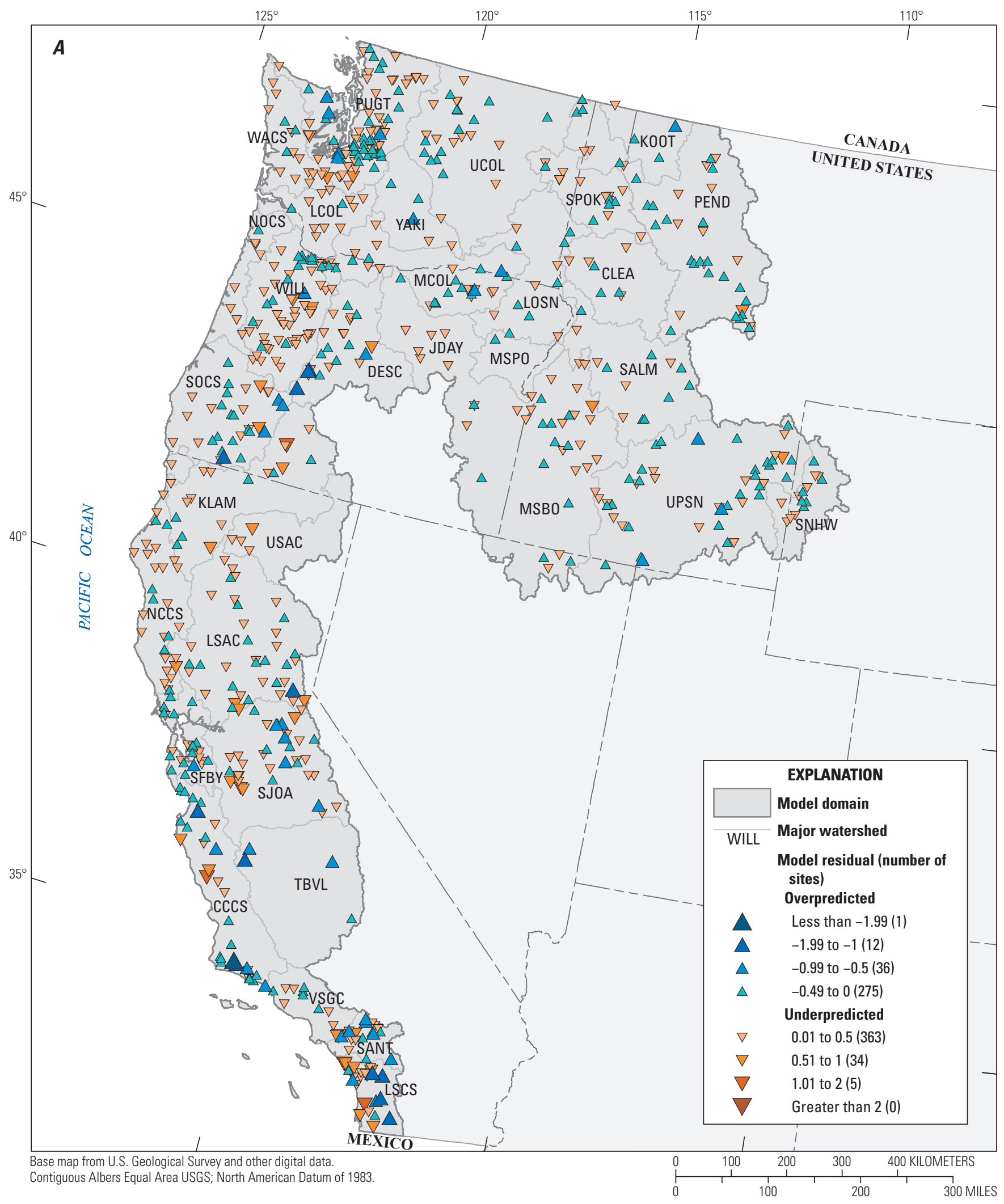

Figure 7. Spatial distribution of conditioned $(A)$ and unconditioned $(B)$ residuals from the Pacific region SPARROW (SPAtially Referenced Regression On Watershed attributes) streamflow model. [Conditioned residuals are based on the difference between the log of measured calibration streamflow and the log of predicted accumulated streamflow that was reset to the measured streamflow at the calibration stations. Unconditioned residuals are based on the difference between the log of measured calibration streamflow and the log of predicted accumulated streamflow that was not reset to the measured streamflow at the calibration stations.] 


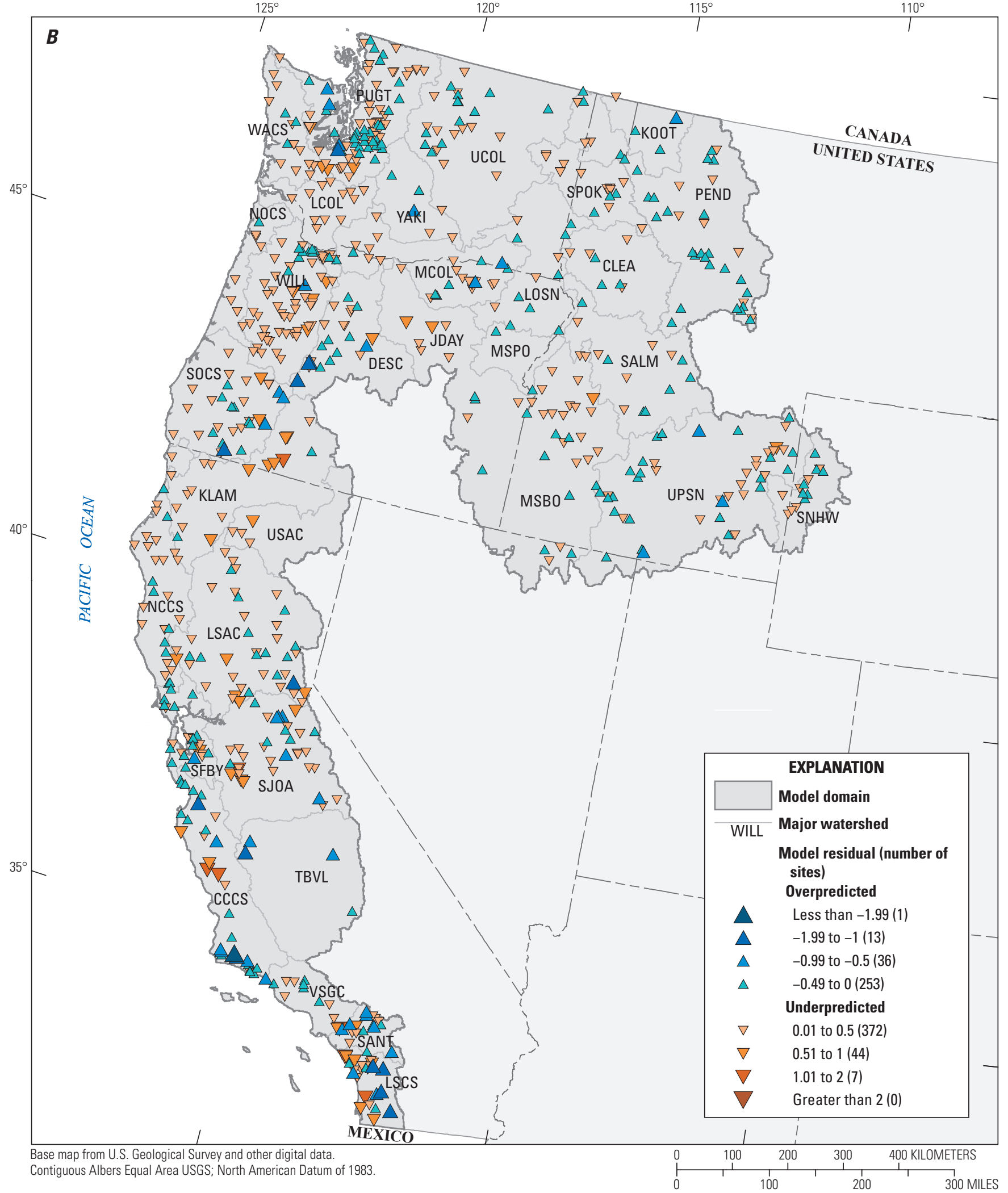

Figure 7.-Continued. 


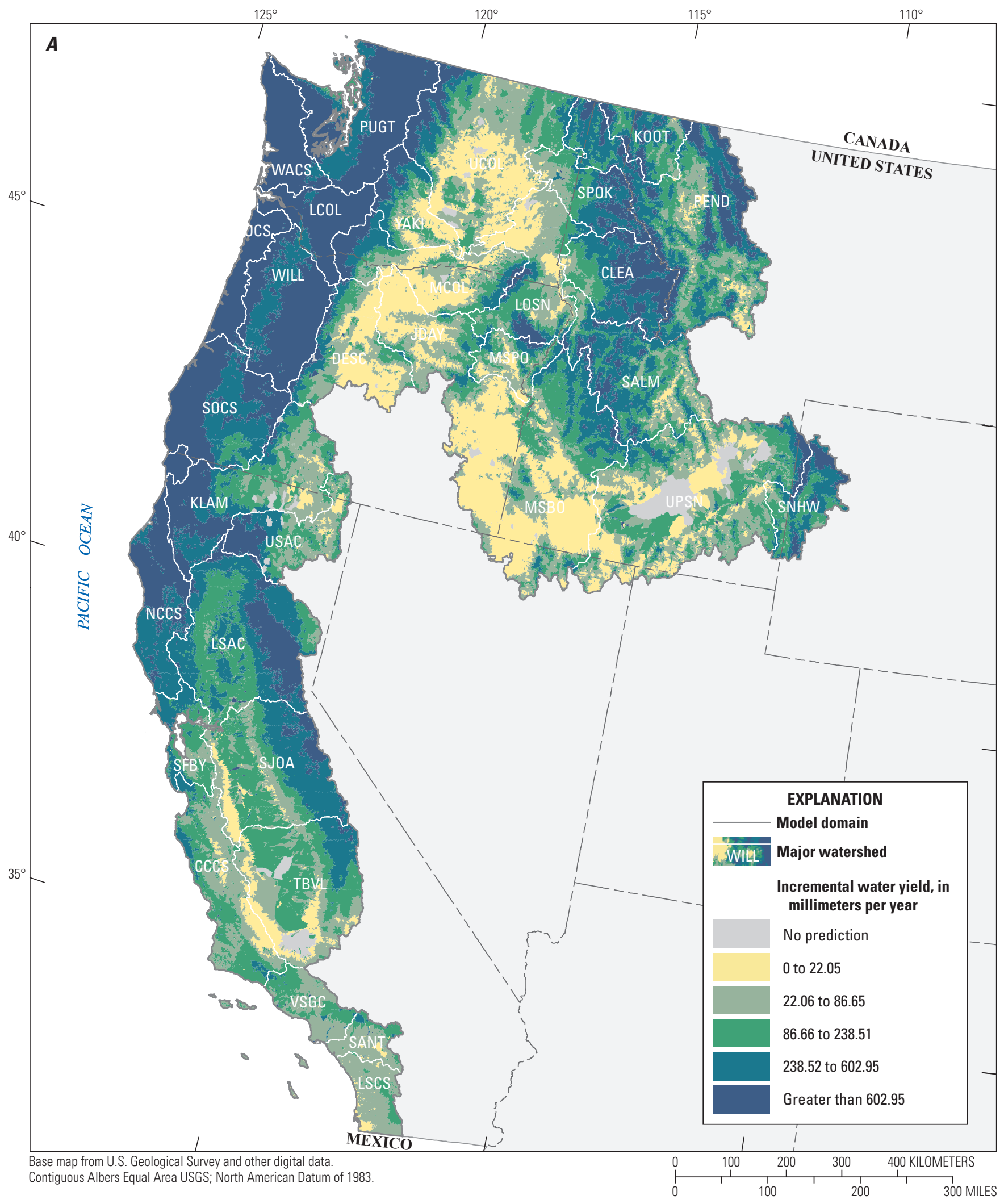

Figure 8. Predicted mean annual incremental yield $(A)$ and delivered incremental yield $(B)$ of water from the Pacific region SPARROW (SPAtially Referenced Regression On Watershed attributes) streamflow model. 


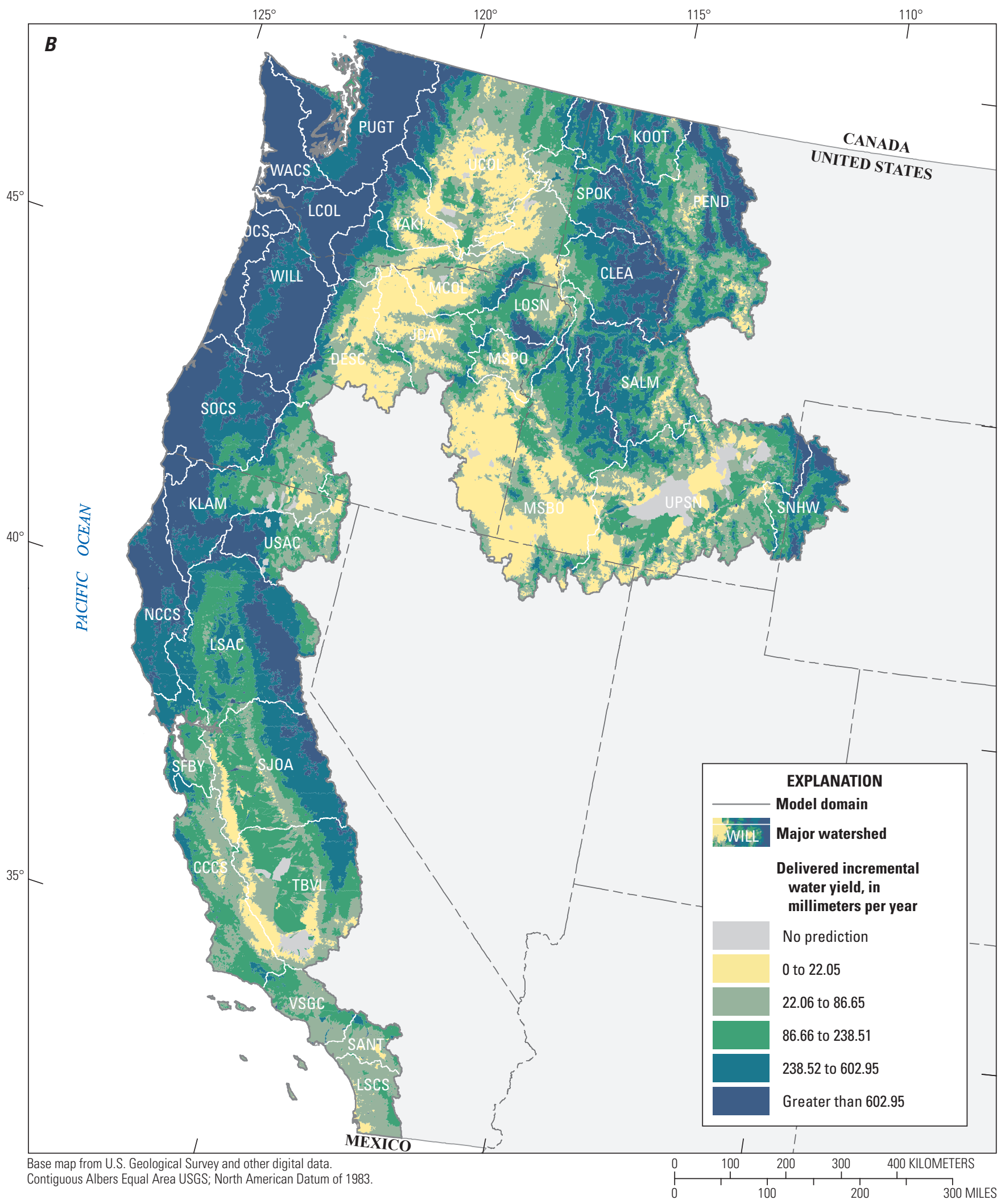

Figure 8.-Continued. 


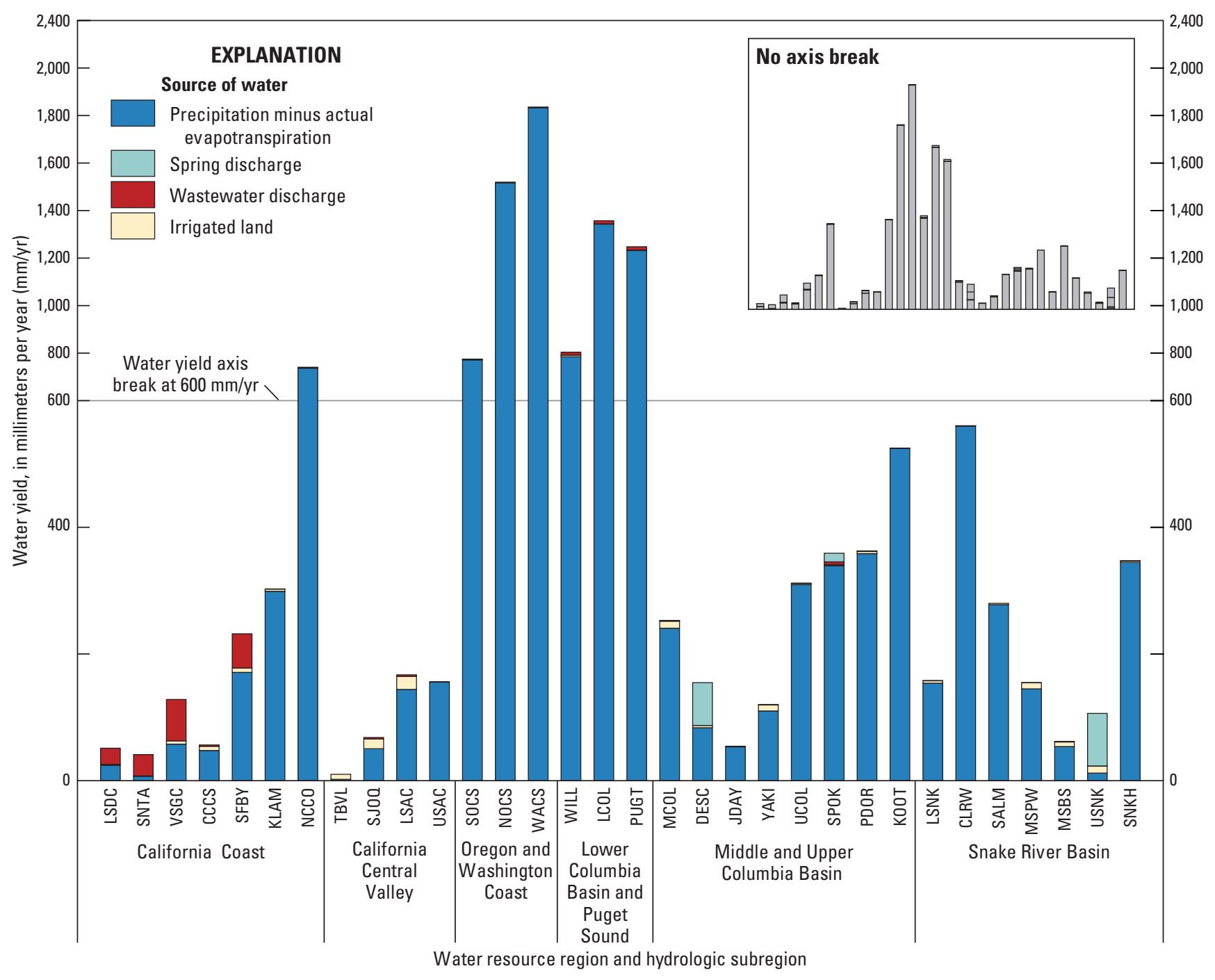

Figure 9. Predicted mean annual water yield, by source, for Hydrologic Unit Code 6 (HUC6) watersheds in the Pacific region of the United States.

predicted for watersheds in the arid areas of the region (the Central Valley of California and east of the Cascade Range).

\section{Total Nitrogen}

The total nitrogen model included seven source terms, three land-to-water delivery terms, and three aquatic loss terms (table 4). Agricultural fertilizer represented the sum of commercial nitrogen fertilizer and nitrogen in livestock manure that was applied to cultivated crops and pastureland. These two sources were combined into one source because they were too strongly correlated to statistically distinguish them as separate sources. Additionally, the estimated coefficients were very close in value when each source was included by itself, implying that each contributed nitrogen to streams at about the same rate. The manure used as fertilizer, however, only represented the amount retained and applied to the farmland surrounding each AFO because the agricultural fertilizer source term was not significant when it included the amount exported to market. Background fixation of nitrogen on forest land (represented by the area of forest land) and grazing cattle manure were not significant, but this did not necessarily mean that they are negligible source of nitrogen - especially since forest land was a significant source in the total nitrogen models previously developed for both the Pacific Northwest and California (Wise and Johnson, 2013; Saleh and Domagalski, 2015). The lack of significance for forest land and grazing cattle manure was likely due to the strong, positive relations between those sources and the amount of atmospheric nitrogen deposited in a catchment. Onsite wastewater treatment was also not a significant source but, as was the case for forest land and grazing manure, this result does not mean that it is not an important surface-water nitrogen in some areas. Rather, the lack of significance was 


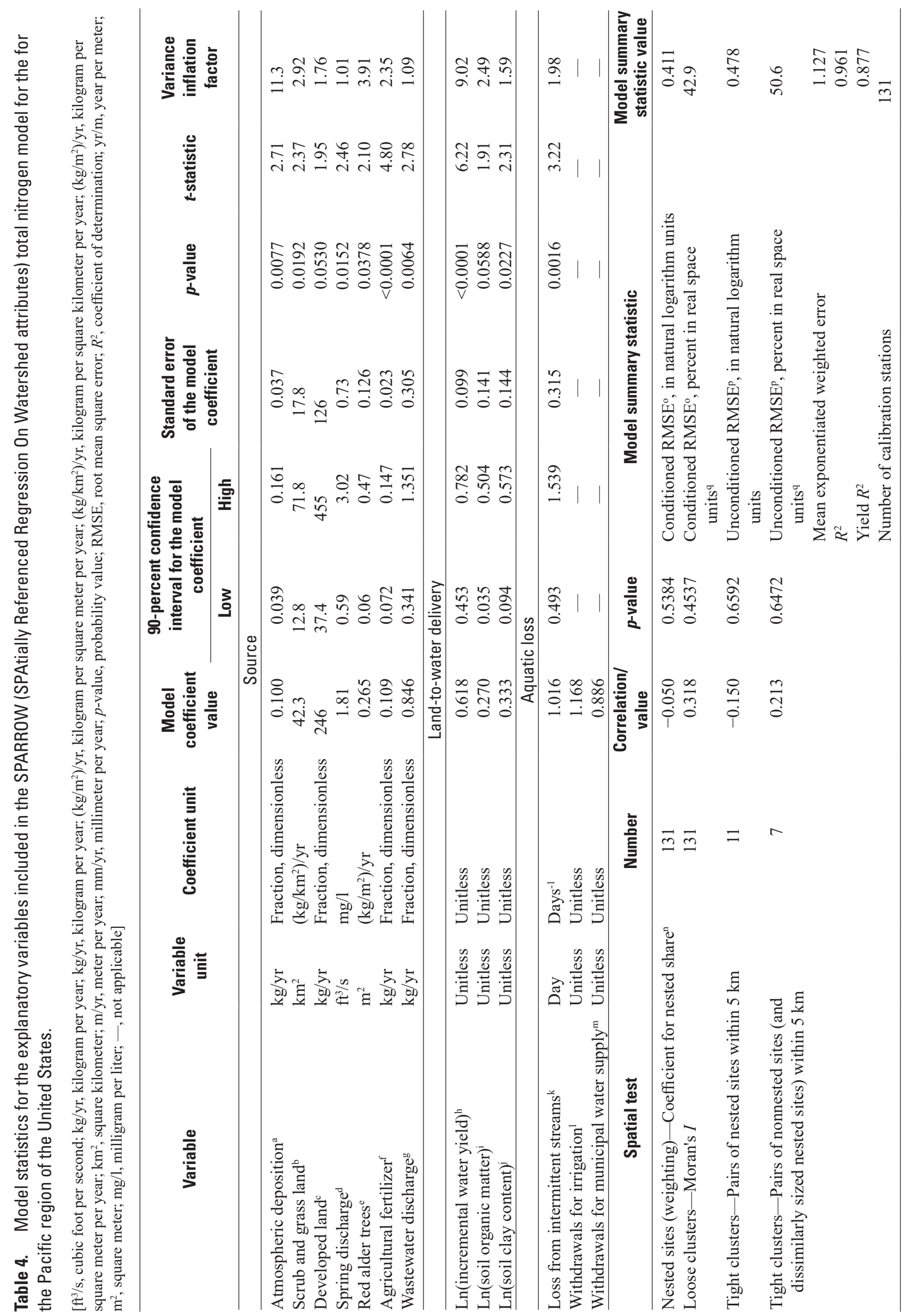




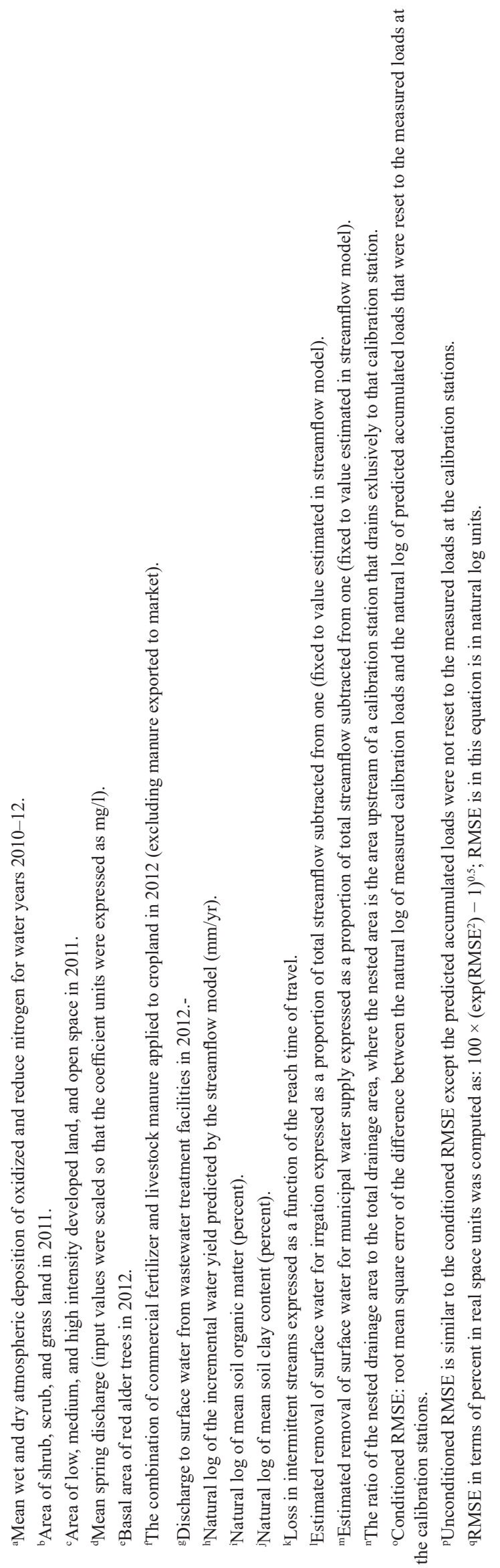


likely due to the strong, positive relation between this source and the area of developed land. And while it was possible to build models that included forest land or grazing cattle manure without atmospheric deposition or on-site wastewater treatment without developed land, the resulting models would be missing important sources of nitrogen across the entire modeling domain.

The model results indicated that about 10 percent (on average) of the nitrogen from both atmospheric deposition and agricultural fertilizer reaches streams, and that developed land yields an average of $246\left[\left(\mathrm{~kg} / \mathrm{km}^{2}\right)\right] / \mathrm{yr}$ and scrub and grass land yields an average of $42\left(\mathrm{~kg} / \mathrm{km}^{2}\right) / \mathrm{yr}$ of nitrogen to surface waters. The coefficient for spring discharge (1.81 milligrams per liter $[\mathrm{mg} / \mathrm{l}]$ ) represents the mean total nitrogen concentration in that source and the coefficient for red alder trees $\left(0.265 \mathrm{~kg} / \mathrm{m}^{2}-\mathrm{yr}\right)$ represents the nitrogen fixation rate for that species, which was close to the higher rates found in a compilation of results from 20 in-situ fixation studies (Binkley and others, 1994). The coefficient of 0.846 for wastewater discharge indicated that the estimated total nitrogen discharged to streams in 2012 was slightly less than the actual discharge. The positive coefficients for all three delivery terms were consistent with expectations. Nitrogen in the form of ammonium can sorb to the surfaces of clays and finer sediments or to soil organic matter, which can then be mobilized and delivered to streams. Many other climate and landscape factors were evaluated as potential delivery terms but were not included because they were not significant.

The total nitrogen model also included an aquatic loss term for intermittent streams, but aquatic loss was not significant in perennial streams or impoundments. The coefficient for aquatic loss in intermittent streams was substantially greater than the stream loss coefficients estimated in previous SPARROW models of total nitrogen (for example, Alexander and others, 2008; Smith and others, 1997). The reason for this discrepancy was not clear, but it might have been related to aquatic loss being limited to intermittent streams in this application whereas in the previous applications that limitation was not used. The total nitrogen model also included loss terms representing municipal water supply intakes and irrigation diversions with coefficients that were set to the values estimated in the streamflow model.
Figure 10 shows the diagnostic plots for the calibration of the total nitrogen model, which explained about 88 percent of the variability in measured total nitrogen yield. The variance of the model residuals was relatively constant across the range of conditioned predicted total nitrogen loads (fig. 10A) and conditioned total nitrogen yields (fig. 10B). The conditioned RMSE (0.411) and unconditioned RMSE (0.478) were close in value, which is reflected in the similarities between the plots shown in figures $10 C$ and $10 D$ and the similarities between the conditioned and unconditioned residuals shown in figure 11. The nested areas for the calibration stations were not a significant predictor of the squares of the residuals from the total nitrogen model and, therefore, were not used as weights in its calibration. There was no significant spatial correlation among either loose clusters of residuals or tight clusters of nested or nonnested residuals.

The mean incremental yields predicted by the total nitrogen model are shown in figure 12, where the total incremental yields represent the total amount of nitrogen generated within each incremental catchment and the delivered incremental yields represent the amount generated within each catchment that was delivered to an estuary or the Pacific Ocean. Wastewater discharge and atmospheric deposition are the largest contributors to the total nitrogen yield from the Pacific region, together accounting for about one-half of the total amount. However, most of the total nitrogen from wastewater originates in four watersheds along the California coast-Laguna-San Diego Coastal (LSCS), Santa Ana River (SANT), Ventura-San Gabriel Coastal (VSCS), and San Francisco Bay (SFBY), as shown in figure 13, and, except for San Francisco Bay, most of the wastewater from those watersheds is discharge through diffusers located far offshore and likely has minimal impact on near-shore water quality. There are many watersheds, however, where sources other than wastewater discharge and atmospheric deposition are important (fig. 13 and table 2.2). For example, red alder trees contribute a substantial amount of the total nitrogen yield from the watersheds draining the Washington and Oregon coast ranges and commercial fertilizer and livestock manure contribute a substantial amount of the total nitrogen yield from many of the watersheds in the California Central Valley and the Snake River Basin. 

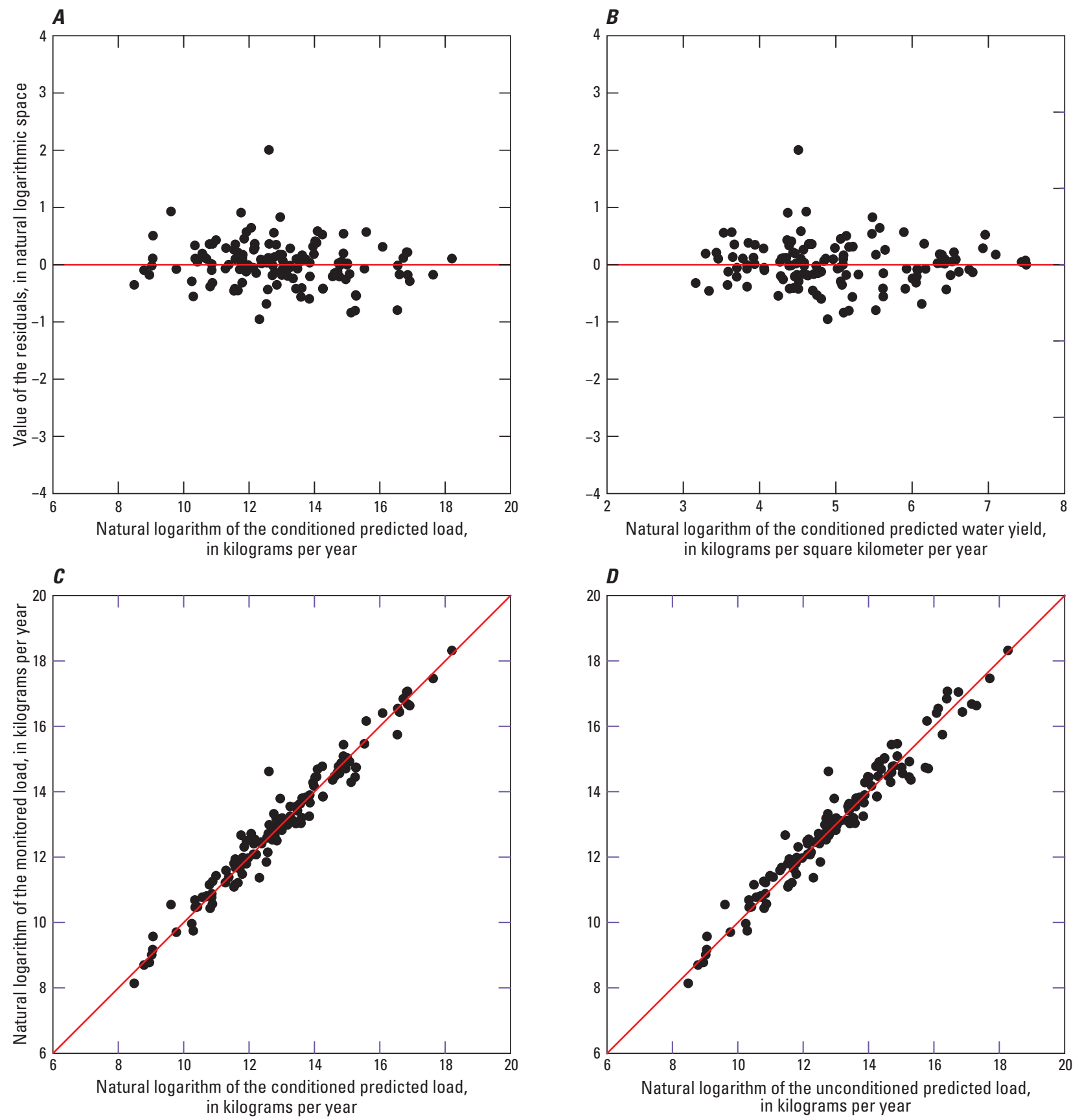

Figure 10. Diagnostic plots for the Pacific region SPARROW (SPAtially Referenced Regression On Watershed attributes) total nitrogen model. [( $A)$ Residuals versus predicted load. $(B)$ Residuals versus predicted yield. $(C)$ Measured streamflow versus conditioned predicted load (model calibration). (D) Measured load versus unconditioned predicted load (full prediction).] 


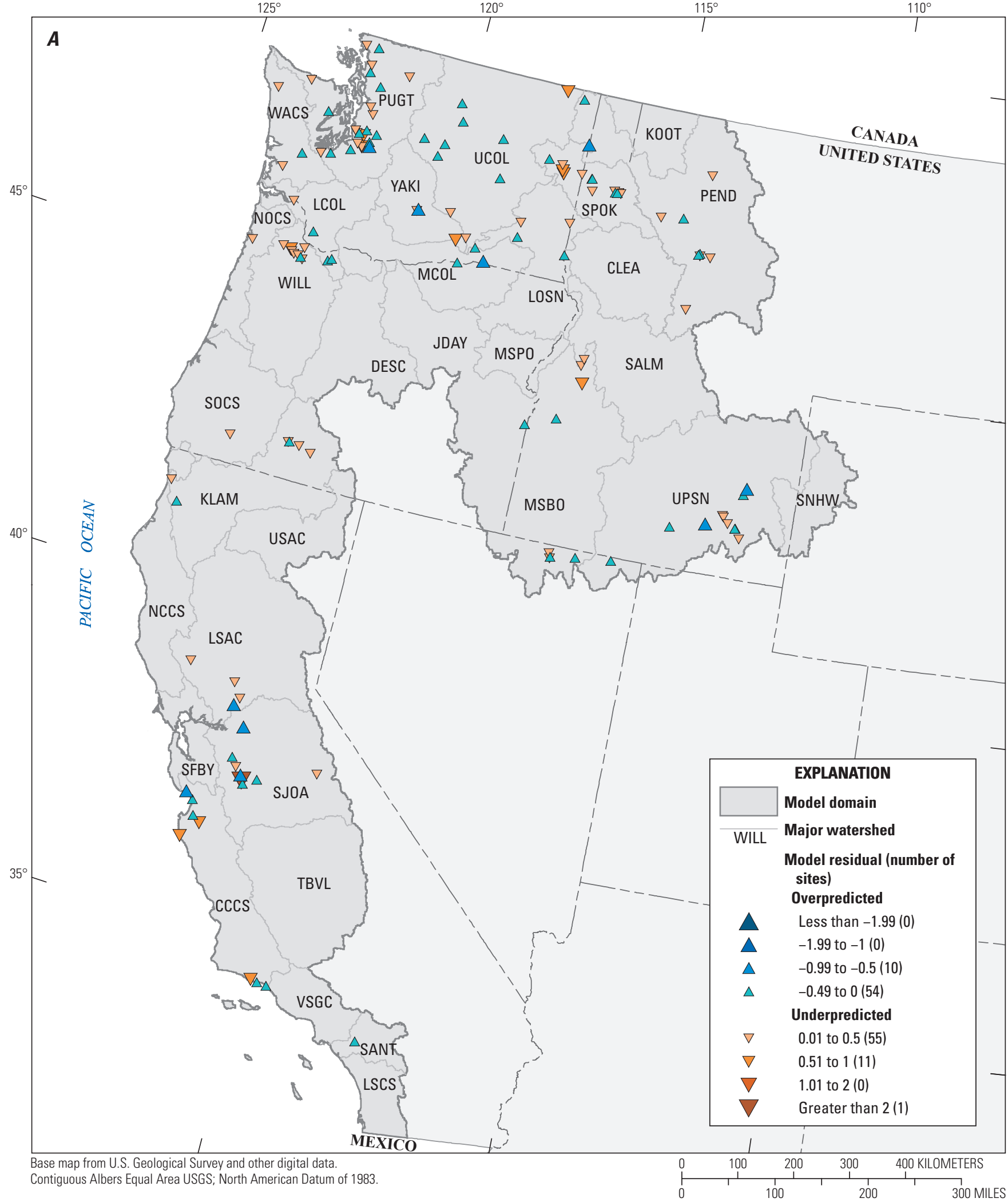

Figure 11. Spatial distribution of conditioned $(A)$ and unconditioned $(B)$ residuals from the Pacific region SPARROW (SPAtially Referenced Regression On Watershed attributes) total nitrogen model. [Conditioned residuals are based on the difference between the log of measured calibration loads and the log of predicted accumulated loads that were reset to the measured loads at the calibration stations. Unconditioned residuals are based on the difference between the log of measured calibration loads and the log of predicted accumulated loads that were not reset to the measured loads at the calibration stations.] 


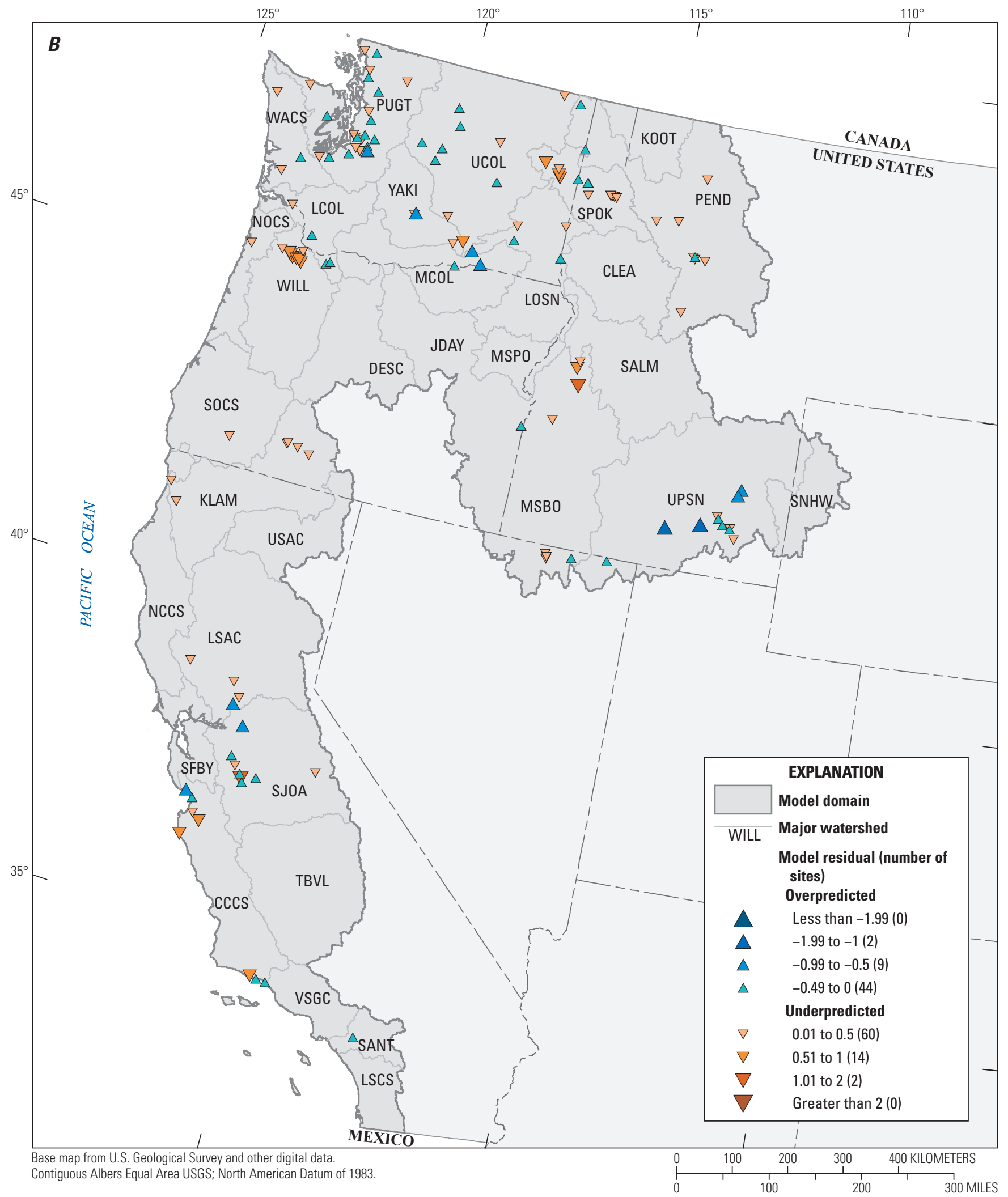

Figure 11.-Continued. 


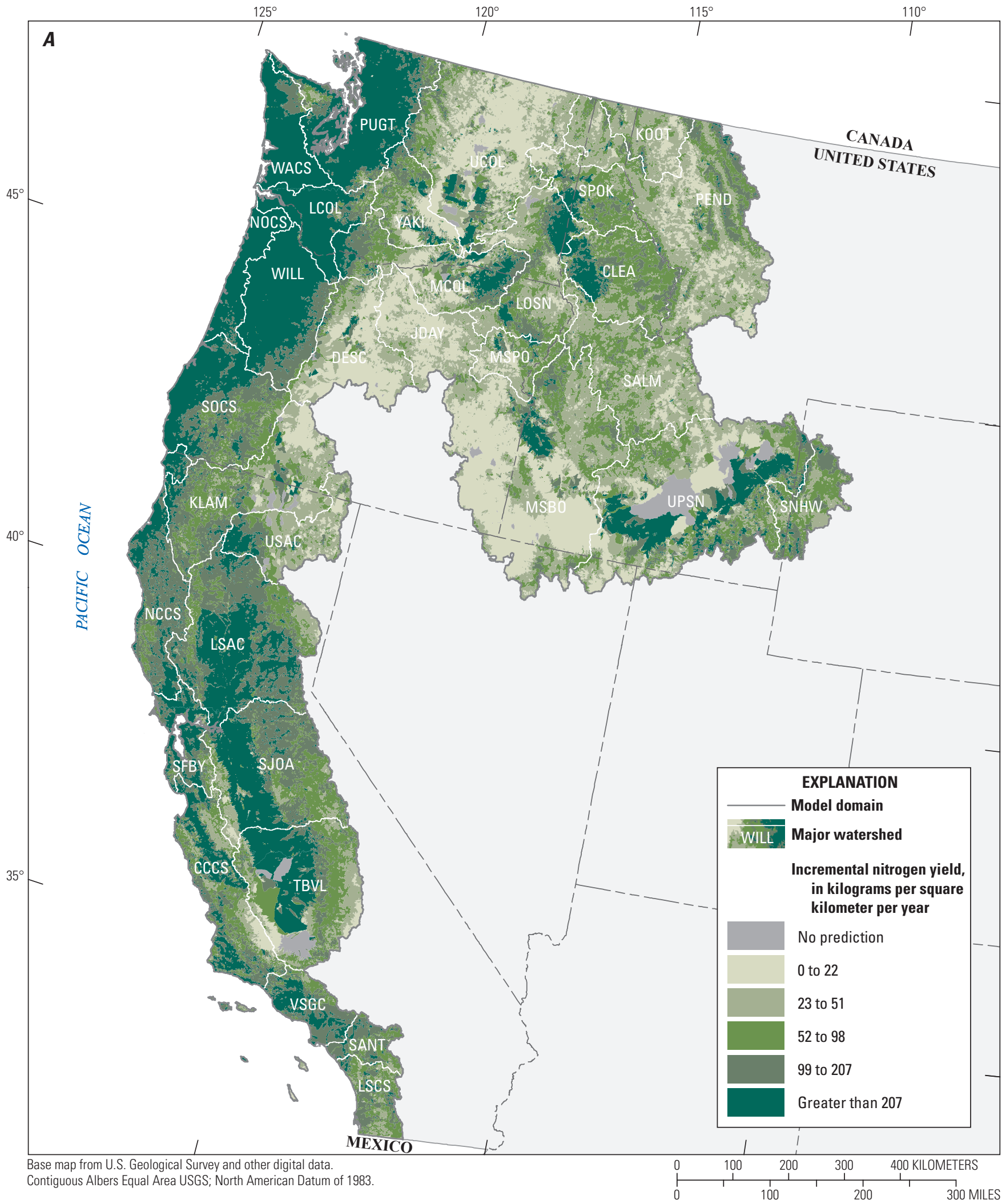

Figure 12. Predicted mean annual incremental yield $(A)$ and delivered incremental yield $(B)$ of total nitrogen from the Pacific region SPARROW (SPAtially Referenced Regression On Watershed attributes) total nitrogen model. 


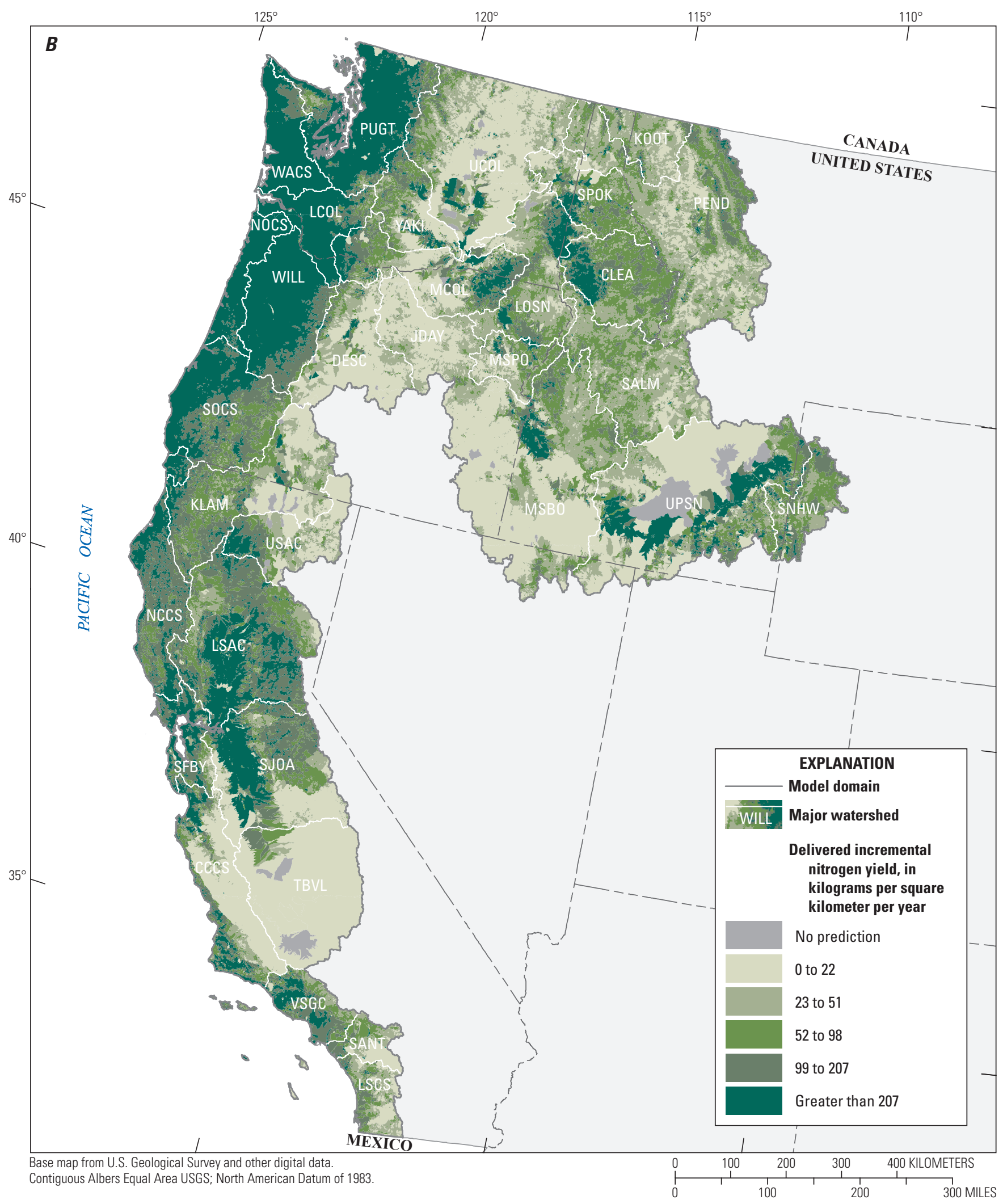

Figure 12.-Continued. 


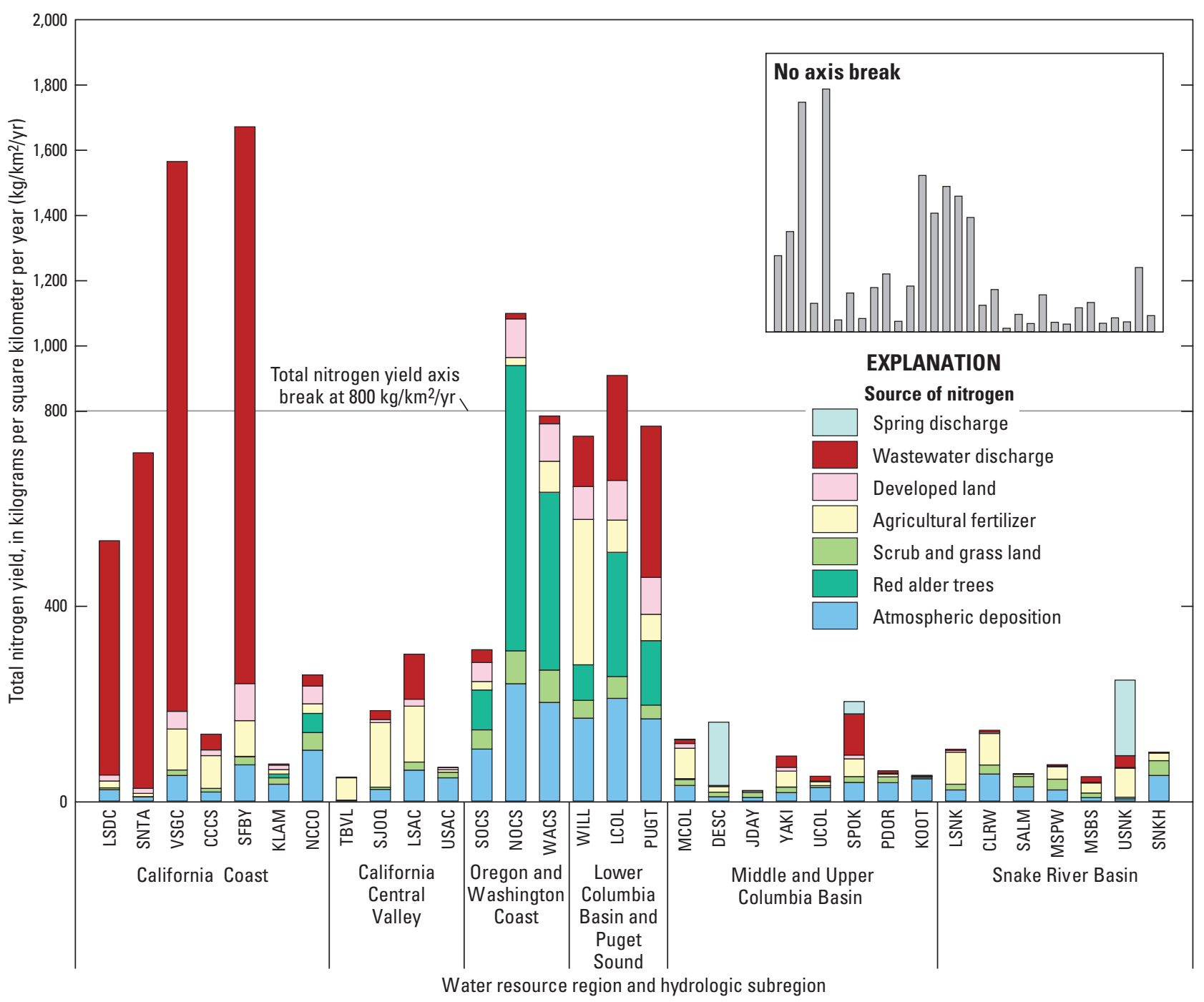

Figure 13. Predicted mean annual total nitrogen yield, by source, for Hydrologic Unit Code 6 (HUC6) watersheds in the Pacific region of the United States.

\section{Total Phosphorus}

The total phosphorus model included seven source terms five land-to-water delivery terms, but no aquatic loss terms (table 5). Agricultural fertilizer represented the sum of commercial phosphorus fertilizer and phosphorus in livestock manure that was applied to cultivated crops and pastureland, and these two sources were combined into one source for the same reasons as for the total nitrogen model. The model results indicated that on average 2.9 percent of the phosphorus in agricultural fertilizer and 4.7 percent of the phosphorus in grazing cattle manure reaches streams, developed land yields on average $11.1\left(\mathrm{~kg} / \mathrm{km}^{2}\right) / \mathrm{yr}$, and the mean total phosphorus concentration in spring discharge is $0.064 \mathrm{mg} / \mathrm{l}$. The contribution of phosphorus from channel erosion was represented in the model by using stream reach length as a source term that was acted upon exclusively by a delivery term representing the natural phosphorus content of local soil and rock. The contribution from upland natural phosphorus was represented by using the incremental area of each catchment as a source term that was scaled by an estimate of the natural phosphorus content of local soil and rock. The estimated coefficients indicated that, on average, channel erosion contributes $4.01 \mathrm{~kg} / \mathrm{km}$ per year $[(\mathrm{kg} / \mathrm{km}) / \mathrm{yr}]$ of total phosphorus to in-stream load and that $0.0014\left(\mathrm{~kg} / \mathrm{km}^{2}\right) / \mathrm{yr}$ is contributed from geologic phosphorus in upland areas when accounting for the natural phosphorus content of local soil and rock. The coefficient was 1.386 for wastewater discharge, implying that the actual total phosphorus discharged to streams in 2012 was greater than the estimated point source discharge estimates. All five delivery terms in the total phosphorus model had positive coefficients, and these results were consistent with expectations. The positive coefficients for perennial ice and snow and wildfire disturbance were expected because phosphorus adsorbed to soil particles can 


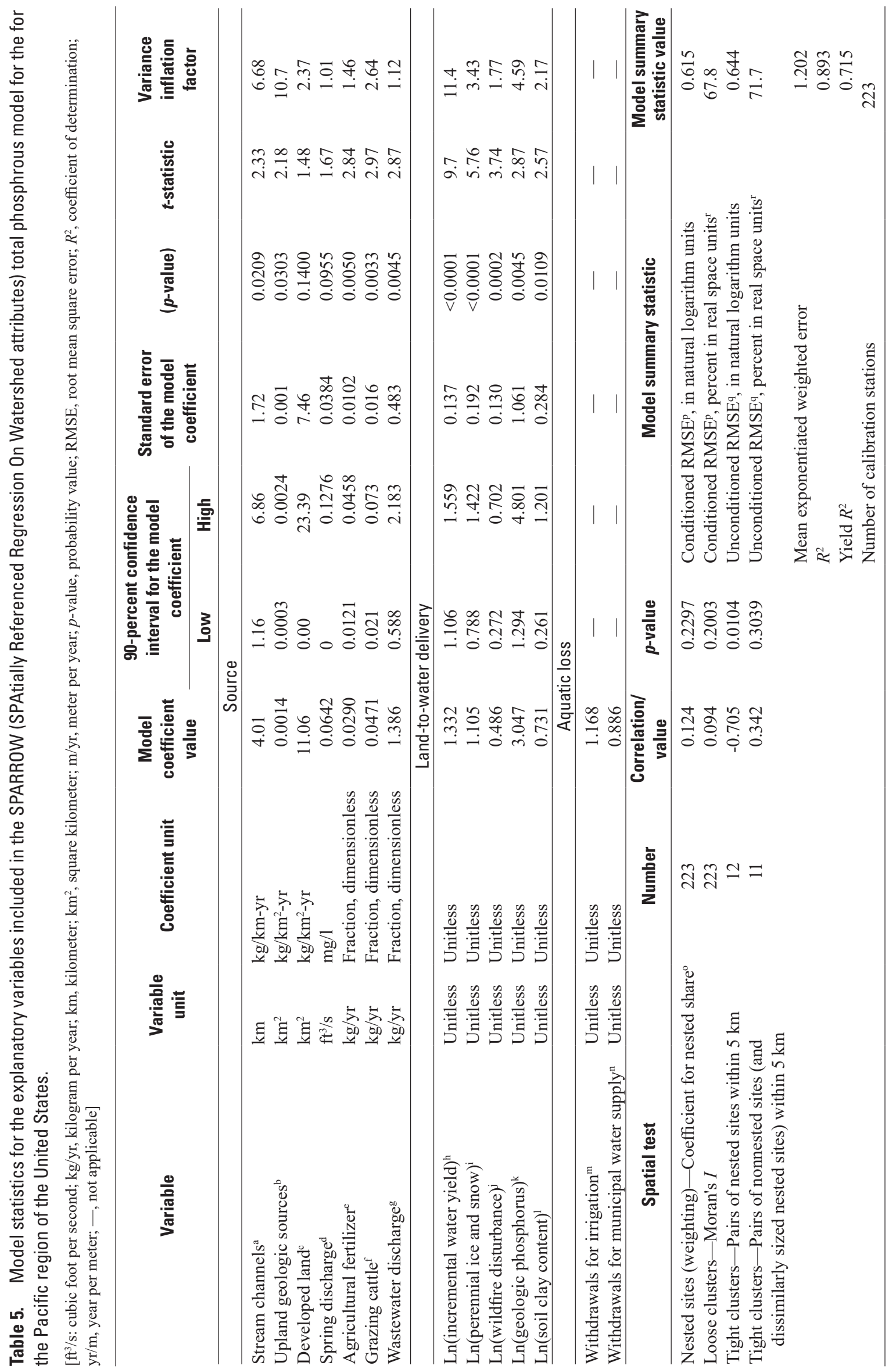




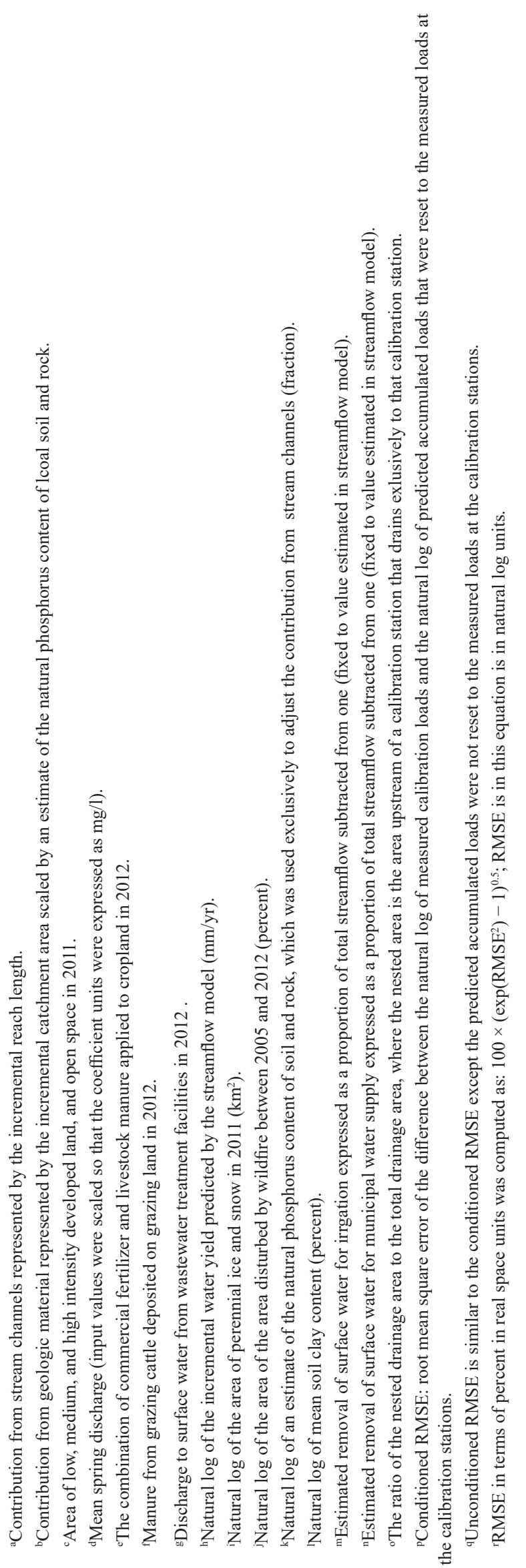


be mobilized in outwash from snowfields and glaciers and erosion from recently burned areas. Many other climate and landscape factors were evaluated as potential delivery terms but were not included because they were

not significant.

The lack of a significant aquatic loss term for freeflowing streams indicated that, over the 15 -year period represented by the model calibration, any seasonal settling of particulate phosphorus and plant uptake of bio-available phosphorus was balanced by particulate re-suspension and plant decay and re-cycling. The lack of a significant aquatic loss term for impoundments was an indication that most ponds, lakes, and reservoirs in the Pacific region do not permanently remove substantial amounts of phosphorus, and it is consistent with the results from SPARROW total phosphorus models that have previously been developed for the Pacific Northwest (Wise and Johnson, 2013) and California (Domagalski, and Saleh, 2015). The total phosphorus model also included loss terms representing municipal water supply intakes and irrigation diversions with coefficients that were set to the values estimated in the streamflow model.

Figure 14 shows the diagnostic plots for the calibration of the total phosphorus model, which explained about 72 percent of the variability in measured total phosphorus yield. The variance of the model residuals was relatively constant across the range of conditioned predicted total phosphorus loads (14A) and conditioned total phosphorus yields $(14 B)$. The conditioned RMSE (0.615) and unconditioned RMSE (0.644) were close in value, which is reflected in the similarities between the plots shown in fig. $14 \mathrm{C}$ and fig. 14D and the similarities between the conditioned and unconditioned residuals shown in figure 15. The nested areas for the calibration stations were not a significant predictor of the squares of the residuals from the total phosphorus model and, therefore, were not used as weights in its calibration. There was no significant spatial correlation among loose clusters of residuals or significant spatial correlation among tight clusters of nonnested residuals and nested residuals that had dissimilar drainage areas, but there was significant spatial correlation among 12 pairs of nested residuals that had similar drainage areas. The upstream station in each one of these nested pairs was removed from the calibration dataset, leaving 223 calibration stations in the final model (and no significant spatial correlation among the residuals).

The mean incremental yields predicted by the total phosphorus model are shown in figure 16, where the total incremental yields represent the total amount of phosphorus generated within each incremental catchment and the delivered incremental yields represent the amount generated within each catchment that was delivered to an estuary or the Pacific Ocean. Wastewater discharge is, by far, the largest contributor to the total phosphorus yield from the Pacific region, accounting for about 52 percent of the total amount. As is the case with total nitrogen, however, most of the total phosphorus from wastewater originates in four watersheds along the California coast-Laguna-San Diego Coastal (LSCS), Santa Ana River (SANT), Ventura-San Gabriel Coastal (VSCS), and San Francisco Bay (SFBY), as shown in figure 17 , and most of the wastewater from three of those watersheds (LSCS, SANT, VSCS) is discharged through diffusers located far offshore. There were many watersheds, however, where sources other than wastewater discharge are important (fig. 17 and table 2.3). For example, the combination of agricultural fertilizer, manure from grazing cattle, and developed land are responsible for more than one-half of the total phosphorus yield from nine watersheds. 

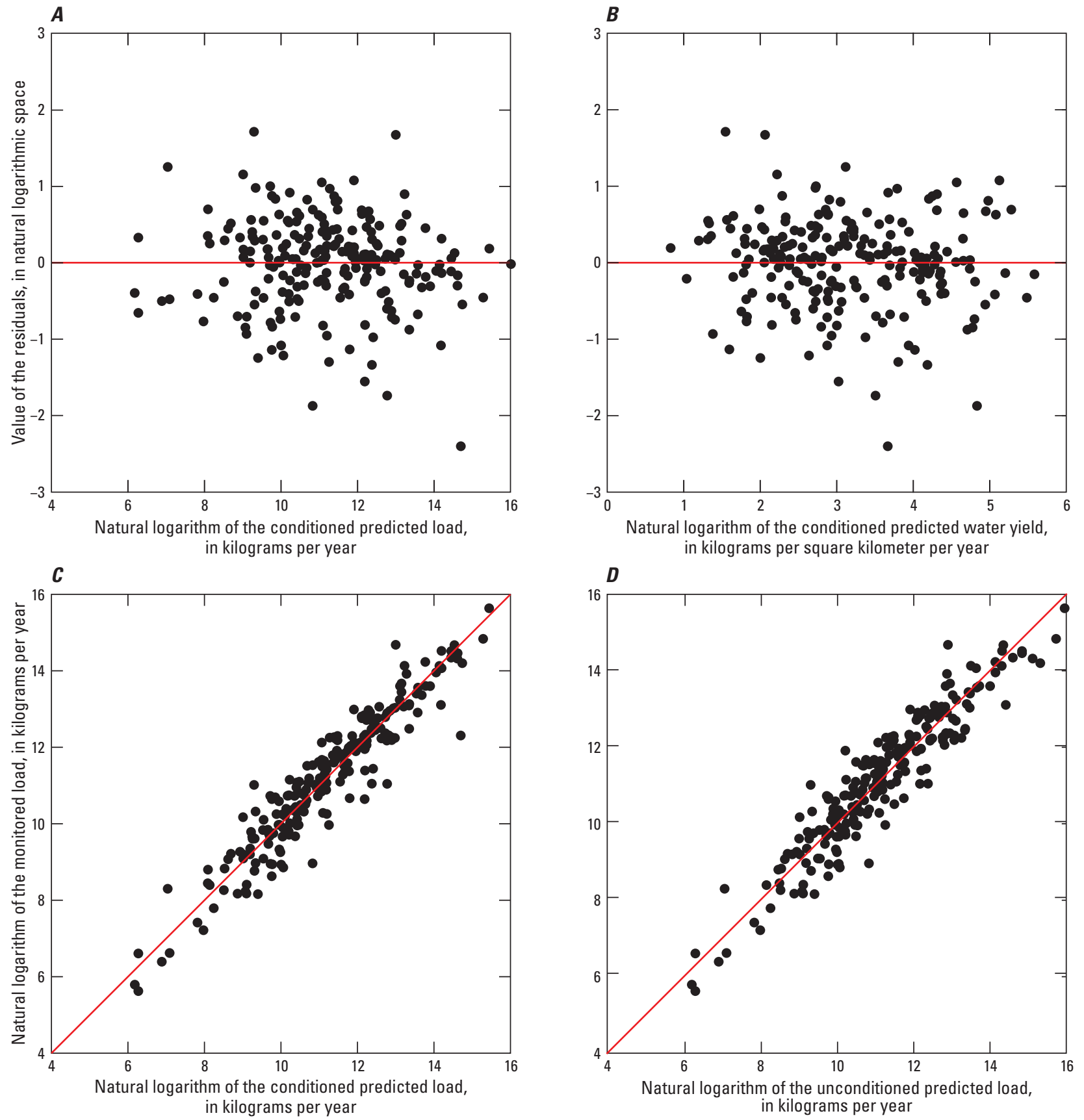

Figure 14. Diagnostic plots for the Pacific region SPARROW (SPAtially Referenced Regression On Watershed attributes) total phosphorus model. [( $A)$ Residuals versus predicted load. (B) Residuals versus predicted yield. (C) Measured streamflow versus conditioned predicted load (model calibration). (D) Measured load versus unconditioned predicted load (full prediction).] 


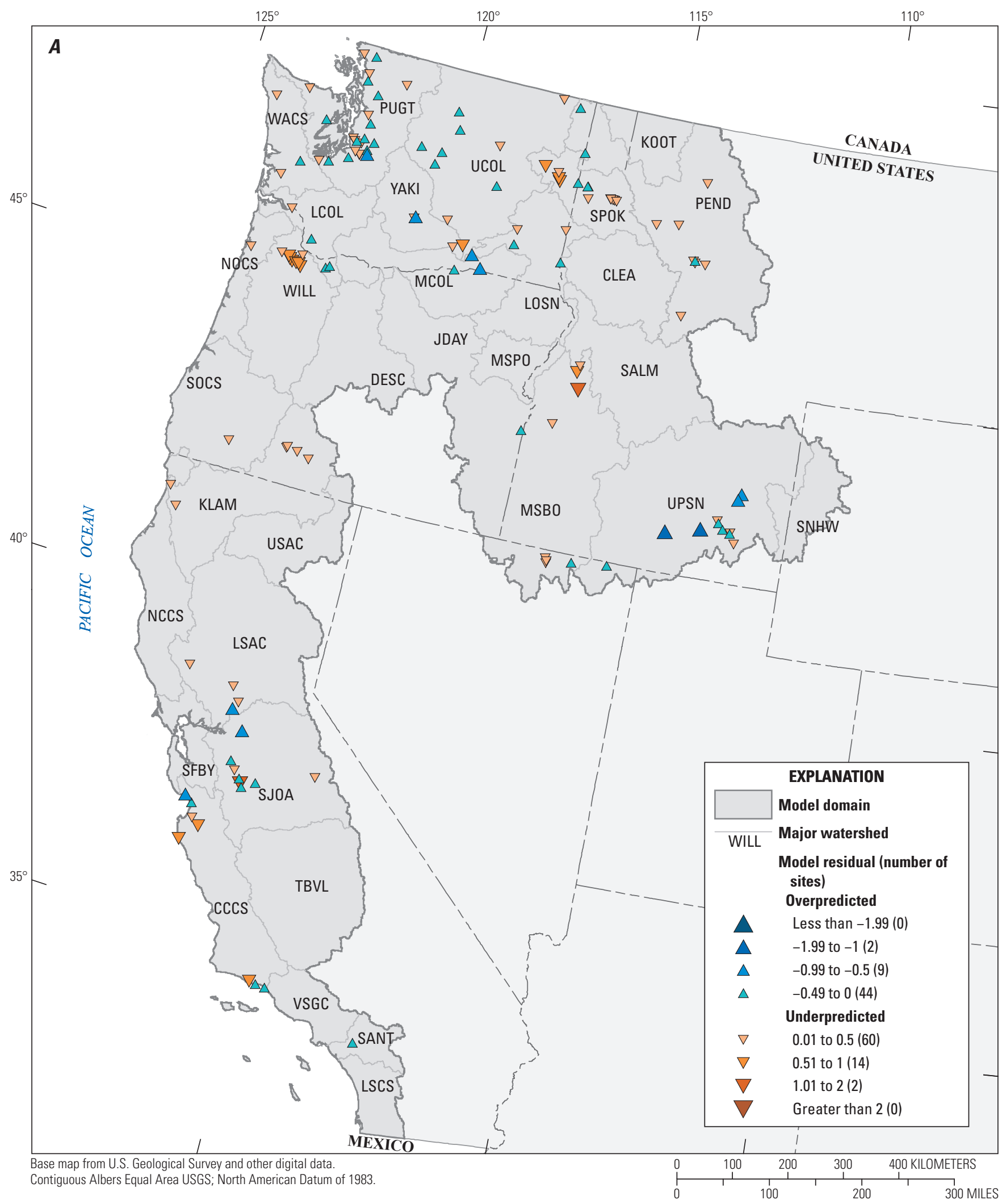

Figure 15. Spatial distribution of conditioned $(A)$ and unconditioned $(B)$ residuals from the Pacific region SPARROW (SPAtially Referenced Regression On Watershed attributes) total phosphorus model. [Conditioned residuals are based on the difference between the log of measured calibration loads and the log of predicted accumulated loads that were reset to the measured loads at the calibration stations. Unconditioned residuals are based on the difference between the log of measured calibration loads and the log of predicted accumulated loads that were not reset to the measured loads at the calibration stations.] 


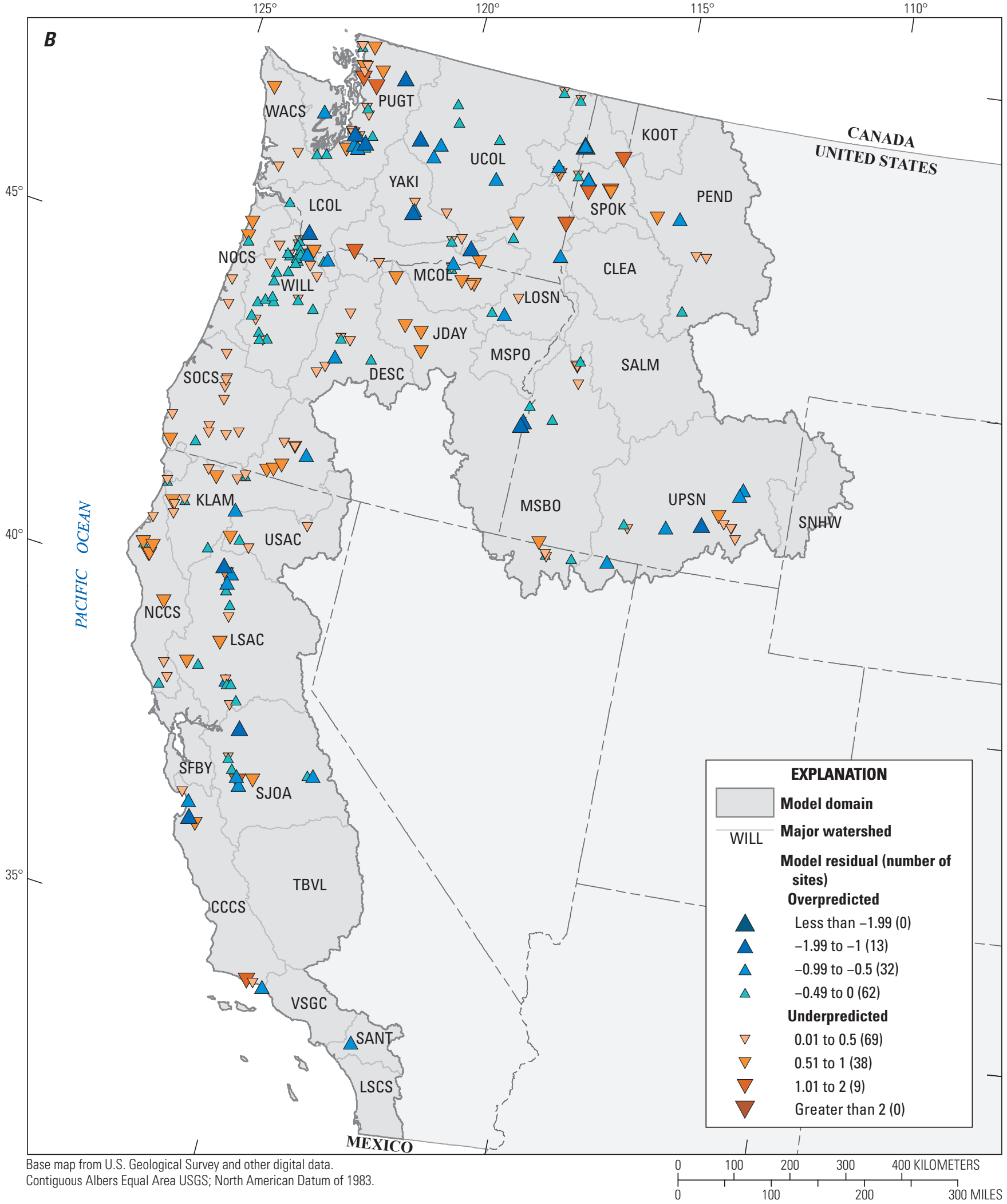

Figure 15.-Continued 


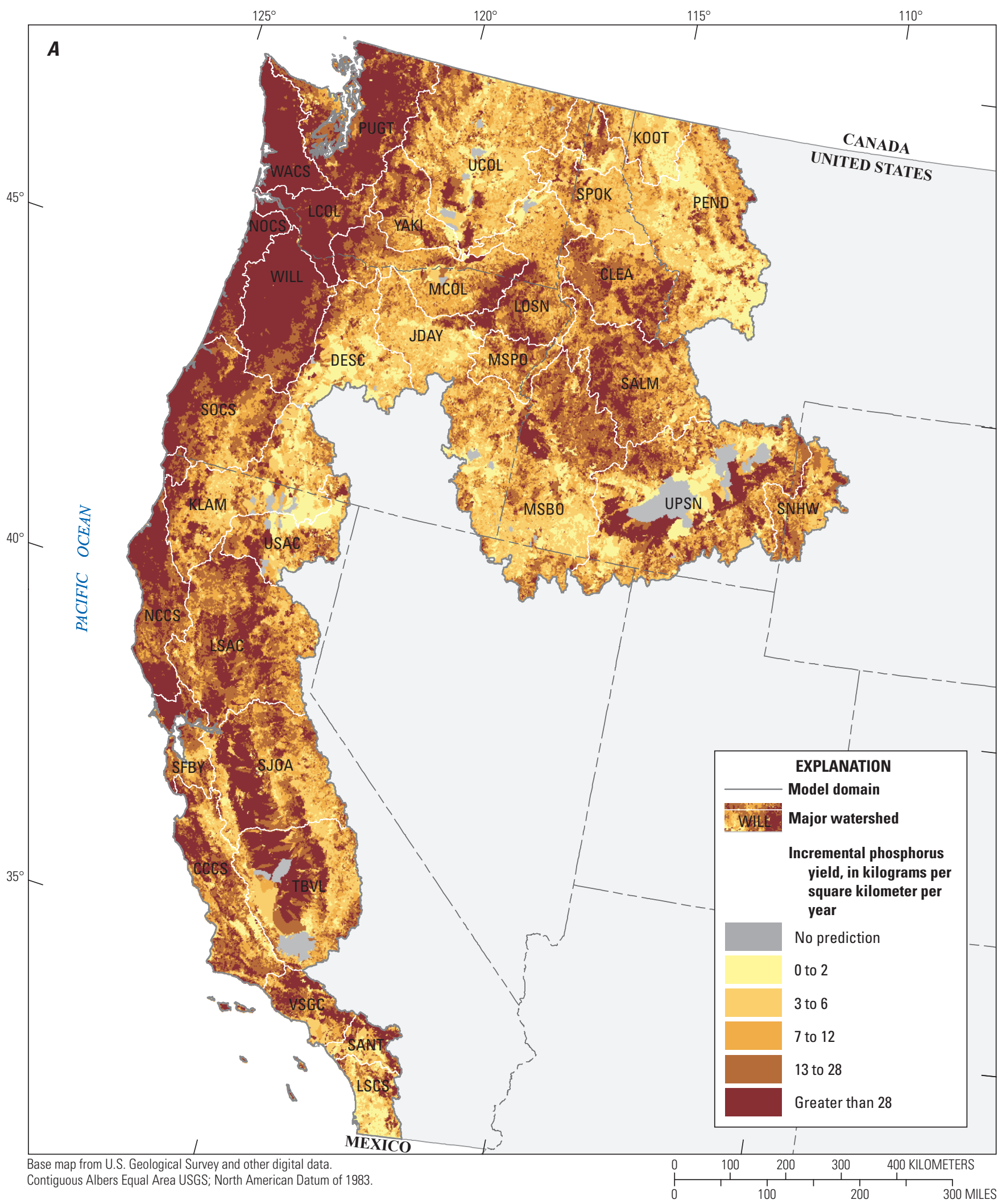

Figure 16. Predicted mean annual incremental yield $(A)$ and delivered incremental yield $(B)$ of total phosphorus from the Pacific region SPARROW (SPAtially Referenced Regression On Watershed attributes) total phosphorus model. 


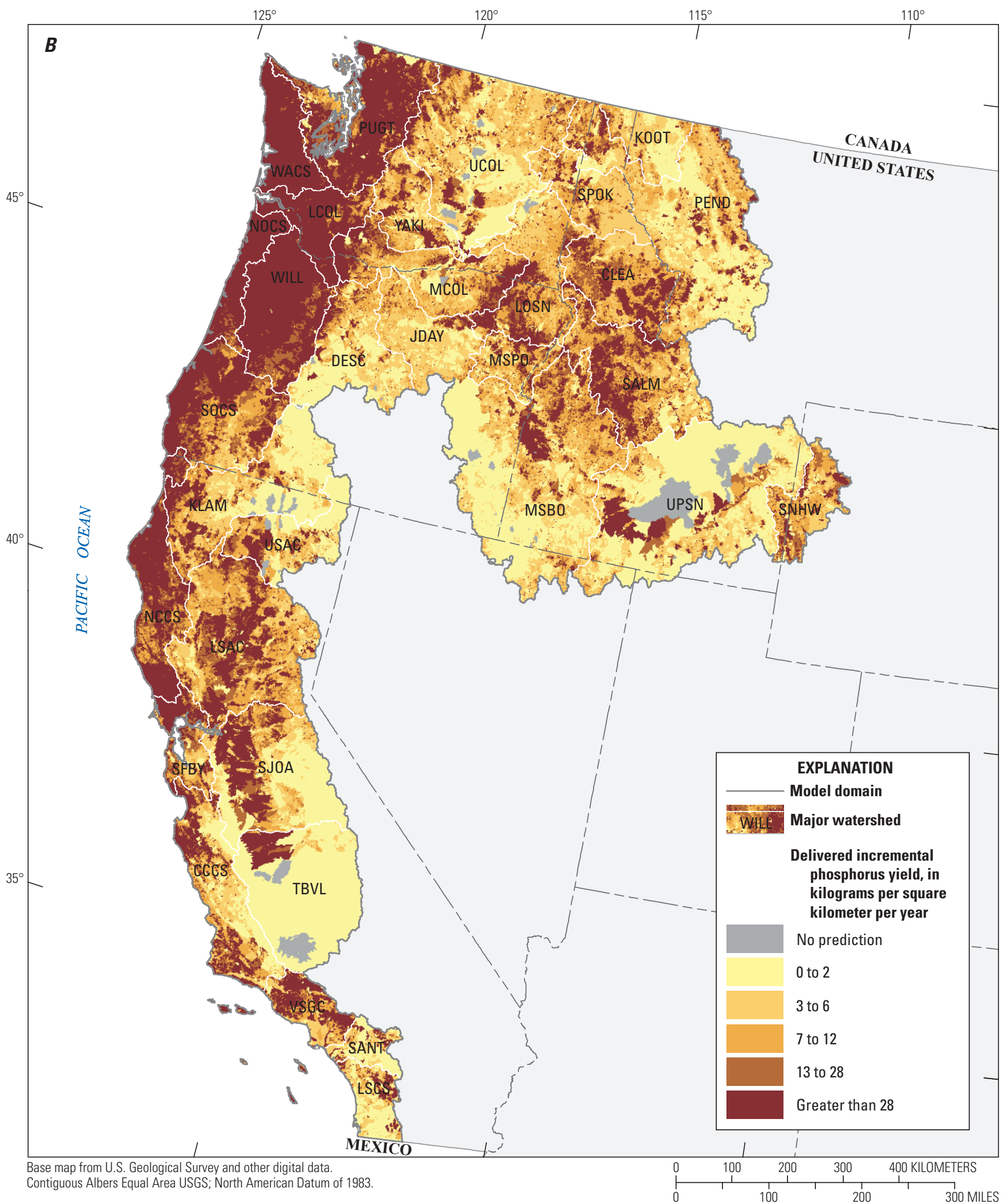

Figure 16.-Continued 


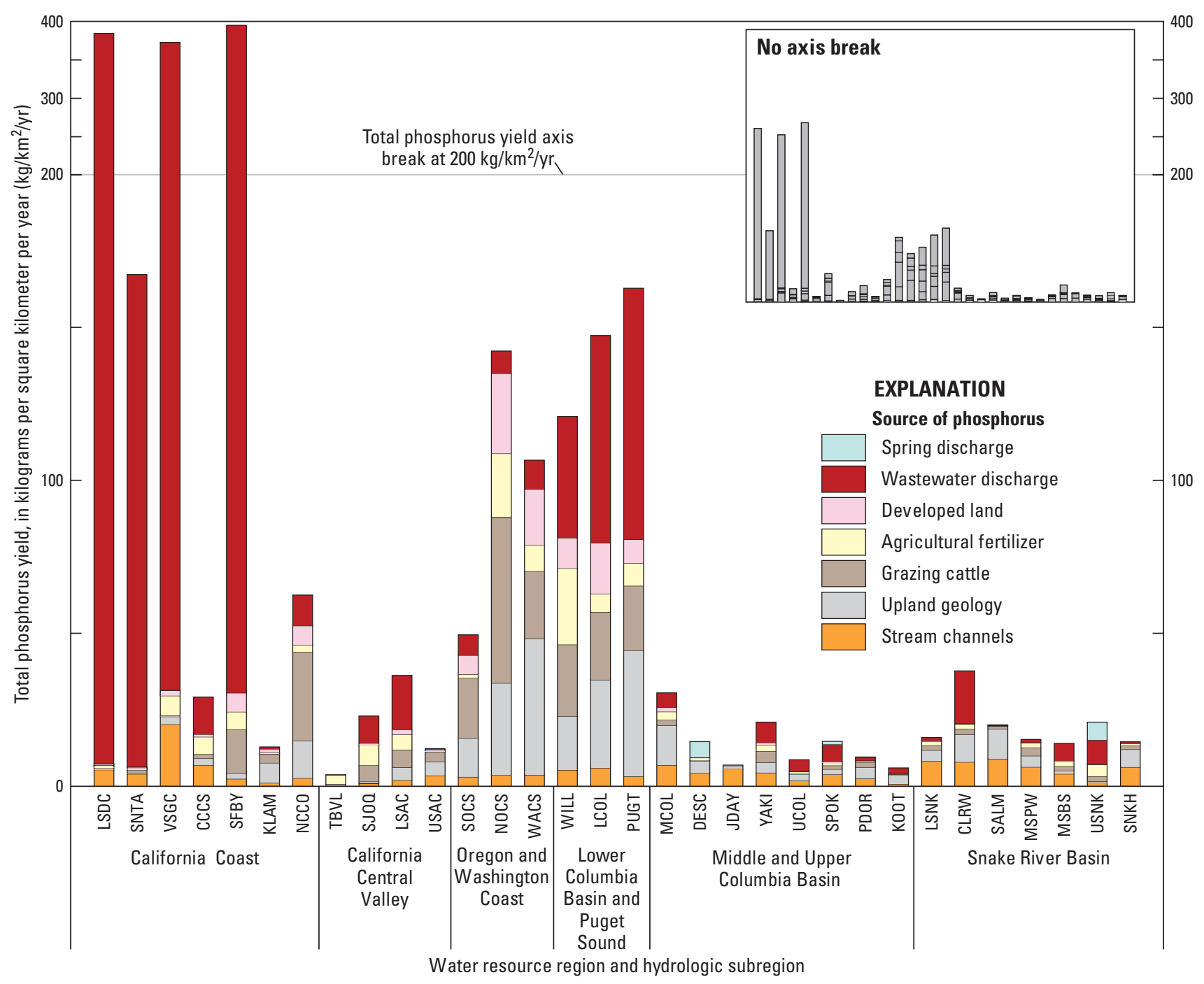

Figure 17. Predicted mean annual total phosphorus yield, by source, for Hydrologic Unit Code (HUC6) watersheds in the Pacific region of the United States.

\section{Suspended Sediment}

The suspended-sediment model included four source terms, four land-to-water delivery terms, five aquatic loss terms, and a calibration load conversion term (table 6). The coefficient estimated for stream channels ( 8.575 tons per kilometer per year $[(\mathrm{t} / \mathrm{km}) / \mathrm{yr}])$ represents the average contribution from channel erosion and resuspension of bed sediment to in-stream load. As expected, igneous and metamorphic rocks were not a significant source of suspended sediment. The model results indicated that suspendedsediment yields from areas not consisting of those rock types average $42.39\left[\mathrm{t} / \mathrm{km}^{2}\right] / \mathrm{yr}$ from agricultural land, $30.65 \mathrm{t} /$ $\mathrm{km}^{2}$-yr from developed land, and $17.09 \mathrm{t} / \mathrm{km}^{2}$-yr from forest land. All four delivery terms in the suspended-sediment model had positive coefficients. The positive coefficients for grazing density, wildfire disturbance, and the area of perennial snow and ice were expected because areas that have been recently disturbed by wildfire or cattle grazing should yield more sediment than areas that have not experienced such disturbances, and fine soil is readily transported in the outwash from snowfields and glaciers. Many other climate and landscape factors were evaluated as potential delivery terms but were not included because they were not significant.

The model calibration results showed that free-flowing streams and impoundments were important locations for sediment loss, and that the remediation activities in Blacktail Creek (U.S. Environmental Protection Agency, 2018b) were substantial enough to be a significant process for in-stream sediment loss. The suspended-sediment model also included loss terms representing municipal water supply intakes and irrigation diversions with coefficients that were set to the values estimated in the streamflow model. 


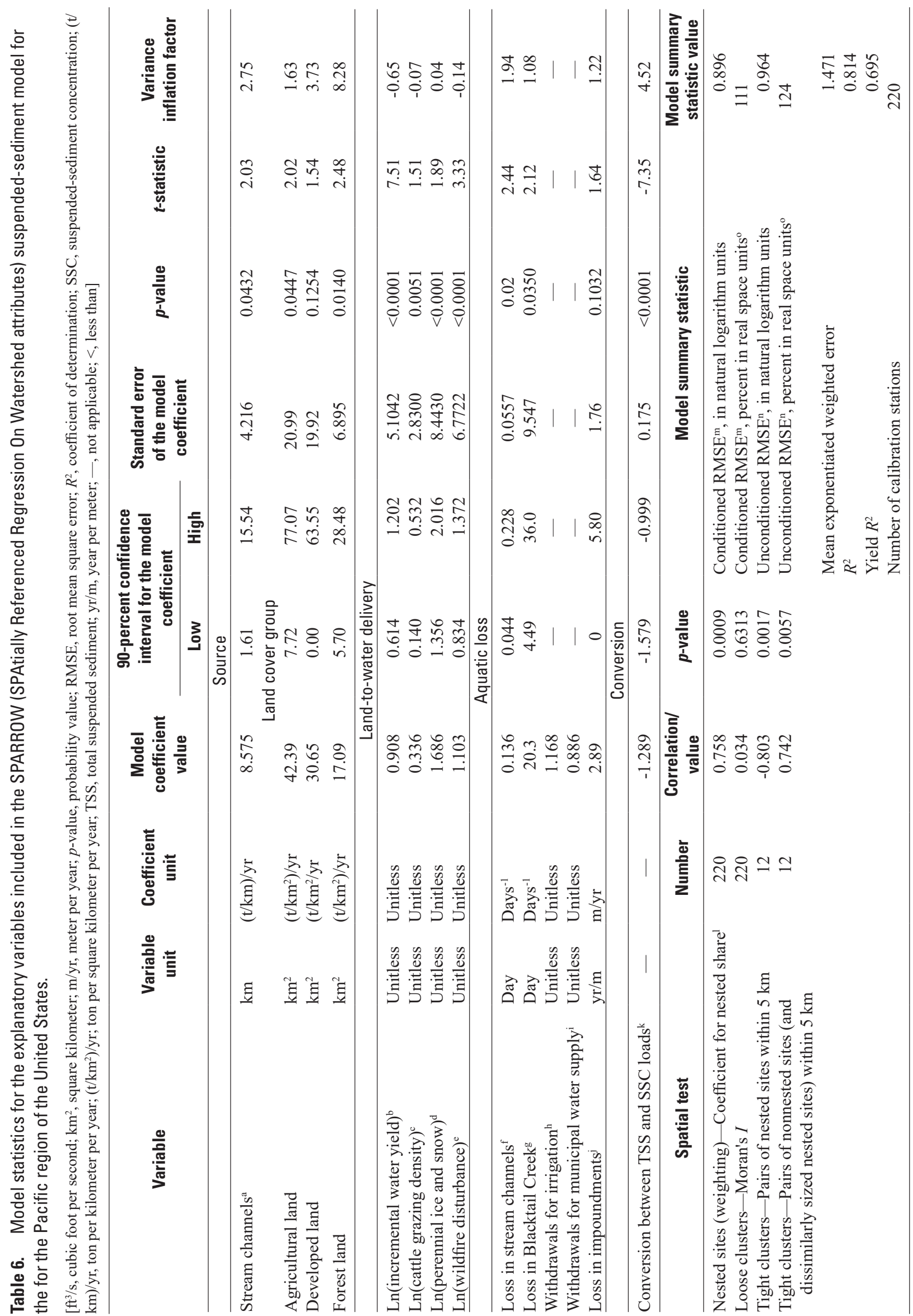




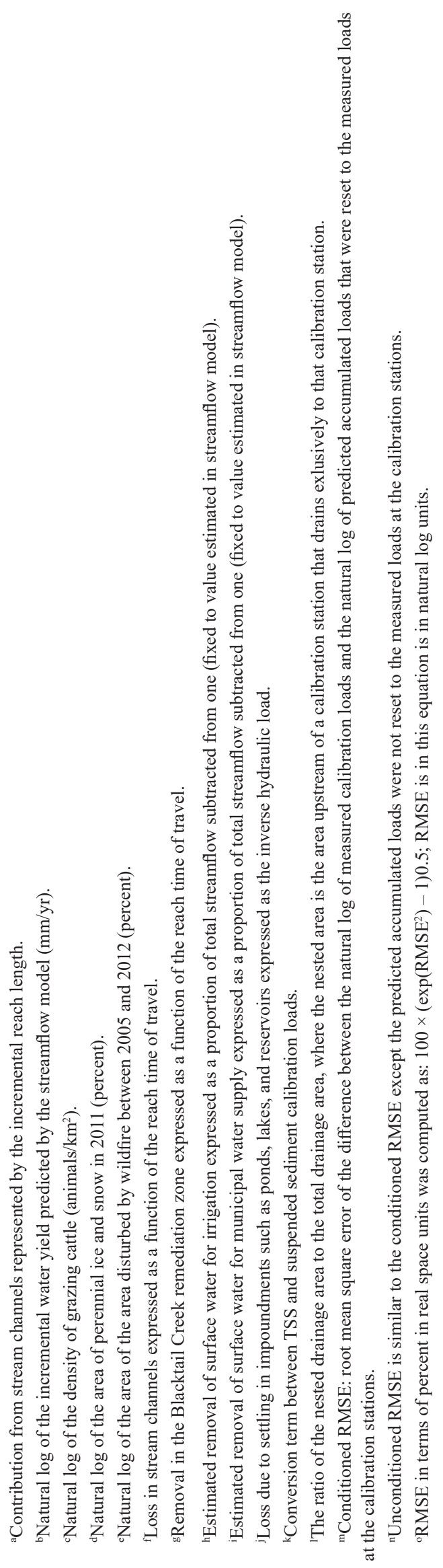


The model identified a significant difference between the TSS and suspended-sediment loads in the calibration data set, and this is presumed to be related to differences in field sampling techniques (surface grab sampling versus depth and width integrated sampling) and laboratory analytical techniques (suspended-sediment concentration compared to TSS concentration). The results showed that on average a factor of 3.502 was needed to convert between TSS and suspendedsediment loads, and this factor was substantially higher than the average value (1.622) for the only other results found in the literature (Groten and Johnson, 2018, for streams in Minnesota where the results ranged from $1.000-3.888$ ). The reason for such a large difference between the results for the Pacific region and the average value for the streams in Minnesota is not known, but one possibility is that the Pacific region streams contain a larger fraction of sand compared to the Minnesota streams.

Figure 18 shows the diagnostic plots for the calibration of the suspended-sediment model, which explained about 70 percent of the variability in measured suspended-sediment yield. The values shown on the plots reflect any scaling necessary to convert TSS loads to equivalent suspendedsediment loads. The variance of the model residuals was relatively constant across the range of conditioned predicted suspended-sediment loads (fig. 18A) and conditioned suspended-sediment yields (fig. 18B). The conditioned RMSE (0.896) and unconditioned RMSE (0.964) were close in value, which is reflected in the similarities between the plots shown in figures $18 \mathrm{C}$ and $18 \mathrm{D}$ and the similarities between the conditioned and unconditioned residuals shown in figure 19. The nested areas for the calibration stations were a significant predictor of the squares of the residuals from the suspendedsediment model and, therefore, were used as weights in its calibration. There was no significant spatial correlation among loose clusters of residuals, but there was significant spatial correlation among 12 pairs of tight clusters of nonnested residuals and nested residuals that had dissimilar drainage areas, and significant spatial correlation among 12 pairs of nested residuals that had similar drainage areas. One station was randomly selected from each pair in the first group of residuals and removed from the calibration dataset, and the upstream station was selected from each pair in the second group and removed from the calibration dataset, leaving 220 calibration stations in the final model (and no significant spatial correlation among the residuals).

The mean incremental yields predicted by the suspendedsediment model are shown in figure 20, where the total incremental yields represent the total amount of sediment generated within each incremental catchment and the delivered incremental yields represent the amount generated within each catchment that was delivered to an estuary or the Pacific Ocean. Forest land is, by far, the largest contributor to the suspended-sediment yield from the Pacific region, accounting for about 74 percent of the total amount, and is the largest contributor for most of the HUC6 watersheds in the Pacific region (fig. 21 and table 2.4). The notable exceptions are the five highly urbanized watersheds along the California coastLaguna-San Diego Coastal (LSCS), Santa Ana River (SANT), Ventura-San Gabriel Coastal (VSCS), Central California Coastal (CCCS), and San Francisco Bay (SFBY), where developed land is the largest individual contributor to the suspended-sediment yield. Except for those watersheds with substantial areas of developed land, the highest suspended-sediment yields were predicted for watersheds with the highest water yields.

Although most of the coastal watersheds of Washington, Oregon, and northern California are forest land, those watersheds still have relatively high suspended-sediment yields from developed land and open space-ranking in the top one-third for this metric compared to all 32 HUC6 watersheds in the Pacific region. While these high yields are partly related to high precipitation, they also likely reflect the impact from logging activities. The coastal watersheds of Washington, Oregon, and northern California contain thousands of miles of unpaved logging roads that are categorized as open space in the NLCD. The open space within those coastal watersheds, which primarily represents unpaved roads, made up between 59 and 88 percent of the total area of the "developed land and open space" source term used in the suspended-sediment model. There is strong evidence, therefore, that much of the suspended-sediment yields attributed to developed land and open space within those coastal watersheds are likely due to erosion from unpaved logging roads. This interpretation is consistent with the results from field studies of sediment runoff from unpaved forest roads in some of those watersheds (MacDonald and Coe, 2008), which showed very high localized sediment yields during precipitation events (with annual estimates as high as $6,600 \mathrm{t} / \mathrm{km}^{2} / \mathrm{yr}$ ).

\section{Yields Summarized by Land Cover}

The SPARROW model can estimate the yields for catchments that are dominated by different types of land cover, even land cover types that are not represented in a model as a source. For this analysis, yields were summarized for catchments that are were predominately one type of land cover. Table 7 shows the median incremental yields of total nitrogen, total phosphorus, and suspended sediment for catchments where at least 90 percent of the total area is covered by forest land, scrub and grass land, agricultural land, or developed land. The median total nitrogen and total phosphorus yields were highest for agricultural and developed land while the median suspended-sediment yield was highest for forest land. 

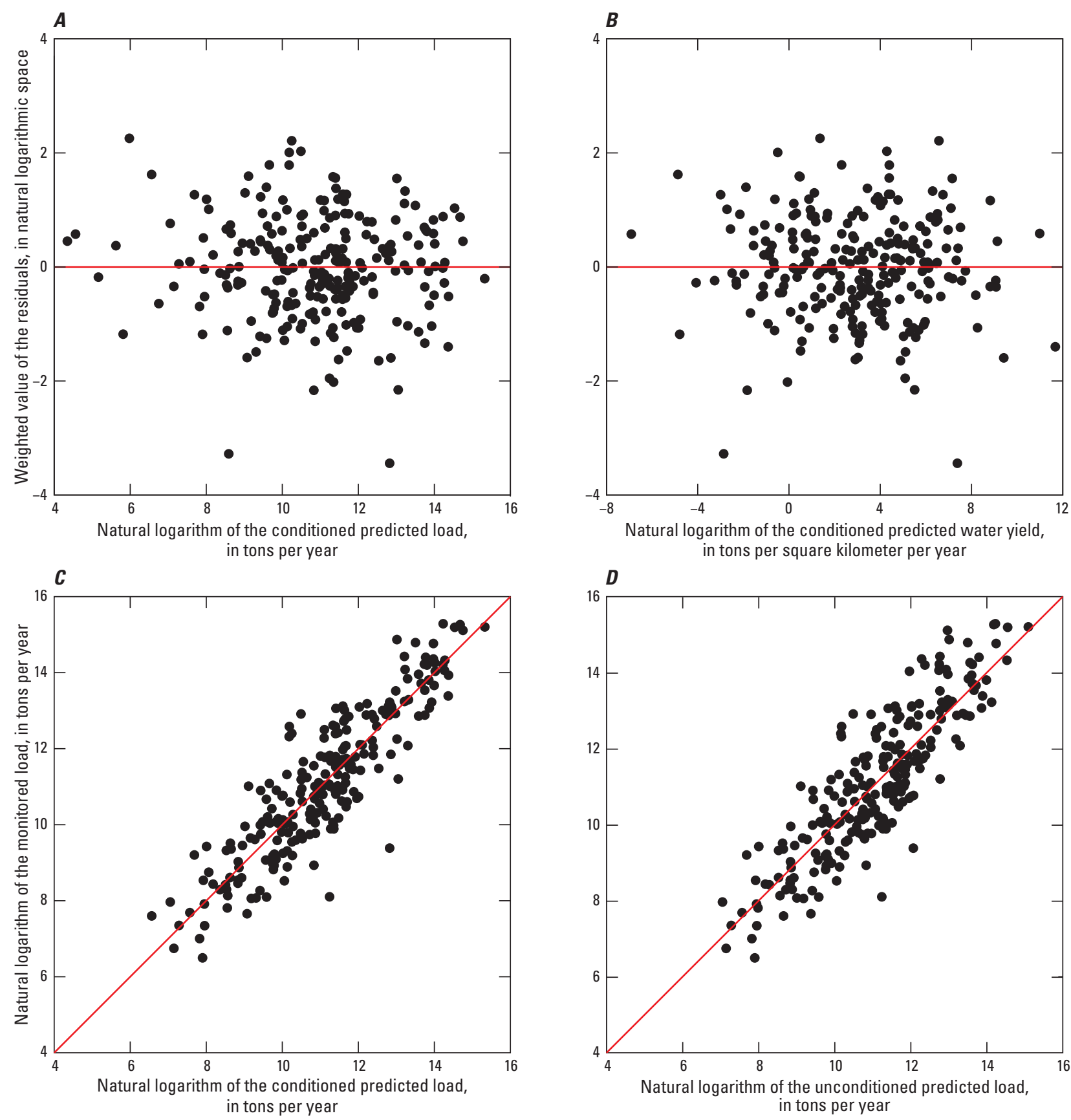

Figure 18. Diagnostic plots for the Pacific region SPARROW (SPAtially Referenced Regression On Watershed attributes) suspended-sediment model. [( $A)$ Weighted residuals versus predicted load. $(B)$ Weighted residuals versus predicted yield. (C) Measured streamflow versus conditioned predicted load (model calibration). (D) Measured load versus unconditioned predicted load (full prediction).] 


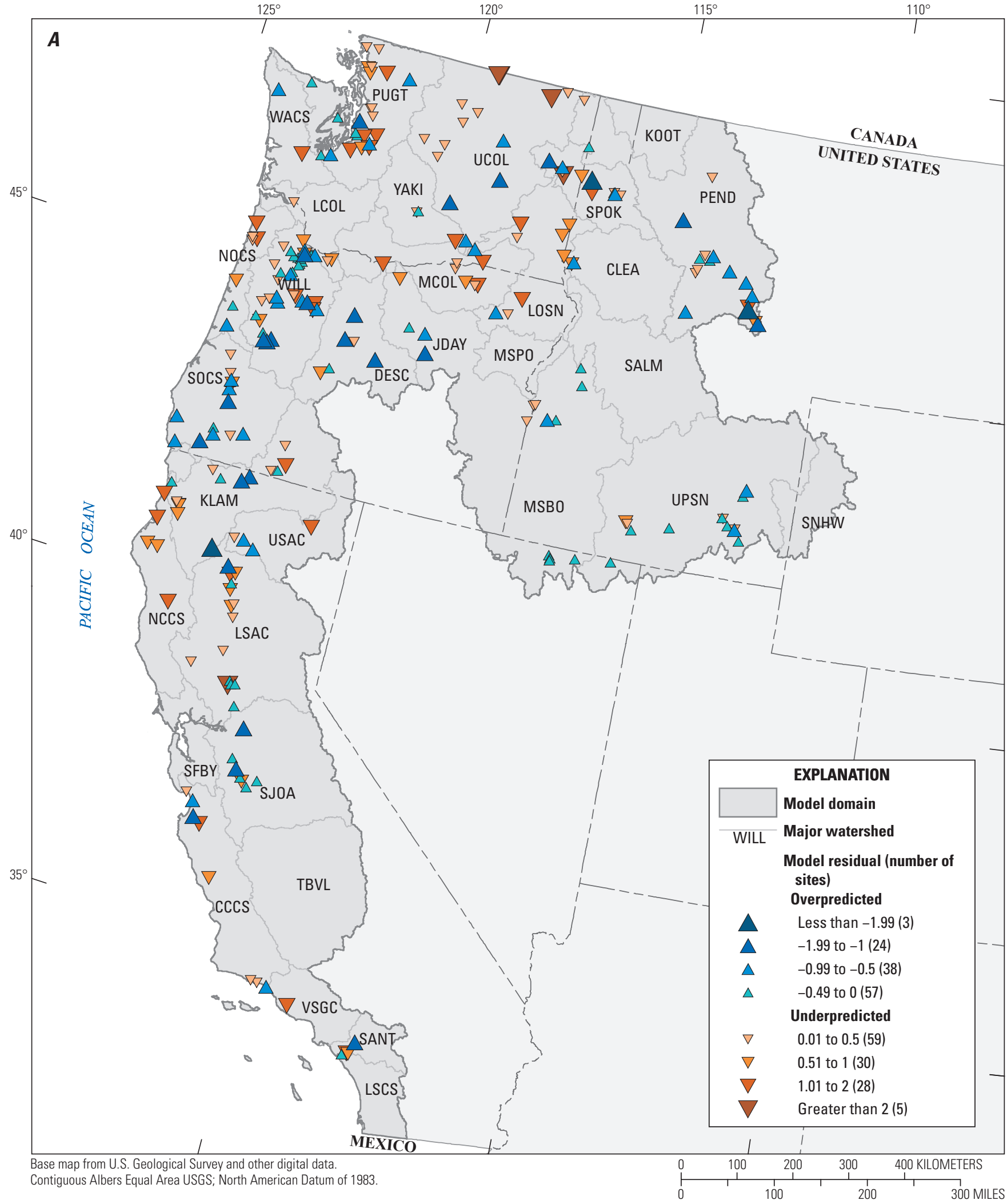

Figure 19. Spatial distribution of conditioned $(A)$ and unconditioned $(B)$ residuals from the Pacific region SPARROW (SPAtially Referenced Regression On Watershed attributes ) suspended-sediment model. [Conditioned residuals are based on the difference between the log of measured calibration loads and the log of predicted accumulated loads that were reset to the measured loads at the calibration stations. Unconditioned residuals are based on the difference between the log of measured calibration loads and the log of predicted accumulated loads that were not reset to the measured loads at the calibration stations.] 


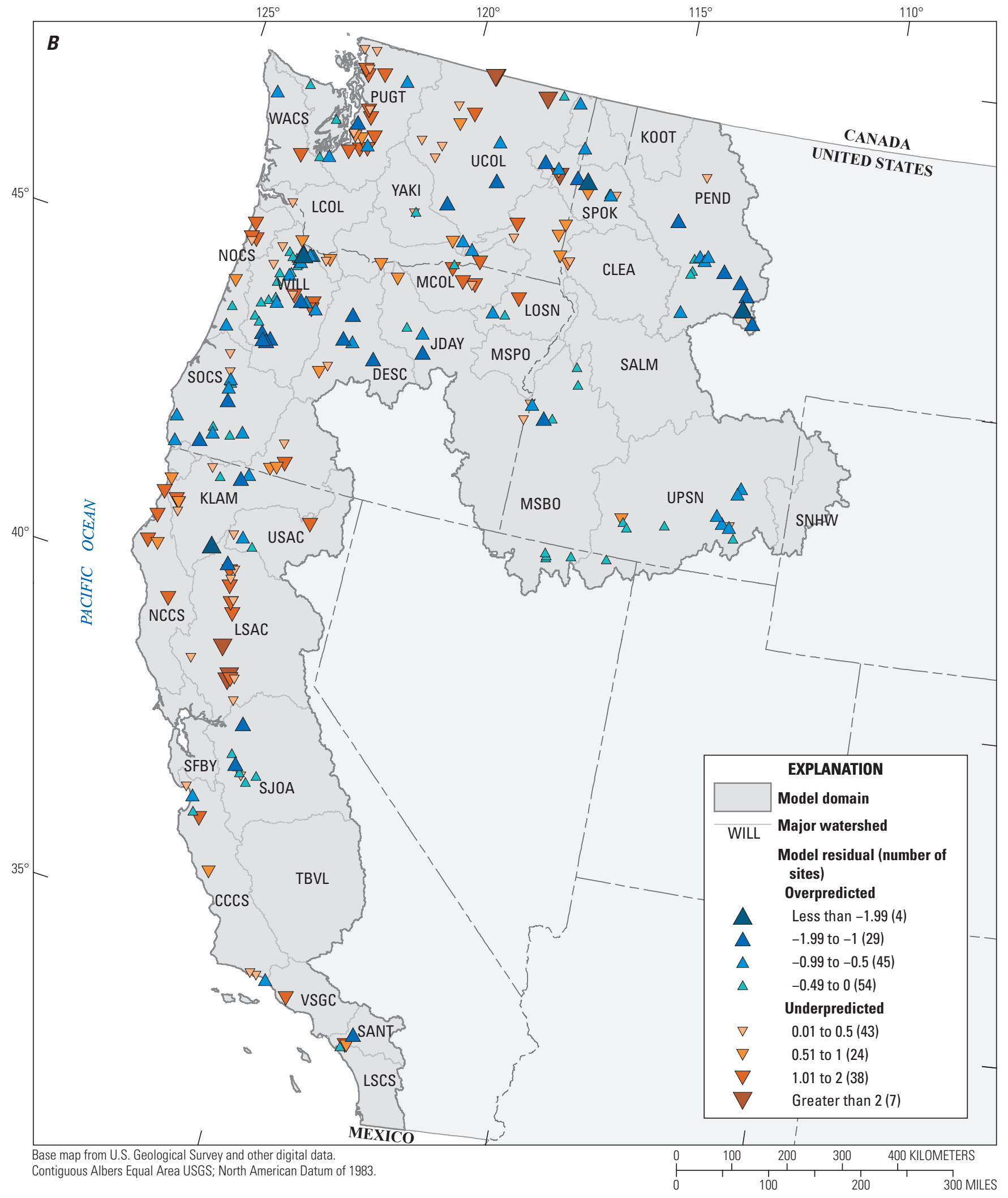

Figure 19.-Continued 


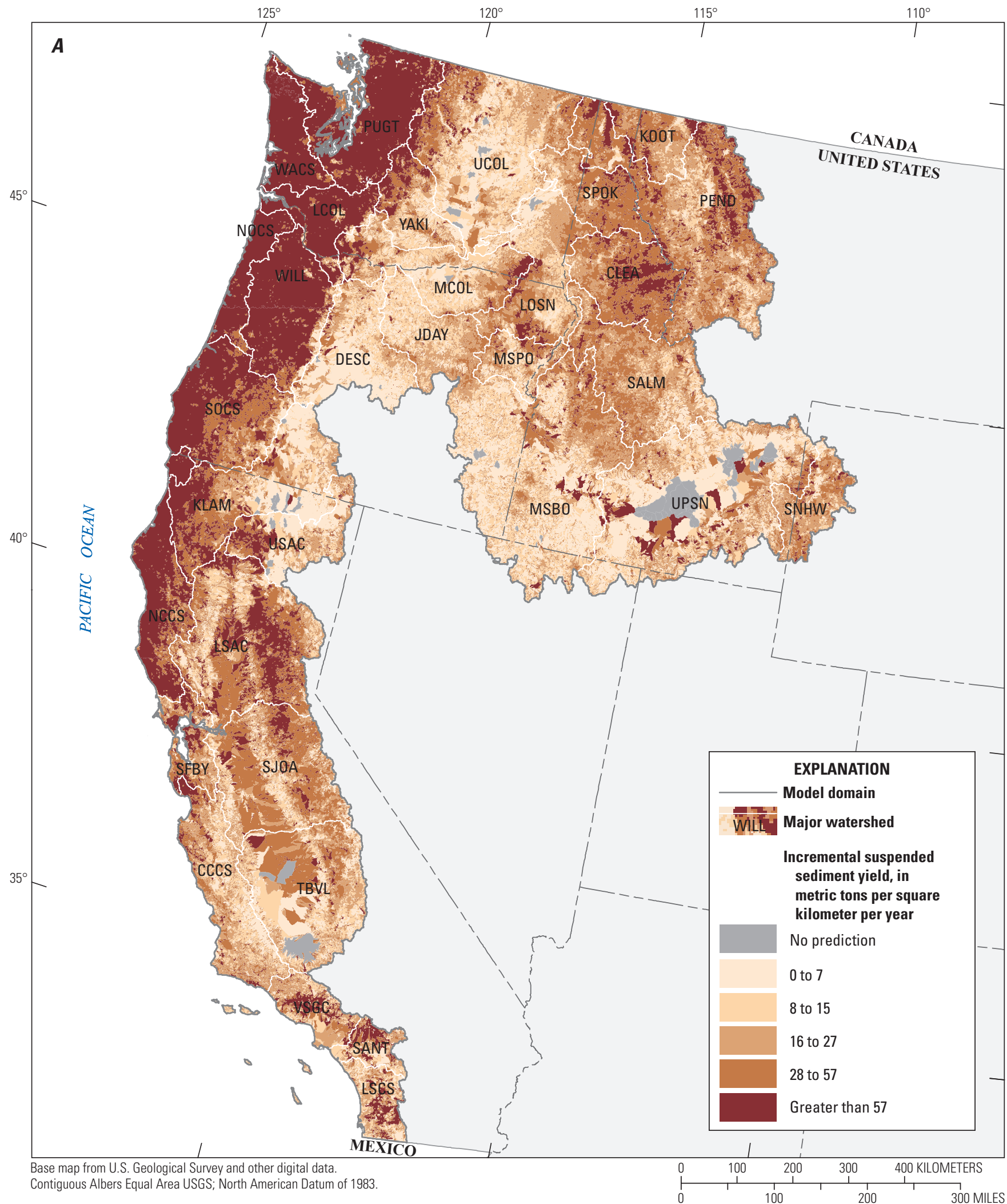

Figure 20. Predicted mean annual incremental yield $(A)$ and delivered incremental yield $(B)$ of total phosphorus from the Pacific region SPARROW (SPAtially Referenced Regression On Watershed attributes) suspended-sediment model. 


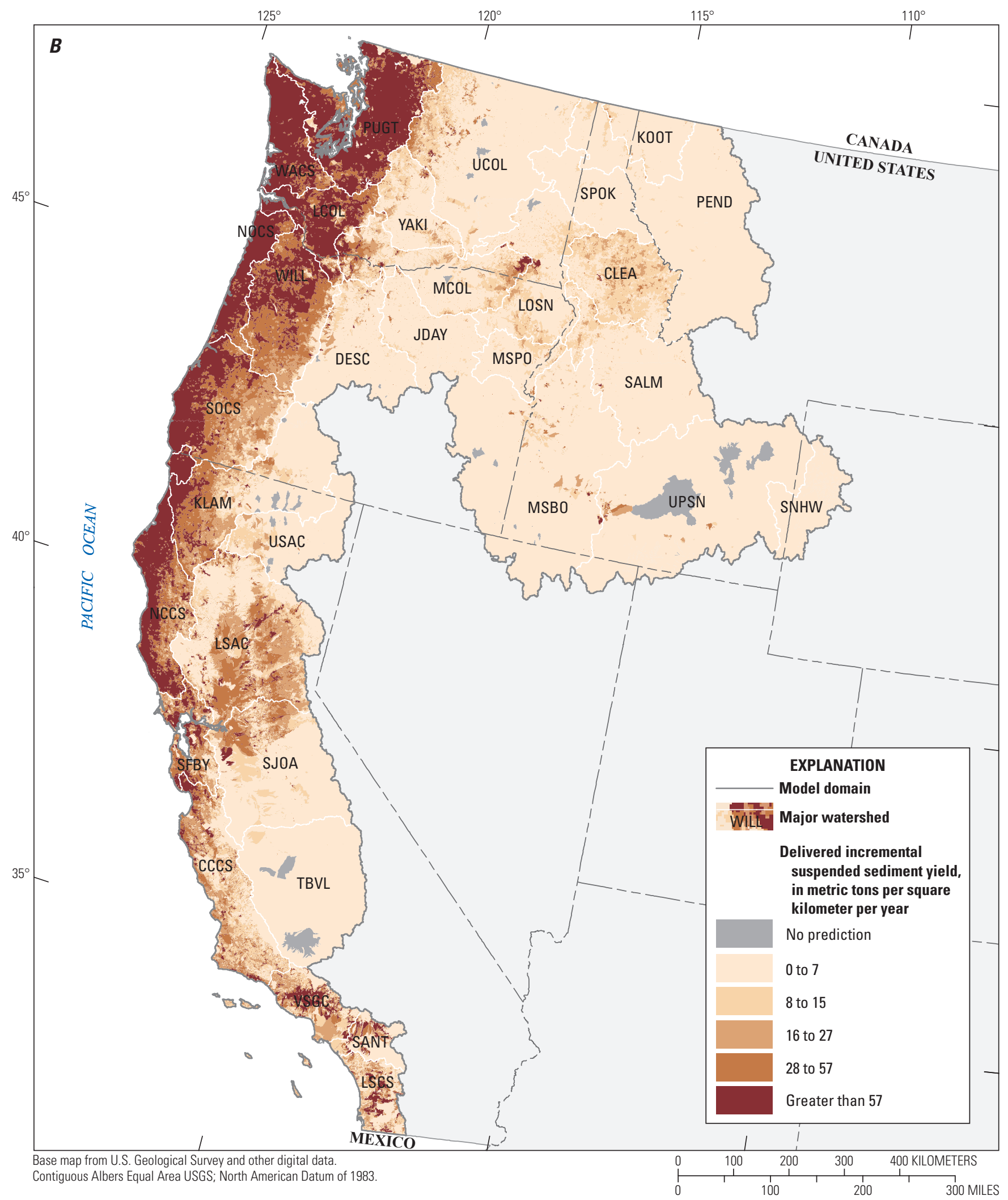

Figure 20.-Continued 


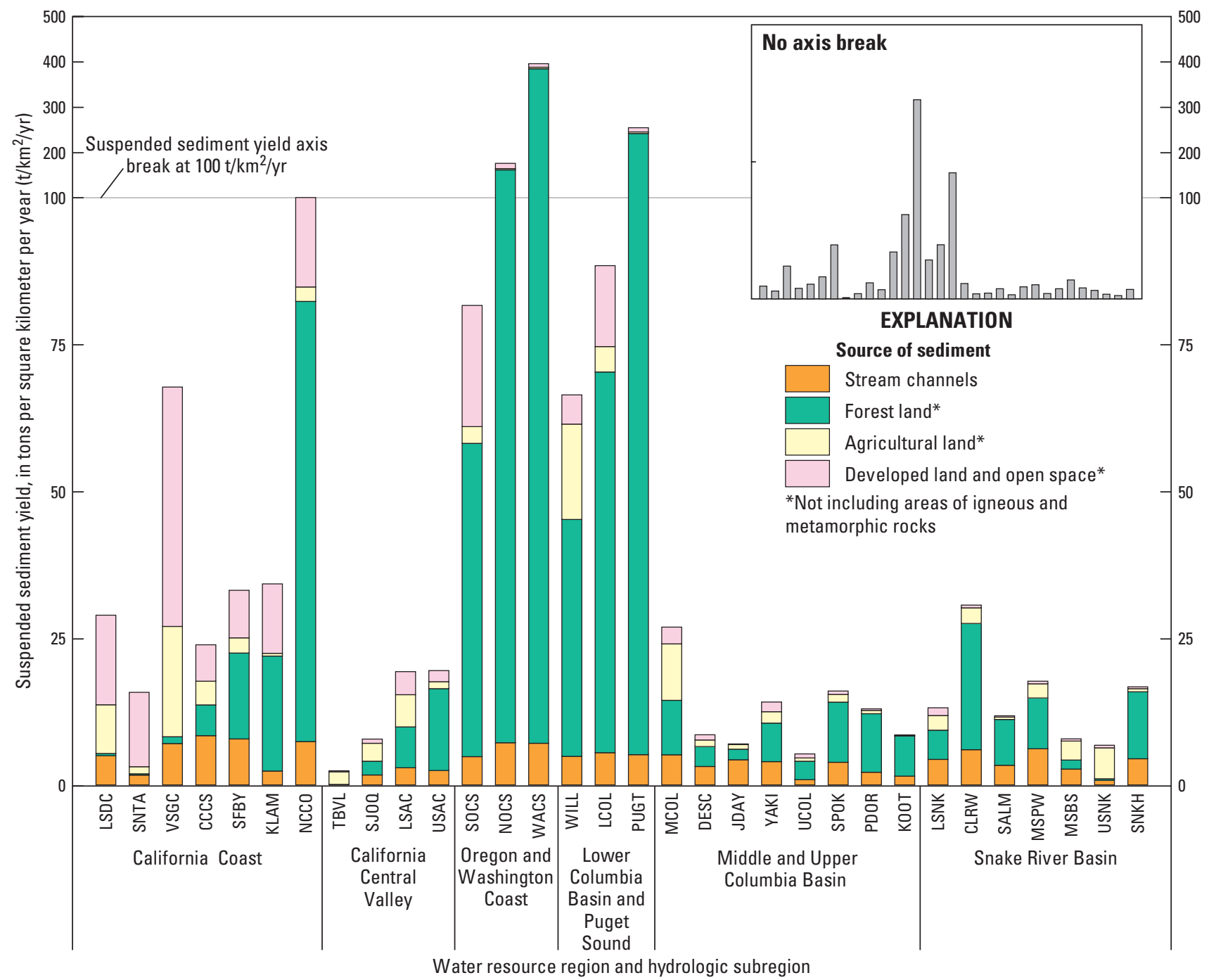

Figure 21. Predicted mean annual suspended-sediment yield, by source, for Hydrologic Unit Code 6 (HUC6) watersheds in the Pacific region of the United States.

Table 7. Median yields of total nitrogen, total phosphorus, and suspended sediment from areas dominated by different land cover types in the Pacific region of the United States dominated by different land cover types.

[Median values are for incremental NHDPlus catchments that were made up of at least 90 percent of each land cover category. Abbreviations: $\left(\mathrm{kg} / \mathrm{km}^{2}\right) /$ $\mathrm{yr}$, kilogram per square kilometer per year; $\left(\mathrm{t} / \mathrm{km}^{2}\right) / \mathrm{yr}$, ton per square kilometer per year]

\begin{tabular}{lccc}
\hline \multirow{2}{*}{$\begin{array}{c}\text { Dominant land } \\
\text { cover }\end{array}$} & \multicolumn{3}{c}{ Median incremental yield } \\
\cline { 2 - 4 } & $\begin{array}{c}\text { Total nitrogen } \\
\left(\left[\mathbf{k g} / \mathbf{k m}^{2}\right] / \mathbf{y r}\right)\end{array}$ & $\begin{array}{c}\text { Total } \\
\mathbf{p h o s p h o r u s} \\
\left(\left[\mathbf{k g} / \mathbf{k m}^{2}\right] / \mathbf{y r}\right)\end{array}$ & $\begin{array}{c}\text { Suspended } \\
\text { sediment } \\
\left(\left[\mathbf{t} / \mathbf{k m}^{2}\right] / \mathbf{y r}\right)\end{array}$ \\
\hline Forest land & 72.3 & 15.42 & 58.6 \\
Scrub and grass land & 40.5 & 11.18 & 15.4 \\
Agricultural land & 380 & 22.3 & 44.4 \\
Developed land & 253 & 17.2 & 40.0 \\
\hline
\end{tabular}

\section{Discussion}

The assumptions and simplifications in model specification need to be considered when using the results from any SPARROW application, with the primary assumption that the quantity and quality of the explanatory and calibration data is adequate. Although every effort was made to identify and quantify the sources of streamflow, nutrients, and sediment in the Pacific region SPARROW models, the models might not account for all sources in all areas of the modeling domain. This is due to limitations in the availability and accuracy of input data or, in the case of the total nitrogen model, strong spatial correlation between sources that could not be combined into one source. The limited number of calibration stations used in the total phosphorus, suspended sediment, and especially total nitrogen models might also 
compromise the accuracy of the models. State and local monitoring programs provided most of the water-quality data used to estimate the calibration loads for the SPARROW models and, due to limited resources, these programs tend to focus their efforts on relatively large streams. This means that the smaller streams, especially headwater streams. are poorly represented in the calibration data set. This is a potential source of bias in the total nitrogen, total phosphorus, and suspended-sediment models because headwater areas have a profound influence on shaping downstream water quality (Alexander and others, 2007).

The results from the four SPARROW models provide insights into the important climate and landscape controls on streamflow and nutrient and suspended-sediment yields across the Pacific region. Mean annual precipitation is a common feature across all four SPARROW models, whether expressed as part of a source term in the streamflow model or as part of a delivery term in the constituent models. Two other landscape properties, the area of perennial ice and snow and the area disturbed by recent wildfire, were significant in two models, indicating that both processes influence the delivery of phosphorus and sediment from land to water. Wildfires can leave behind either exposed, loose soil that is easily erodible or hardened soil that increases the erosive power of rainwater and snowmelt, increasing the risk of eutrophication and sedimentation in streams and reservoirs and adversely affecting the water supplies on which many cities and towns in the Pacific region rely.

There were other landscape properties, however, that were expected to be important but were not included in the models. One of these was catchment slope which, based on the results from other SPARROW suspended-sediment applications (Brakebill and others, 2010; Schwarz, 2008) and many empirical models of sediment erosion (for example, Wischmeier and Smith, 1978), was expected to have a positive effect on sediment delivery. The fact that catchment slope was not significant in the suspended-sediment model is likely due to the strong positive relation between slope and precipitation and the finding that water yield (which is precipitation dependent) explained much of the variation in suspendedsediment yields across the region. Some other landscape properties that were not significant were the use of conservation practices as a control on nutrient and sediment runoff from farmland, stream power change as a controlling factor in stream channel sediment generation and loss, and soil erodibility as a control on phosphorus and sediment runoff. The reasons these landscape properties were not significant for the Pacific region was not apparent, but SPARROW models developed for smaller areas within that region might lead to different results. For example, conservation practices might be significant in a model that includes primarily agricultural watersheds.

The models developed for this study used datasets that improved upon existing national data or represented landscape attributes that were compiled specifically for the Pacific region. These new datasets allowed for characterization of the hydrologic and water-quality conditions in the Pacific region more completely than in previous models. Examples of this include a more rigorous accounting of streamflow and water diversions and transfers, quantifying the contribution of nutrients from different sources of livestock manure, identifying a strong signal from unpaved logging roads in the suspended-sediment yields from forested coastal watersheds, evaluating the influence of recent wildfire disturbance on phosphorus and sediment delivery to streams, and evaluating the sensitivity of sediment delivery to streams to the intensity of cattle grazing. Direct comparisons between the accuracy of the models developed for this study and previous SPARROW models developed for the same modeling domain are not possible, however, because of differences in the calibration datasets and some of the modeling techniques that were used.

The datasets used in this study, especially the ones that were compiled specifically for the Pacific region, and the results from the models themselves could help complement research and inform water-quality management activities in the region. The reach-scale estimates of nutrient and suspended-sediment conditions could be used as a screening tool for identifying potentially impaired waterbodies and helping to guide remediation efforts where impairment has been documented. Another application could be the use of the input data and the model results (for example, streamflow, surface-water diversions for consumptive use, nutrient loads and concentrations, suspended-sediment loads and concentrations), in addition to other regional data such as modeled water temperature, to help explain the spatial patterns in the harmful algal blooms that are an increasingly serious concern throughout the Pacific region. Finally, the results from this study could provide estimates of sediment and nutrient loadings to Pacific coast estuaries, especially where such data are scarce or nonexistent. These estimates could be used to establish baseline conditions for studies of dynamic systems such as climate, hydrology, vegetation, and human development. 


\section{Summary}

This report described the development of SPARROW models for the Pacific region of the U.S. for streamflow and three water-quality constituents-total nitrogen, total phosphorus, and suspended sediment. The streamflow model was used to characterize the complex hydrology of the Pacific region and provide the best available estimates of local water yield as input to the constituent models, which were then used to estimate local total nitrogen, total phosphorus, and suspended-sediment yields. The four SPARROW models were also used to estimate the water, total nitrogen, total phosphorus, and suspended-sediment yields for the entire Pacific region as well as the 32 large watersheds that make up the region, and the relative contribution of different sources to those yields. In addition to providing estimates of local and watershed yields, the four SPARROW models provided insight into the watershed properties that control the delivery of water, nutrients, and sediment to streams and the hydrologic properties that control how much water, nutrients, and sediment is ultimately transported to downstream receiving waters. Inputs and outputs from the 2012 Pacific region SPARROW models are available in a USGS data release (Wise, 2020).

\section{Acknowledgments}

The author would like to acknowledge the many staff of the Federal, State, and local agencies that collected the data that were used as input to the models documented within this report. The accomplishments of this study could only have been made on the foundation they provided.

\section{References Cited}

Alexander, R.B., Boyer, E.W., Smith, R.A., Schwarz, G.E., and Moore, R.B., 2007, The role of headwater streams in downstream water quality: Journal of the American Water Resources Association, v. 43, no. 1, p. 41-59.

Alexander, R.B., Smith, R.A., and Schwarz, G.E., 2008, Effect of stream channel size on the delivery of nitrogen to the Gulf of Mexico: Nature, v. 403, no. 6771, p. 758-761.

American Society for Testing and Materials, 2006, Standard test methods for determining sediment concentration in water samples: Basel, Switzerland, Water, , p. 395-400.
Anderson, M.T., and Woosley, L.H., Jr., 2005, Water availability for the Western United States-Key scientific challenges: U.S. Geological Survey Circular 1261, 85 p. [Also available at https://doi.org/10.3133/cir1261.]

Ator, S.W., Brakebill, J.W., and Blomquist, J.D., 2011, Sources, fate, and transport of nitrogen and phosphorus in the Chesapeake Bay watershed-An empirical model: U.S. Geological Survey Scientific Investigations Report 2011-5167, 27 p. [Also available at https://doi.org/10.3133/ sir20115167.]

Binkley, D., Cromack, K., Jr., and Baker, D.D., 1994, Nitrogen fixation by Red Alder-BioloAy, rates, and controls, in Hibbs, D.E., DeBell, D.S., and Tarrant, R.F., The biology \& management of Red Alder: Corvallis, Oregon State University Press, p. 57-72.

Brakebill, J.W., Ator, S.W., and Schwarz, G.E., 2010, Sources of suspended-sediment flux in streams of the Chesapeake Bay watershed - A regional application of the SPARROW model: Journal of the American Water Resources Association, v. 46, no. 4, p. 757-776.

Brakebill, J.W., Schwarz, G.E., and Wieczorek, M.E., 2020, An enhanced hydrologic stream network based on the NHDPlus medium resolution dataset: U.S. Geological Survey Scientific Investigations Report 2019-5127, 49 p., https://doi.org/10.3133/sir20195127.

California Department of Water Resources, 2010, California water plan update 2009: Integrated Water Management, Volume 3-Regional Reports, Bulletin 160-09, accessed December 12, 2017, at http://www.water.ca.gov/waterplan/ cwpu2009/final/index.cfm\#Volume3.

California Water Resources Control Board, 2017, Final California 2012 Integrated report (303(d) List/305(b) Report): California Water Resources Control Board, Supporting Information, accessed July 3, 2017, at https:// www.waterboards.ca.gov/water_issues/programs/ tmdl/2012state_ir_reports/table_of_contents.shtml.

Domagalski, J.L., and Saleh, D., 2015, Sources and transport of phosphorus to rivers in California and adjacent states, U.S., as determined by SPARROW modeling: Journal of the American Water Resources Association, v. 51, no. 6, p. 1463-1486.

Garcia, A.M., Hoos, A.B., and Terziotti, S., 2011, A regional modeling framework of phosphorus sources and transport in streams of the southeastern United States: Journal of the American Water Resources Association, v. 47, no. 5, p. 991-1010.

Gellis, A.C., Fitzpatrick, F.A., and Schubauer-Berigan, M.K., 2016, A manual to identify sources of fluvial sediment: U.S. Environmental Protection Agency, EPA/600/R-16/210, 124 p. 
Gray, J.R., Glysson, G.D., Turcios, L.M., and Schwarz, S.E., 2000, Comparability of suspended-sediment concentration and total-suspended solids data: U.S. Geological Survey Water-Resources Investigations Report 00-4191, 14 p.

Griffiths, W.H., and Walton, B.D., 1978, The effects of sedimentation on the aquatic biota: Edmonton, Alberta, Alberta Oil Sands Environmental Research Program Report $35,86 \mathrm{p}$.

Gronberg, J.M., and Spahr, N.E., 2012, County-level estimates of nitrogen and phosphorus from commercial fertilizer for the conterminous United States, 1987-2006: U.S. Geological Survey Scientific Investigations Report 20125207, 20 p. [Also available at https://doi.org/10.3133/ sir20125207.]

Gronberg, J.M., and Arnold, T.L., 2017, County-level estimates of nitrogen and phosphorus from animal manure for the conterminous United States, 2007 and 2012: U.S. Geological Survey Open-File Report 2017-1021, 6 p. [Also available at https://doi.org/10.3133/ofr20171021.]

Groten, J.T., and Johnson, G.D., 2018, Comparability of river suspended-sediment sampling and laboratory analysis methods: U.S. Geological Survey Scientific Investigations Report 2018-5023, 23 p. [Also available at https://doi. org $/ 10.3133 / \operatorname{sir} 20185023$.]

Guy, H.P., 1969, Laboratory theory and methods for sediment analysis: U.S. Geological Survey Techniques of WaterResources Investigations 05-C1, $58 \mathrm{p}$.

Homer, C.G., Dewitz, J.A., Yang, L., Jin, S., Danielson, P., Xian, G., Coulston, J., Herold, N.D., Wickham, J.D., and Megown, K., 2015, Completion of the 2011 National Land Cover Database for the conterminous United StatesRepresenting a decade of land cover change information: Photogrammetric engineering and remote sensing, v. 81, no. 5 , p. $345-354$.

Horizon Systems, 2013, NHDPlusV2Data: Horizon Systems database, accessed March 18, 2013, at http://www.horizonsystems.com/nhdplus/.

Idaho Department of Environmental Quality, 2017, Idaho's 2012 Integrated Report: Idaho Department of Environmental Quality, accessed July 3, 2017, at http://www.deq.idaho.gov/water-quality/surface-water/ monitoring-assessment/integrated-report.aspx.

Lee, C.J., Hirsch, R.M., Schwarz, G.E., Holtschlag, D.J., Preston, S.D., Crawford, C.G., and Vecchia, A.V., 2016, An evaluation of methods for estimating decadal stream loads: Journal of Hydrology, v. 542, p. 185-203.
MacDonald, L.H., and Coe, D.B.R., 2008, Road sediment production and delivery-Processes and management: Tokyo, Proceedings of the First World Landslide Forum, International Programme on Land-slides and International Strategy for Disaster Reduction, p. 57-72.

Maupin, M.A., and Ivehnenko, T., 2011, Nutrient loadings to streams of the continental United States from municipal and industrial effluent: Journal of the American Water Resources Association, v. 47, no. 5, p. 950-964.

McCabe, G.J., and Wolock, D.M., 2011, Independent effects of temperature and precipitation on modeled runoff in the conterminous United States: Water Resources Research, v. 47 , no. 11 , W11522.

Montana Department of Environmental Quality, 2017, 2012 Integrated report: Montana Department of Environmental Qualit, accessed July 3, 2017, at http://deq.mt.gov/Water/ WQPB/cwaic/reports.

Moore, R.B., Johnson, C.M., Robinson, K.W., and Deacon, J.R., 2004, Estimation of total nitrogen and phosphorus in New England streams using spatially referenced regression Models: U.S. Geological Survey Scientific Investigations Report 2004-5012, 42 p. [Also available at https://doi. org/10.3133/sir20045012.]

Morris, G.L., and Fan, J., 1998, Reservoir sedimentation handbook - Design and management of dams, reservoirs, and watersheds for sustainable use: New York, McGrawHill, 805 p.

Nardi, M.R., 2014, Watershed potential to contribute phosphorus from geologic materials to receiving streams, conterminous United States: U.S. Geological Survey, Water Resources NSDI Node, accessed August 3, 2018, at https:// water.usgs.gov/lookup/getspatial?pmapnatl.

National Research Council, 2001, Assessing the TMDL Approach to Water Quality Management: Washington, D.C., National Academy Press, 109 p.

O’Connor, J.E., Mangano, J.F., Anderson, S.W., Wallick, J.R., Jones, K.L., and Keith, M.K., 2014, Geologic and physiographic controls on bed-material yield, transport, and channel morphology for alluvial and bedrock rivers, western Oregon: Geological Society of America Bulletin, v. 126, no. $3 / 4$, p. 377-397.

Oregon Department of Environmental Quality, 2017, Water quality assessment — Oregon's 2012 integrated report assessment database and 303(d) list: Oregon Department of Environmental Quality, accessed July 3, 2017, at https:// www.deq.state.or.us/wq/assessment/rpt2012/search.asp. 
Oregon State University, 2019, Landscape ecology, modeling, mapping, and analysis maps and data portal: Oregon State University, accessed September 23, 2019, at https://lemma. forestry.oregonstate.edu/data.

Pervez, M.S., and Brown, J.F., 2010, Mapping irrigated lands at 250-m scale by merging MODIS data and national agricultural statistics: Remote Sensing, v. 2, no. 10, p. 2388-2412.

Preston, S.D., Alexander, R.B., Woodside, M.D., and Hamilton, P.A., 2009, SPARROW modeling-Enhancing understanding of the Nation's water quality: U.S. Geological Survey Fact Sheet 2009-3019, 6 p. [Also available at https://pubs.usgs.gov/fs/2009/3019/.]

Preston, S.D., Alexander, R.B., and Wolock, D.M., 2011, SPARROW modeling to understand water-quality conditions in major regions of the United States-A featured collection introduction: Journal of the American Water Resources Association, v. 47, no. 5, p. 887-890.

Rice, E.W., Baird, R.B., Eaton, A.D., and Clesceri, L.S., eds., 2012, Standard methods for the examination of water and wastewater (22nd ed.): American Public Health Association, American Water Works Association, and Water Pollution Control Federation, 20121, 496 p.

Saad, D.A., Schwarz, G.E., Argue, D.M., Anning, D.W., Ator, S.W., Hoos, A.B., Preston, S.D., Robertson, D.M., and Wise, D.R., 2019, Estimates of long-term mean daily streamflow and annual nutrient and suspended-sediment loads considered for use in regional SPARROW models of the conterminous United States, 2012 base year: U.S. Geological Survey Scientific Investigations Report 2019-5069. [Also available at https://doi.org/10.3133/ $\operatorname{sir} 20195069]$

Saleh, Dina, and Domagalski, Joseph, 2015, SPARROW modeling of nitrogen sources and transport in rivers and streams of California and adjacent states: U.S. Journal of the American Water Resources Association, v. 51, no. 6, p. 1487-1507.

Schwarz, G.E., Hoos, A.B., Alexander, R.B., and Smith, R.A., 2006, The SPARROW surface water-quality model-Theory, applications and user documentation: U.S. Geological Survey Techniques and Methods, book 6, chap. B3, 248 p. [Also available on CD-ROM and at https://pubs. usgs.gov/tm/2006/tm6b3/.].

Schwarz, G.E., 2008, A Preliminary SPARROW model of suspended sediment for the conterminous United States: U.S. Geological Survey Open-File Report 2008-1205, 8 p. [Also available at https://pubs.usgs.gov/of/2008/1205 https://doi.org/10.3133/ofr20081205.]
Seaber, P.R., Kapinos, F.P., and Knapp, G.L., 1987 , Hydrologic unit maps: U.S. Geological Survey WaterSupply Paper 2294, 63 p.

Simley, J.D., and Carswell, W.J., Jr., 2009, The National Map-Hydrography: U.S. Geological Survey Fact Sheet 2009-3054, 4 p.

Skinner, K.D.,and Wise, D.R., 2019, Point-source nutrient loads to streams of the conterminous United States, 2012: U.S. Geological Survey data release. [Also available at https://doi.org/10.5066/P9PYVPFT.].

Smith, R.A., Schwarz, G.E., and Alexander, R. B., 1997, Regional interpretation of water-quality monitoring data: Water Resources Research, v. 33, no. 12, p. 2781-2798.

Soller, D.R., Reheis, M.C., Garrity, C.P., and Van Sistine, D.R., 2009, Map database for surficial materials in the conterminous United States: U.S. Geological Survey Data Series 425. [Also available at https://pubs.usgs.gov/ds/425.]

Stewart, J.S., Schwarz, G.E., Brakebill, J.W., and Preston, S.D., 2019, Catchment-level estimates of nitrogen and phosphorus agricultural use from commercial fertilizer sales for the conterminous United States, 2012: U.S. Geological Survey Scientific Investigations Report 2018-5145, 52 p. [Also available at https://doi.org/10.3133/sir20185145.]

Swanson, F.J., Fredrikson, A.L., and McCorison, F.M., 1982, Material transfer in a Western Oregon forested watershed, in Edmonds, R.L., ed., Coniferous forest ecosystems in the western United States: The Institute of Ecology, p. 233-291.

U.S. Environmental Protection Agency, 1990, Permit compliance system: U.S. Environmental Protection Agency, 20W-4001, 21 p.

U.S. Environmental Protection Agency, 2010, Nutrients in estuaries - Summary report of the national estuarine experts workgroup, 2005-2007: U.S. Environmental Protection Agency, 188 p.

U.S. Environmental Protection Agency, 2017, 2012 clean watersheds needs survey: U.S. Environmental Protection Agency, accessed December 12, 2017, at https://ofmpub. epa.gov/apex/cwns2012/f?p=134:25.

U.S. Environmental Protection Agency, 2018a, Community multiscale air quality modeling System (CMAQ) - CMAQ Data, accessed November 1, 2018, at https://www.epa.gov/ cmaq/cmaq-data.

U.S. Environmental Protection Agency, 2018b, Summary of BPSOU Conceptual Agreement, accessed March 12, 2018, at https://semspub.epa.gov/src/collection/08/SC37422. 
U.S. Geological Survey, 1999, The quality of our nation's waters-Nutrients and pesticides: U.S. Geological Survey Circular 1225, $82 \mathrm{p}$.

U.S. Geological Survey, 2015, Water-data site information for the nation: U.S. Geological Survey National Water Information System, accessed March 9, 2015, at https:// waterdata.usgs.gov/nwis/si.

Washington Department of Environmental Conservation, 2017, Washington State Water Quality Assessment, accessed July 3, 2017, at https://fortress.wa.gov/ecy/approvedwqa/ ApprovedSearch.aspx.

Wellen, C., Kamran-Disfani, A.R., Arhonditsis, G.B., 2015, Evaluation of the current state of distributed watershed nutrient water quality modeling: Environmental Science and Technology, v. 49, no. 6, p. 3278-3329.

Wieczorek, M.E., Jackson, S.E., and Schwarz, G.E., 2019, Select attributes for NHDPlus version 2.1 reach catchments and modified network routed upstream watersheds for the conterminous United States (version 2.0, October 2019): U.S. Geological Survey Data Release, https://doi. org/10.5066/F7765D7V.

Wischmeier, W.H., and Smith, D.D., 1978, Predicting rainfall erosion losses-A guide to conservation planning: U.S. Department of Agriculture Agricultural Handbook No. 537,58 p.

Wise, D.R., and O'Connor, J.E., 2016, A spatially explicit suspended-sediment load model for western Oregon: U.S. Geological Survey Scientific Investigations Report 20165079, 25 p. [Also available at http://dx.doi.org/10.3133/ sir20165079.]

Wise, D.R., and Johnson, H.M., 2013, Application of the SPARROW model to assess surface-water nutrient conditions and sources in the United States Pacific Northwest: U.S. Geological Survey Scientific Investigations Report 2013-5103, 32 p. [Also available at https:// pubs.usgs.gov/sir/2013/5103/ https://doi.org/10.3133/ sir20135103.]

Wise, D.R., 2019a, Application of manure nutrients generated at cattle animal feeding operations to farmland within the Pacific drainages of the United States, 2012: U.S. Geological Survey. [Also available at https://doi:10.5066/ P9SCZMJB.]
Wise, D.R., 2019b, Application of manure nutrients generated by non-cattle livestock to farmland within the Pacific drainages of the United States, 2012: U.S. Geological Survey. [Also available at https://doi:10.5066/P9V1RY3N.]

Wise, D.R., 2019c, Application of manure nutrients generated by grazing cattle to grazing land within the Pacific drainages of the United States, 2012: U.S. Geological Survey. [Also available at https://doi:10.5066/P9RCPKPC.]

Wise, D.R., 2019d, Population with On-Site Wastewater Treatment within the Pacific Drainages of the United States, 2010: U.S. Geological Survey. [Also available at https://doi. org/10.5066/P979BBCQ.]

Wise, D.R., 2019e, Distribution of grazing cattle within the Pacific drainages of the United States, 2012: U.S. Geological Survey. [Also available at https://doi. org/10.5066/P92EZQO3.]

Wise, D.R., 2020, SPARROW model inputs and simulated streamflow, nutrient and suspended-sediment loads in streams of the Pacific Region of the United States, 2012 Base Year (ver 1.1, June 2020): U.S. Geological Survey data release, https://doi.org/10.5066/P9AXLOSM.

Wyoming Department of Environmental Quality, 2017, Wyoming water quality assessment and impaired waters list (2012 Integrated 305[b] and 303[d] report): Wyoming Department of Environmental Quality, accessed July 3, 2017, at http://sgirt.webfactional.com/wqd/water-qualityassessment/resources/reports/.

Yang, C.T., and Stall, J.B., 1974, Unit stream power for sediment transport in natural rivers: Urbana-Champaign, Illinois, University of Illinois at Urbana-Champaign Water Resources Center, UILU-WRC, p. 74-0088., 38 p. 


\section{Appendix 1. Summary Of Wastewater Nutrient Discharge For Hydrologic Unit Code 6 Watersheds In The Pacific Region Of The United States}

Table 1.1. Summary of wastewater nutrient discharge for hydrologic unit code 6 watersheds within the Pacific region of the United States.

[Abbreviation: kg. kilogram; - , not applicable because the watershed does not directly drain to an estuary or the ocean]

\begin{tabular}{|c|c|c|c|c|c|c|c|c|}
\hline \multirow[b]{2}{*}{ Region } & \multirow[b]{2}{*}{$\begin{array}{c}\text { HUC6 } \\
\text { watershed }\end{array}$} & \multirow[b]{2}{*}{ HUC6 name } & \multicolumn{3}{|c|}{ Discharge to inland surface water } & \multicolumn{3}{|c|}{ Discharge to estuaries and ocean } \\
\hline & & & $\begin{array}{c}\text { Number } \\
\text { of NPDES } \\
\text { facilities that } \\
\text { discharged } \\
\text { wastewater }\end{array}$ & $\begin{array}{c}\text { Total } \\
\text { nitrogen } \\
\text { discharged } \\
(\mathrm{kg})\end{array}$ & $\begin{array}{c}\text { Total } \\
\text { phosphorus } \\
\text { discharged } \\
(\mathbf{k g})\end{array}$ & $\begin{array}{c}\text { Number } \\
\text { of NPDES } \\
\text { facilities that } \\
\text { discharged } \\
\text { wastewater }\end{array}$ & $\begin{array}{c}\text { Total } \\
\text { nitrogen } \\
\text { discharged } \\
(\mathbf{k g})\end{array}$ & $\begin{array}{c}\text { Total } \\
\text { phosphorus } \\
\text { discharged } \\
\text { (kg) }\end{array}$ \\
\hline Oregon and & WACS & Washington Coastal & 31 & 153,535 & 26,227 & 13 & 106,158 & 61,122 \\
\hline Washington & NOCS & Northern Oregon Coastal & 20 & 136,757 & 27,095 & 7 & 58,698 & 21,965 \\
\hline Coast & SOCS & Southern Oregon Coastal & 29 & 950,936 & 128,658 & 2 & 30,391 & 4,393 \\
\hline Lower & PUGT & Puget Sound & 76 & $2,152,986$ & 365,967 & 81 & $9,720,050$ & $1,426,415$ \\
\hline Columbia & LCOL & Lower Columbia & 58 & $4,037,407$ & 621,263 & - & - & - \\
\hline $\begin{array}{l}\text { River Basin } \\
\text { and Puget } \\
\text { Sound }\end{array}$ & WILL & Willamette & 77 & $3,433,702$ & 742,138 & - & - & - \\
\hline Upper & KOOT & Kootenai & 5 & 17,079 & 3,844 & - & - & - \\
\hline Columbia & PEND & Pend Oreille & 46 & 326,967 & 44,906 & - & - & - \\
\hline \multirow[t]{6}{*}{ River Basin } & SPOK & Spokane & 28 & $1,515,719$ & 57,859 & - & - & - \\
\hline & UCOL & Upper Columbia & 50 & 763,626 & 139,985 & - & - & - \\
\hline & YAKI & Yakima & 23 & 594,703 & 98,346 & - & - & - \\
\hline & JDAY & John Day & 0 & 0 & 0 & - & - & - \\
\hline & DESC & Deschutes & 6 & 6,998 & 2,175 & - & - & - \\
\hline & MCOL & Middle Columbia & 37 & 151,177 & 44,194 & - & - & - \\
\hline Snake River & SNHW & Snake headwaters & 4 & 7,146 & 3,920 & - & - & - \\
\hline \multirow[t]{6}{*}{ Basin } & UPSN & Upper Snake & 121 & $2,084,733$ & 400,633 & - & - & - \\
\hline & MSBO & Middle Snake-Boise & 31 & $1,062,017$ & 299,763 & - & - & - \\
\hline & MSPO & Middle Snake-Powder & 4 & 27,491 & 6,370 & - & - & - \\
\hline & SALM & Salmon & 7 & 16,315 & 4,809 & - & - & - \\
\hline & CLEA & Clearwater & 29 & 92,184 & 122,035 & - & - & - \\
\hline & LOSN & Lower Snake & 27 & 88,184 & 18,650 & - & - & - \\
\hline California & NCCS & Northern California Coastal & 16 & 349,833 & 108,274 & 7 & 218,619 & 35,963 \\
\hline \multirow[t]{6}{*}{ Coast } & KLAM & Klamath & 4 & 98,623 & 16,402 & - & - & - \\
\hline & SFBY & San Francisco Bay & 12 & $1,970,979$ & 596,968 & 34 & $14,855,737$ & $1,848,673$ \\
\hline & CCCS & Central California Coastal & 12 & 357,042 & 55,596 & 14 & 770,481 & 172,317 \\
\hline & VSCS & $\begin{array}{l}\text { Ventura-San Gabriel } \\
\text { Coastal }\end{array}$ & 18 & $2,110,821$ & 736,048 & 7 & $15,545,934$ & $1,649,708$ \\
\hline & SANT & Santa Ana & 13 & $1,877,397$ & 397,091 & 1 & $4,697,270$ & 482,436 \\
\hline & LSCS & Laguna-San Diego Coastal & 1 & 13,806 & 314 & 11 & $6,390,299$ & $2,886,885$ \\
\hline California & USAC & Upper Sacramento & 5 & 11,341 & 4,201 & - & - & - \\
\hline Central & $\mathrm{LSAC}^{1}$ & Lower Sacramento & 40 & $1,299,071$ & 244,509 & 7 & $4,794,348$ & 425,016 \\
\hline \multirow[t]{2}{*}{ Valley } & TBVL & Tulare-Buena Vista Lakes & 4 & 420,414 & 38,046 & - & - & - \\
\hline & $\mathrm{SJOA}^{1}$ & San Joaquin & 16 & 594,854 & 89,716 & 9 & 624,109 & 193,821 \\
\hline \multicolumn{3}{|c|}{ All HUC6 watersheds } & 850 & $26,723,843$ & $5,446,002$ & 193 & $57,812,094$ & $9,208,714$ \\
\hline
\end{tabular}

${ }^{1}$ While these watersheds do not discharge directly to an estuary, their lower sections are within the Legal Delta for San Francisco Bay and are tidally influenced. Therefore, wastewater released within the Legal Delta were considered estuary discharges. 


\section{Appendix 2. Summary Of Water, Total Nitrogen, Total Phosphorus, And Suspended-Sediment Yields For Hydrologic Unit Code 6 Watersheds In The Pacific Region Of The United States}

Table 2.1. Summary of water yields for hydrologic unit code 6 watersheds within the Pacific region of the United States.

[The contributions from inter-basin and local transfers are not shown because they mostly represent transfers of water within individual HUC6 watersheds. Precipitation minus actual evapotranspiration: Mean annual difference between precipitation and evapotranspiration for water years 2000-14. Irrigated land: Runoff from land with active irrigation in 2012. Wastewater discharge: Discharge to surface water from wastewater treatment facilities in 2012. Spring discharge: Mean spring discharge. Abbreviation: mm/yr, millimeter per year; <, less than]

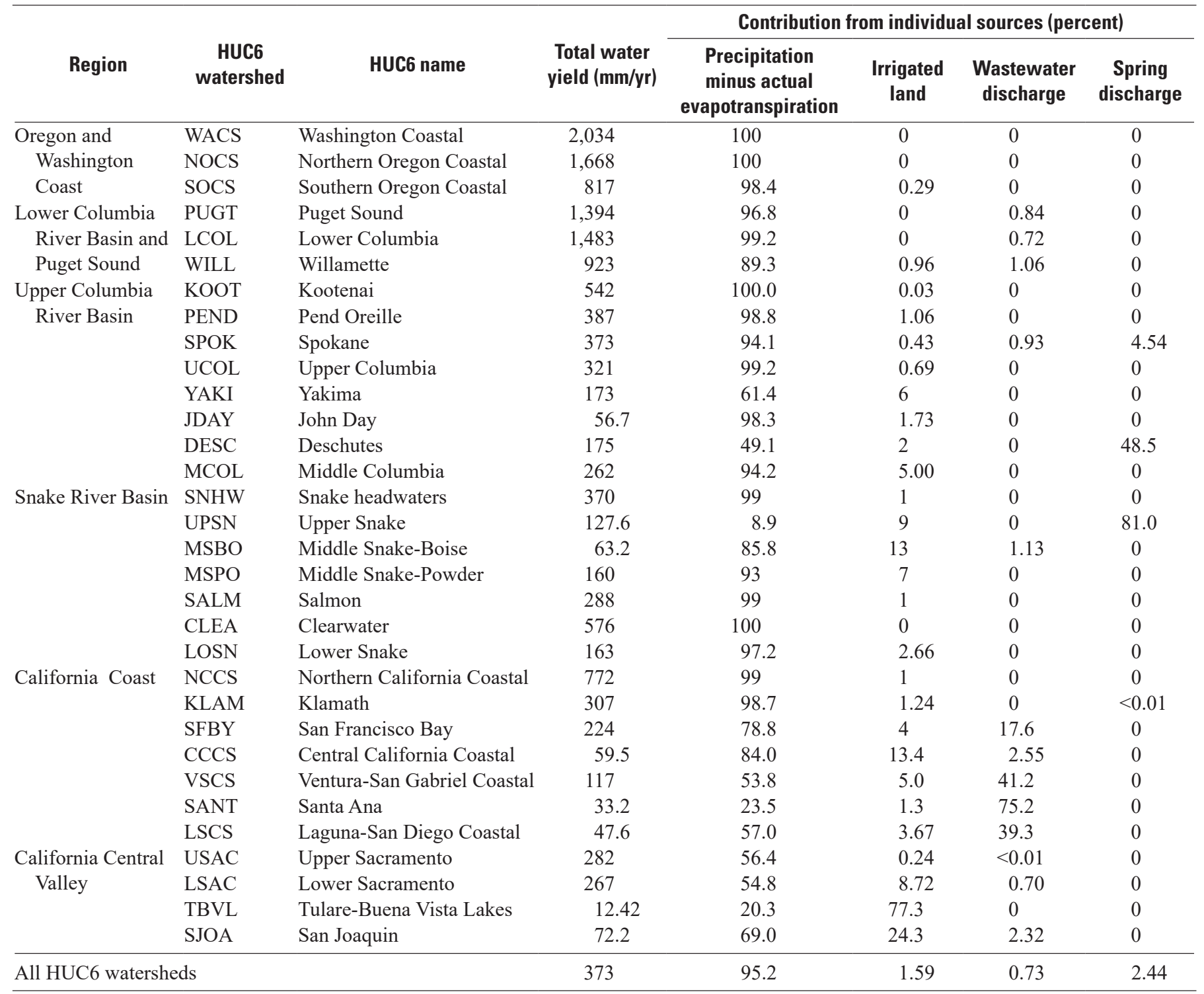


Table 2.2. Summary of total nitrogen yields for hydrologic unit code 6 watersheds within the Pacific region of the United States.

[Atmospheric deposition: Mean wet and dry atmospheric deposition of oxidized and reduce nitrogen for water years 2010-12. Scrub and grass land: Area of shrub, scrub, and grass land in 2011. Red alder trees: Basal area of red alder trees in 2012. Agricultural fertilizer: The combination of commercial fertilizer and livestock manure applied to cropland in 2012. Developed land: Area of low, medium, and high intensity developed land, and open space in 2011. Wastewater discharge: Discharge to surface water from wastewater treatment facilities in 2012. Spring discharge: Mean spring discharge. Abbreviations: HUC6, Hydrologic Unit Code 6; $\left(\mathrm{kg} / \mathrm{km}^{2}\right) / \mathrm{yr}$, kilogram per square meter per year]

\begin{tabular}{|c|c|c|c|c|c|c|c|c|c|c|}
\hline \multirow[b]{2}{*}{ Region } & \multirow[b]{2}{*}{$\begin{array}{c}\text { HUC6 } \\
\text { watershed }\end{array}$} & \multirow[b]{2}{*}{ HUC6 name } & \multirow{2}{*}{$\begin{array}{c}\text { Total } \\
\text { nitrogen } \\
\text { yield } \\
\text { ([kg/ } \\
\text { km²]/yr) }^{2}\end{array}$} & \multicolumn{7}{|c|}{ Contribution from individual sources (percent) } \\
\hline & & & & $\begin{array}{l}\text { Atmospheric } \\
\text { deposition }\end{array}$ & $\begin{array}{l}\text { Scrub and } \\
\text { grass land }\end{array}$ & $\begin{array}{l}\text { Red } \\
\text { alder } \\
\text { trees }\end{array}$ & $\begin{array}{c}\text { Agricultural } \\
\text { fertilizer }\end{array}$ & $\begin{array}{l}\text { Developed } \\
\text { land }\end{array}$ & $\begin{array}{l}\text { Wastewater } \\
\text { discharge }\end{array}$ & $\begin{array}{c}\text { Spring } \\
\text { discharge }\end{array}$ \\
\hline Oregon and & WACS & Washington Coastal & 790 & 25.8 & 8.37 & 46.1 & 8.03 & 9.69 & 2.03 & 0 \\
\hline Washington & NOCS & Northern Oregon Coastal & 1,100 & 22.0 & 6.12 & 57.4 & 2.26 & 10.7 & 1.52 & 0 \\
\hline Coast & SOCS & Southern Oregon Coastal & 312 & 34.8 & 12.6 & 26.2 & 5.57 & 12.4 & 8.43 & 0 \\
\hline Lower & PUGT & Puget Sound & 769 & 22.1 & 3.66 & 17.1 & 7.00 & 9.83 & 40.2 & 0 \\
\hline Columbia & LCOL & Lower Columbia & 910 & 23.3 & 4.93 & 27.9 & 7.22 & 8.93 & 27.7 & 0 \\
\hline $\begin{array}{l}\text { River Basin } \\
\text { and Puget } \\
\text { Sound }\end{array}$ & WILL & Willamette & 748 & 23.0 & 4.86 & 9.70 & 39.7 & 8.99 & 13.7 & 0 \\
\hline Upper & KOOT & Kootenai & 54.8 & 86.9 & 6.06 & 0 & 3.35 & 1.03 & 2.64 & 0 \\
\hline Columbia & PEND & Pend Oreille & 64.0 & 62.3 & 18.4 & 0 & 8.33 & 3.45 & 7.22 & 0.23 \\
\hline \multirow[t]{6}{*}{ River Basin } & SPOK & Spokane & 206 & 19.6 & 5.82 & 0.01 & 17.5 & 3.85 & 40.9 & 12.3 \\
\hline & UCOL & Upper Columbia & 52.9 & 56.6 & 7.47 & 0.01 & 14.9 & 1.98 & 19.1 & 0 \\
\hline & YAKI & Yakima & 94 & 20.7 & 11.7 & 0.44 & 34.4 & 8.33 & 24.4 & 0 \\
\hline & JDAY & John Day & 23.9 & 39.6 & 43.6 & 0 & 12.7 & 4.03 & 0 & 0 \\
\hline & DESC & Deschutes & 163 & 6.63 & 5.79 & 0 & 7.02 & 1.20 & 0.14 & 79.2 \\
\hline & MCOL & Middle Columbia & 129 & 26.6 & 9.37 & 1.43 & 48.3 & 7.59 & 5.90 & 0.85 \\
\hline Snake River & SNHW & Snake headwaters & 102 & 53.6 & 29.4 & 0 & 15.2 & 1.29 & 0.45 & 0 \\
\hline \multirow[t]{6}{*}{ Basin } & UPSN & Upper Snake & 249 & 2.64 & 1.46 & 0 & 23.7 & 0.58 & 9.68 & 61.9 \\
\hline & MSBO & Middle Snake-Boise & 52.0 & 17.7 & 18.2 & 0 & 39.5 & 2.79 & 21.9 & 0 \\
\hline & MSPO & Middle Snake-Powder & 76.4 & 32.7 & 28.5 & 0.01 & 32.9 & 2.67 & 3.22 & 0 \\
\hline & SALM & Salmon & 58.1 & 53.5 & 37.0 & 0 & 7.49 & 1.24 & 0.74 & 0 \\
\hline & CLEA & Clearwater & 147 & 39.0 & 12.6 & 0 & 43.9 & 1.90 & 2.60 & 0 \\
\hline & LOSN & Lower Snake & 108.2 & 23.1 & 10.8 & 0.03 & 60.5 & 3.03 & 2.54 & 0 \\
\hline \multirow[t]{7}{*}{$\begin{array}{c}\text { California } \\
\text { Coast }\end{array}$} & NCCS & $\begin{array}{l}\text { Northern California } \\
\text { Coastal }\end{array}$ & 260 & 40.8 & 13.9 & 15.1 & 7.56 & 14.0 & 8.70 & 0 \\
\hline & KLAM & Klamath & 77.9 & 46.8 & 17.2 & 9.73 & 11.6 & 11.8 & 2.88 & 0.02 \\
\hline & SFBY & San Francisco Bay & 1,672 & 4.55 & 1.01 & 0.04 & 4.36 & 4.54 & 85.5 & 0 \\
\hline & $\mathrm{CCCS}$ & $\begin{array}{l}\text { Central California } \\
\text { Coastal }\end{array}$ & 139 & 14.9 & 5.32 & 0.02 & 48.2 & 8.36 & 23.2 & 0 \\
\hline & VSCS & $\begin{array}{l}\text { Ventura-San Gabriel } \\
\text { Coastal }\end{array}$ & 1,566 & 3.49 & 0.70 & 0 & 5.36 & 2.31 & 88.1 & 0 \\
\hline & SANT & Santa Ana & 715 & 1.48 & 0.10 & 0 & 0.91 & 1.46 & 96.1 & 0 \\
\hline & LSCS & $\begin{array}{l}\text { Laguna-San Diego } \\
\text { Coastal }\end{array}$ & 535 & 4.75 & 0.71 & 0 & 2.63 & 2.29 & 89.6 & 0 \\
\hline California & USAC & Upper Sacramento & 70.9 & 70.0 & 16.2 & 0.05 & 7.39 & 5.69 & 0.71 & 0 \\
\hline Central & LSAC & Lower Sacramento & 303 & 21.6 & 5.44 & 0.08 & 37.8 & 4.68 & 30.5 & 0 \\
\hline \multirow[t]{2}{*}{ Valley } & TBVL & $\begin{array}{l}\text { Tulare-Buena Vista } \\
\text { Lakes }\end{array}$ & 51.1 & 7.67 & 0.36 & 0 & 89.1 & 2.85 & 0 & 0 \\
\hline & SJOA & San Joaquin & 187 & 13.9 & 2.44 & 0.01 & 70.6 & 3.32 & 9.78 & 0 \\
\hline \multicolumn{3}{|c|}{ All HUC6 watersheds } & 234 & 21.0 & 5.96 & 11.3 & 18.2 & 6.26 & 31.4 & 5.90 \\
\hline
\end{tabular}


Table 2.3. Summary of total phosphorus yields for hydrologic unit code 6 watersheds within the Pacific region of the United States.

[Upland geologic sources are not shown because that source contributed a minimal amount to total watershed yields. Stream channels: Contribution from both perennial and intermittent stream channels represented by the incremental reach length. Grazing cattle: Manure from grazing cattle deposited on grazing land in 2012. Agricultural fertilizer: The combination of commercial fertilizer and livestock manure applied to cropland in 2012. Developed land: Area of low, medium, and high intensity developed land, and open space in 2011. Wastewater discharge: Discharge to surface water from wastewater treatment facilities in 2012. Spring discharge: Mean spring discharge. Abbreviations: HUC6, Hydrologic Unit Code 6; $\left(\mathrm{kg} / \mathrm{km}^{2}\right) / \mathrm{yr}$, kilogram per square meter per year]

\begin{tabular}{|c|c|c|c|c|c|c|c|c|c|c|}
\hline \multirow[b]{2}{*}{ Region } & \multirow[b]{2}{*}{$\begin{array}{c}\text { HUC6 } \\
\text { watershed }\end{array}$} & \multirow[b]{2}{*}{$\begin{array}{l}\text { HUC6 } \\
\text { name }\end{array}$} & \multirow{2}{*}{$\begin{array}{c}\text { Total } \\
\text { phosphorus } \\
\text { yield } \\
{\left[\left(\mathbf{k g} / \mathbf{k m}^{2}\right] / \mathbf{y r}\right)}\end{array}$} & \multicolumn{7}{|c|}{ Contribution from individual sources (percent) } \\
\hline & & & & $\begin{array}{l}\text { Stream } \\
\text { channels }\end{array}$ & $\begin{array}{l}\text { Upland } \\
\text { geologic }\end{array}$ & $\begin{array}{l}\text { Grazing } \\
\text { cattle }\end{array}$ & $\begin{array}{l}\text { Agricultural } \\
\text { fertilizer }\end{array}$ & $\begin{array}{l}\text { Developed } \\
\text { land }\end{array}$ & $\begin{array}{l}\text { Wastewater } \\
\text { discharge }\end{array}$ & $\begin{array}{c}\text { Spring } \\
\text { discharge }\end{array}$ \\
\hline \multirow{3}{*}{$\begin{array}{l}\text { Oregon and } \\
\text { Washington } \\
\text { Coast }\end{array}$} & WACS & Washington Coastal & 106.6 & 3.5 & 41.7 & 20.8 & 8.0 & 17.2 & 8.8 & 0.0 \\
\hline & NOCS & $\begin{array}{l}\text { Northern Oregon } \\
\text { Coastal }\end{array}$ & 142 & 2.55 & 21.15 & 38.0 & 14.7 & 18.4 & 5.14 & 0 \\
\hline & SOCS & $\begin{array}{l}\text { Southern Oregon } \\
\text { Coastal }\end{array}$ & 49.5 & 6.16 & 25.59 & 39.7 & 2.43 & 12.7 & 13.5 & 0 \\
\hline \multirow{3}{*}{$\begin{array}{l}\text { Lower } \\
\text { Columbia } \\
\text { River Basin } \\
\text { and Puget } \\
\text { Sound }\end{array}$} & PUGT & Puget Sound & 163 & 1.99 & 25.28 & 13.0 & 4.57 & 4.75 & 50.4 & 0 \\
\hline & LCOL & Lower Columbia & 147 & 4.06 & 19.53 & 15.1 & 4.07 & 11.3 & 46.0 & 0 \\
\hline & WILL & Willamette & 121 & 4.40 & 14.55 & 19.4 & 20.6 & 8.26 & 32.8 & 0 \\
\hline \multirow{8}{*}{$\begin{array}{l}\text { Upper } \\
\text { Columbia } \\
\text { River Basin }\end{array}$} & KOOT & Kootenai & 5.99 & 12.6 & 50.0 & 2.90 & 2.30 & 0.51 & 31.7 & 0 \\
\hline & PEND & Pend Oreille & 9.53 & 26.3 & 38.8 & 17.5 & 4.29 & 1.28 & 11.7 & 0.06 \\
\hline & SPOK & Spokane & 14.7 & 26.3 & 11.8 & 8.17 & 6.49 & 2.39 & 38.3 & 6.52 \\
\hline & UCOL & Upper Columbia & 8.66 & 20.7 & 25.4 & 2.84 & 6.09 & 0.79 & 44.1 & 0 \\
\hline & YAKI & Yakima & 21.0 & 21.2 & 16.0 & 17.8 & 9.7 & 3.44 & 31.9 & 0 \\
\hline & JDAY & John Day & 7.02 & 83.7 & 9.0 & 6.26 & 0.60 & 0.42 & 0 & 0 \\
\hline & DESC & Deschutes & 14.6 & 29.6 & 27.6 & 2.02 & 4.82 & 0.53 & 0.85 & 34.7 \\
\hline & MCOL & Middle Columbia & 30.6 & 22.5 & 42.6 & 5.9 & 8.7 & 4.61 & 15.5 & 0.14 \\
\hline \multirow{7}{*}{$\begin{array}{l}\text { Snake River } \\
\text { Basin }\end{array}$} & SNHW & Snake headwaters & 14.53 & 43.1 & 39.8 & 8.7 & 4.74 & 0.60 & 3.03 & 0 \\
\hline & UPSN & Upper Snake & 21.0 & 6.06 & 1.60 & 7.97 & 18.3 & 0.29 & 37.9 & 27.9 \\
\hline & MSBO & Middle Snake-Boise & 14.0 & 28.7 & 7.8 & 10.3 & 12.5 & 0.40 & 40.3 & 0 \\
\hline & MSPO & $\begin{array}{l}\text { Middle Snake- } \\
\text { Powder }\end{array}$ & 15.29 & 41.3 & 23.9 & 17.6 & 10.2 & 0.59 & 6.52 & 0 \\
\hline & SALM & Salmon & 20.04 & 44.8 & 48.9 & 4.28 & 0.74 & 0.16 & 1.10 & 0 \\
\hline & CLEA & Clearwater & 37.7 & 21.0 & 24.0 & 4.77 & 4.17 & 0.44 & 45.6 & 0 \\
\hline & LOSN & Lower Snake & 15.93 & 51.6 & 22.3 & 10.0 & 8.6 & 0.96 & 6.56 & 0 \\
\hline \multirow[t]{7}{*}{$\begin{array}{c}\text { California } \\
\text { Coast }\end{array}$} & NCCS & $\begin{array}{l}\text { Northern California } \\
\text { Coastal }\end{array}$ & 62.5 & 4.27 & 19.52 & 46.5 & 3.62 & 10.0 & 16.1 & 0 \\
\hline & KLAM & Klamath & 12.85 & 8.4 & 51.1 & 22.9 & 3.05 & 9.5 & 5.1 & $<0.01$ \\
\hline & SFBY & San Francisco Bay & 395 & 0.61 & 0.46 & 3.63 & 1.45 & 1.57 & 92.3 & 0 \\
\hline & $\mathrm{CCCS}$ & $\begin{array}{l}\text { Central California } \\
\text { Coastal }\end{array}$ & 29.1 & 23.8 & 7.5 & 4.76 & 19.4 & 2.91 & 41.7 & 0 \\
\hline & VSCS & $\begin{array}{l}\text { Ventura-San Gabriel } \\
\text { Coastal }\end{array}$ & 368 & 5.49 & 0.70 & 0.10 & 1.76 & 0.46 & 91.5 & 0 \\
\hline & SANT & Santa Ana & 157 & 2.57 & 0.14 & 0.71 & 0.27 & 0.29 & 96.0 & 0 \\
\hline & LSCS & $\begin{array}{l}\text { Laguna-San Diego } \\
\text { Coastal }\end{array}$ & 382 & 1.42 & 0.10 & 0.09 & 0.19 & 0.10 & 98.1 & 0 \\
\hline \multirow{4}{*}{$\begin{array}{c}\text { California } \\
\text { Central } \\
\text { Valley }\end{array}$} & USAC & Upper Sacramento & 12.29 & 28.3 & 36.7 & 26.7 & 1.74 & 3.90 & 2.71 & 0 \\
\hline & LSAC & Lower Sacramento & 36.2 & 5.44 & 11.59 & 15.9 & 13.8 & 4.42 & 48.8 & 0 \\
\hline & TBVL & $\begin{array}{l}\text { Tulare-Buena Vista } \\
\text { Lakes }\end{array}$ & 3.78 & 1.97 & 2.88 & 14.0 & 78.1 & 3.04 & 0 & 0 \\
\hline & SJOA & San Joaquin & 23.0 & 3.77 & 2.88 & 23.1 & 29.7 & 2.04 & 38.5 & 0 \\
\hline \multicolumn{3}{|c|}{ All HUC6 watersheds } & 44.5 & 7.95 & 14.99 & 12.3 & 6.99 & 4.64 & 52.0 & 1.19 \\
\hline
\end{tabular}


Table 2.4. Summary of suspended sediment yields for hydrologic unit code 6 watersheds within the Pacific region of the United States.

[Stream channels: Contribution from free-flowing stream channels. Forest land: Deciduous, evergreen, and mixed forest land in 2011.Agricultural land: Cultivated crops and pasture in 2011. Developed land: Low, medium, and high intensity developed land and open space in 2011. Abbreviations: HUC6, Hydrologic Unit Code 6; $\left(\mathrm{t} / \mathrm{km}^{2}\right) / \mathrm{yr}$, ton per square kilometer per year]

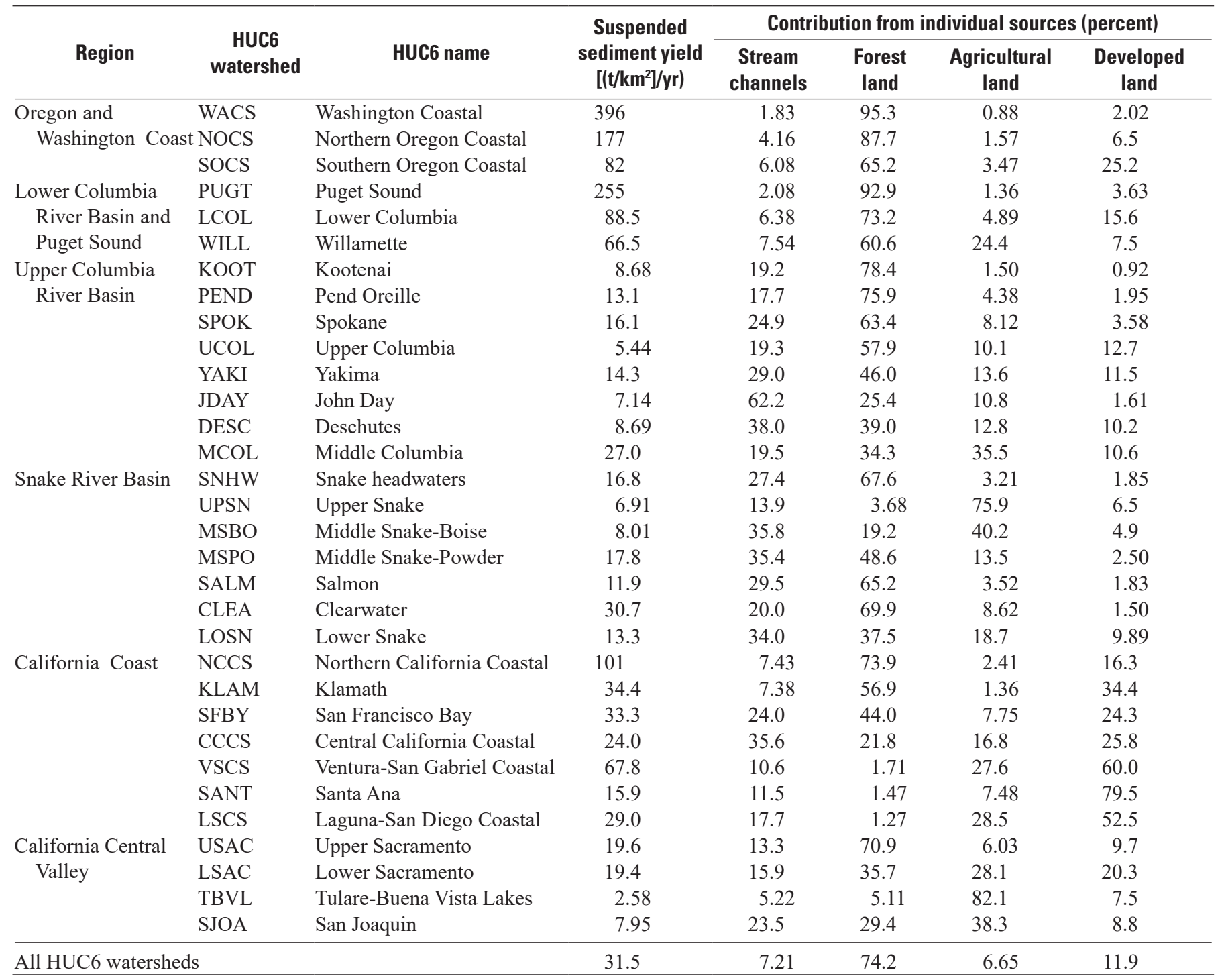


This page left blank intentionally 
For additional information, contact:

NAWOA Chief Scientist

U.S. Geological Survey

12201 Sunrise Valley Drive, MS 413

Reston, VA 20192-0002

Or visit our website at:

https://water.usgs.gov/nawqa/

Email: nawqapublicinfo@usgs.gov

Publishing support provided by the U.S. Geological Survey

Science Publishing Network, Tacoma Publishing Service Center 


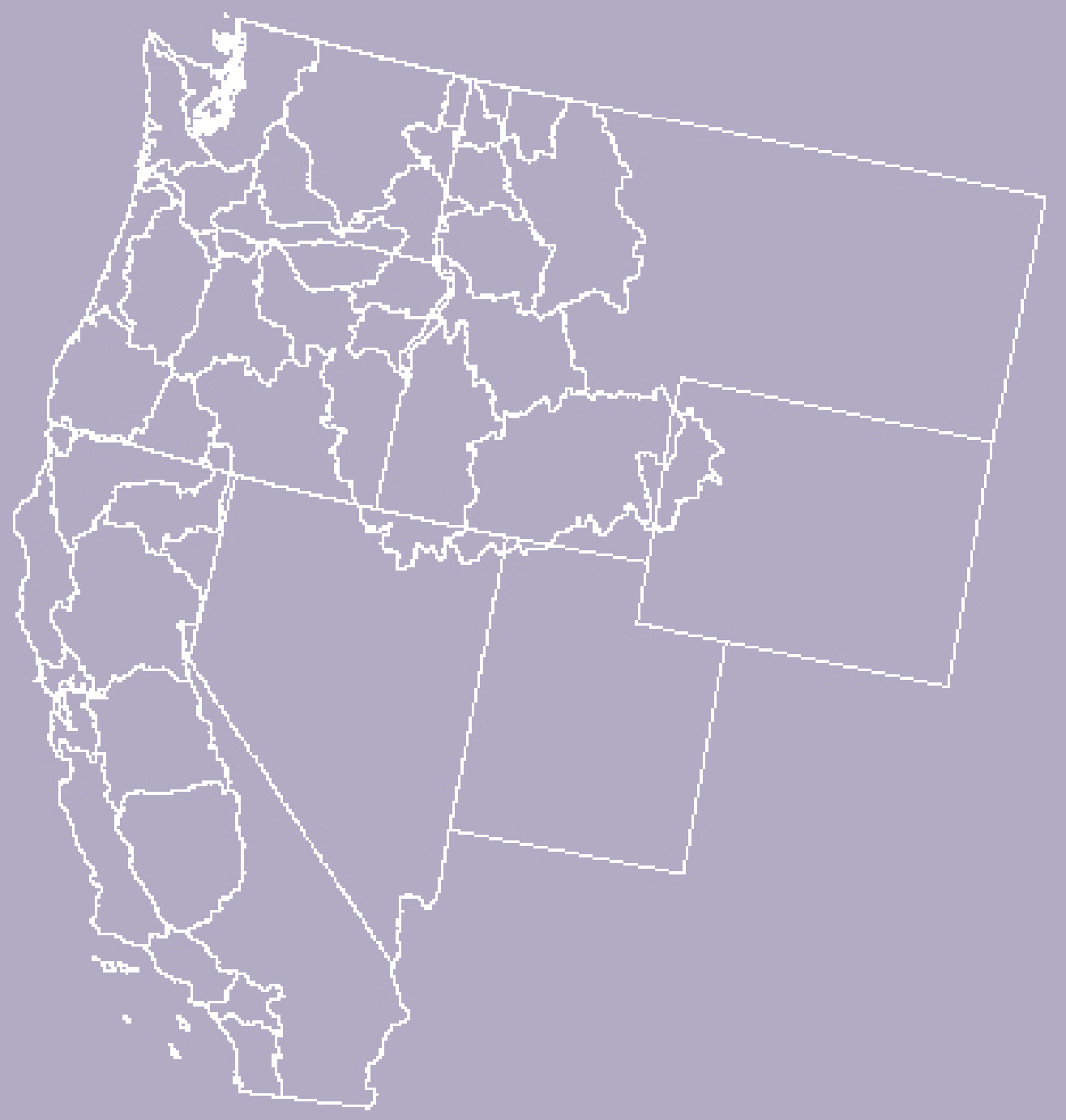

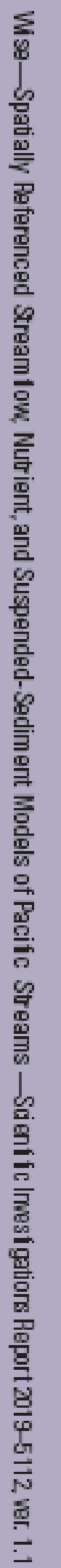

